\title{
Pulsed Laser Deposited Films for Microbatteries
}

\author{
Christian M. Julien *(i) and Alain Mauger \\ Institut de Minéralogie, de Physique des Matériaux et de Cosmochimie (IMPMC), Campus Pierre et Marie Curie, \\ Sorbonne Université, CNRS UMR 7590, 4 Place Jussieu, 75005 Paris, France; alain.mauger@upmc.fr \\ * Correspondence: christian.julien@upmc.fr; Tel.: +33-673-404-684
}

Received: 10 May 2019; Accepted: 10 June 2019; Published: 14 June 2019

\begin{abstract}
This review article presents a survey of the literature on pulsed laser deposited thin film materials used in devices for energy storage and conversion, i.e., lithium microbatteries, supercapacitors, and electrochromic displays. Three classes of materials are considered: Positive electrode materials (cathodes), solid electrolytes, and negative electrode materials (anodes). The growth conditions and electrochemical properties are presented for each material and state-of-the-art of lithium microbatteries are also reported.
\end{abstract}

Keywords: PLD films; energy storage; thin-film electrodes; thin-film solid electrolyte; lithium microbatteries

\section{Introduction}

It has been widely demonstrated that pulsed-laser deposition (PLD) based on the process of the transportation of a material (laser ablation) is a successful technique for the growth of stoichiometric multicomponent oxide films [1,2]. Indeed, PLD has shown unique advantages for the formation of dense films for energy storage and conversion, namely a high reproducibility, easy control of the growth rate, and a high film purity with a variety of substrates, such as amorphous glass, oriented silicon [3], stainless steel [4], (001) $\mathrm{Al}_{2} \mathrm{O}_{3}$ [5], indium tin oxide (ITO)- and ZnO-coated glass, and ITO-coated Upilex polymer [6]. Generally, the stoichiometry of the target phase is preserved in PLD films of oxides but a deviation is observed for lithiated material that implies an Li-enriched target. Consequently, the loss of volatile $\mathrm{Li}$ during deposition is compensated for by using about a $15 \mathrm{wt} . \%$ excess of $\mathrm{Li}_{2} \mathrm{O}[7,8]$. Accurate stoichiometry can be obtained by controlling several parameters of the process. The typical set-up for the fabrication of PLD films consists of a stainless-steel vacuum chamber evacuated down to a residual pressure less than $1 \times 10^{-4}$ Pa before material deposition. Energy (laser fluence) in the range of 1.0 to $3.0 \mathrm{~J} \cdot \mathrm{cm}^{-2}$ is generated by a pulsed-laser beam, which falls onto the target surface with an incidence angle of approximately $45^{\circ}$ (see Table 1 for laser characteristics). Indeed, four PLD parameters are of prime importance for the growth of films: The laser fluence; type of substrate; orientation and lattice parameters, which must match with those of the film for an efficient epitaxy process; substrate temperature $\left(T_{\mathrm{s}}\right)$; and the oxygen partial pressure $\left(P_{\mathrm{O}_{2}}\right)$. In addition, as the capacity of the microbattery depends on the electrode thickness, the duration of the deposition $\left(t_{\mathrm{p}}\right)$ must also be considered. The activity of a thin-film electrode, i.e., specific discharge energy, is proportional to the thickness, thus an increase of the film thickness leads to a power limitation because of the slow transport kinetic of $\mathrm{Li}^{+}$ions. Consequently, PLD is a popular technique due to the growth of a compact and dense film, which is replaced by a thick and porous film. Another advantage of the physical vacuum-like deposition techniques is the possibility of depositing a thin layer on top of the microbattery, which protects the device against a reactivity toward moisture. Moreover, due to the well-defined surface area of PLD films, a direct comparison of the electrochemical activity of materials can be done for different morphologies, from amorphous to single-crystalline materials [9]. 
Table 1. Typical laser beams for PLD films of transition-metal (TM) oxides for energy storage.

\begin{tabular}{|c|c|c|c|c|c|}
\hline Laser & $\begin{array}{l}\text { Wavelength } \\
(\mathrm{nm})\end{array}$ & $\begin{array}{c}\text { Pulse } \\
\text { Width (ns) }\end{array}$ & $\begin{array}{l}\text { Frequency } \\
\quad(\mathrm{Hz})\end{array}$ & $\begin{array}{l}\text { Laser Fluence } \\
\quad\left(\mathrm{J} \cdot \mathrm{cm}^{-2}\right)\end{array}$ & Ref. \\
\hline Excimer KrF & 248 & 20 & 1 & 12 & [10] \\
\hline Excimer ArF & 193 & 10 & 5 & 2 & [11] \\
\hline Excimer $\mathrm{XeCl}$ & 308 & - & - & - & [12] \\
\hline Nd:YAG & $532^{(a)}$ & 8 & 10 & 6 & [13] \\
\hline Nd:YAG & $266^{(b)}$ & - & - & 1.6 & [14] \\
\hline
\end{tabular}

Due to their high energy and power densities, lithium-ion batteries (LIBs) are initial power sources that are widely used in portable devices (laptops, mobile phones, cameras, etc.) and are now employed for sustainable transportation, such as full electric vehicles (EVs) and hybrid electric vehicles (HEVs). The fabrication of electrochemical cells with a thin-film architecture allows the development of microbatteries for powering micro-scaling devices, such as stand-alone sensor systems, medical implants and devices, labs-on-chip, credit cards, etc. In addition to technological applications, positive (cathode) and negative (anode) electrodes in the thin-film form are useful for studying the intrinsic properties of the material without the use of a polymeric binder and carbonaceous additive [15]. The use of thin-film technology may offer various advantages, such as: (i) Thin films are well suited for the design of devices; (ii) thinning of the layers provides a lower resistance in the transverse direction for weakly semiconducting materials; (iii) a reduction of the thickness of the solid electrolyte film allows the use of glassy materials with a low ionic conductivity; (iv) a reduction of the charge-transfer resistance of the electrolyte-electrode interface; (v) easy manufacture of microbatteries using the same technique that is currently used in the microelectronics industry; and (vi) the construction of microbatteries is realized in almost any two-dimensional shape. However, the fabrication of microbatteries also contains many difficulties, which are comprehensively discussed below [16].

In the present review paper, we present the properties of pulsed-laser deposited films used as components of energy storage devices (i.e., batteries, supercapacitors, electrochromics, etc.). The remainder of the article is organized as follows. First, the state-of-the-art of lithium microbatteries using PLD films are summarized in Section 2, providing the characteristics of the best lithium microbatteries fabricated so far. In Sections 3-5, the three classes of active materials constituting electrochemical microdevices, realized via the PLD technique, are considered: (i) Positive electrode materials (cathodes), (ii) electrolytes, and (iii) negative electrode materials (anodes). For each material, the growth conditions and electrochemical properties are presented. Finally, in Section 6, we compare and discuss the growth conditions that allow the best electrochemical performance of each electrochemically active component of microbatteries.

\section{Lithium Microbatteries}

The concept of a thin-film solid-state battery is quite old [17]. The subject of thin-film microbatteries has been discussed in the scientific literature for many years. The review by Kennedy is a good source for work prior to 1977 [18]. The concept and design of all-solid-state planar thin-film microbatteries have been patented by Bates et al. [19-24], who reported on micropower sources using lithium phosphate, lithium phosphorus oxynitride, and lithium phosphorus lithium oxide as a solid thin-film electrolyte. Julien investigated the electrochemical performance of individual layers in a microbattery in relation to the growth mechanism and thin-film structure [25]. Dudney addressed how to build a battery layer-by-layer by vapor deposition [26]. More recently, Oudenhoven et al. reviewed the concepts of three-dimensional (3D) microbatteries [27]. In 2015, Wang et al. discussed the choice of materials for lithium and lithium-ion microbatteries and reviewed the chemistry and electrochemistry for applications in microelectronic devices [28]. Ferrari et al. highlighted the importance of 3D microarchitecture electrodes to fabricate microgenerators for micro-electromechanical systems (MEMSs) [29]. In the 
presentation of in situ analytical microprobes, Meng et al. described PLD-produced thin-film lithium microbatteries using the PLD technique and showing the production of a multilayer structure with dense and smooth films [30].

There are many variations on the general scheme of microbatteries outlined in the literature. Two principal options are shown in Figure 1 [25]. Figure 1a shows a four-layer design on a conducting substrate (i.e., oriented silicon wafer) that can act as a current collector. Figure $1 \mathrm{~b}$ shows a six-layer stack incorporating two metallic current collectors. There are two fast-ion conductor (FIC) layers in this design: A thick layer, which is the solid electrolyte itself, and a thin buffer film that acts as an electrolyte layer between the FIC and the Li metal film to prevent interface passivation. In 1992, a thin-film solid-state microbattery with an overall thickness of approximately $10 \mu \mathrm{m}$, including the $\mathrm{TiS}_{2}$ cathode, oxide-sulfide solid electrolyte, LiI buffer, and Li metal anode, was developed at the Technology Laboratory of Eveready Battery Company (EBC) [31]. Laiik et al. evaluated the performance of three 4-V commercial all-solid-state lithium microbatteries (200- $\mu$ m thick) with a nominal capacity of $700 \mu \mathrm{Ah}$ based on a $\mathrm{LiCoO}_{2}$ cathode material [32]. Note that a typical 1-mWh battery weighs $2.5 \mathrm{mg}$ and has a volume less than $1 \mu \mathrm{L}$, providing a specific energy and power of $400 \mathrm{Wh} \cdot \mathrm{kg}^{-1}$ and $1 \mathrm{kWh} \cdot \mathrm{L}^{-1}$, respectively [26].

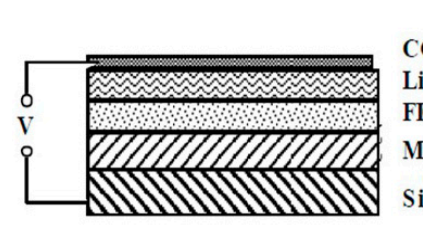

(a)

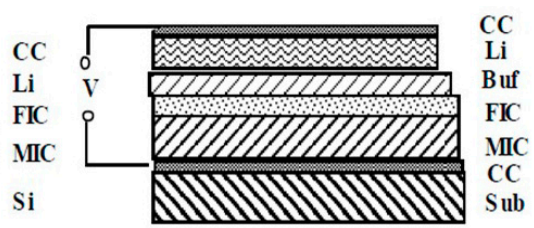

(b)

Figure 1. Design principles for lithium microbatteries composed of a lithium film (Li), fast-ion conductor (FIC), mixed ionic-electronic conductor (MIC), current collector(s) (CC), silicon substrate (Si), glass substrate (Sub), and buffer layer (Buf). (a) four-layer design on a conducting substrate and (b) six-layer stack incorporating two metallic current collectors (Reproduced with permission from [25]. Copyright 2000 Springer).

Regarding the manufacture of thin-film batteries, several start-up companies have marketed micropower sources. Enfucell developed a thin, printable, and flexible SoftBattery ${ }^{\circledR}$ used in various wearable electronics products [33]. Cymbet Corporation fabricates the EnerChip ${ }^{\mathrm{TM}}$ battery, which is a battery bare die and can be embedded with other integrated circuits [34]. Excellatron announced a pilot production line $(10,000$ cells/month) of thin-film solid-state batteries (approximately $0.3 \mu \mathrm{m}$ thick) made of cathode films of $\mathrm{LiCoO}_{2}$ or $\mathrm{LiMn}_{2} \mathrm{O}_{4}$, LiPON as the electrolyte, and Li metal or $\mathrm{Sn}_{3} \mathrm{~N}_{4}$ as the anode based on the technology developed at Oak Ridge National Labs. Using a 2- $\mu \mathrm{m}$ thick positive electrode, these microbatteries have been cycled in excess of 2000 cycles [35]. Some industrial developments of thin film microbatteries are listed in Table 2.

Table 2. Industrial developments of thin film microbatteries.

\begin{tabular}{|c|c|c|c|}
\hline Manufacturer & Electrochemical Chain & Specifications & Ref. \\
\hline Cymbet Co. & EnerChip ${ }^{\mathrm{TM}} \mathrm{LiCoO}_{2} / \mathrm{Li}$ & $60 \mu \mathrm{Ah} \cdot \mathrm{cm}^{-2} \cdot \mu \mathrm{m}^{-1} / 5000$ cycles & [34] \\
\hline Infinite Power Solutions & $\mathrm{LiCoO}_{2}$ or $\mathrm{V}_{2} \mathrm{O} 5 / \mathrm{LiPON} / \mathrm{Li}$ & "Thinergy" $40 \mu \mathrm{Ah} \cdot \mathrm{cm}^{-2} \cdot \mu \mathrm{m}^{-1}$ & [36] \\
\hline Front Edge Technology & $\mathrm{LiCoO}_{2} / \mathrm{LiPON} / \mathrm{Li}$ & "Nanoenergy" $0.9 \mathrm{mAh} \mathrm{cm}^{-2}$ & [37] \\
\hline Ulvac Inc. & $\mathrm{LiCoO}_{2} / \mathrm{Li}_{3} \mathrm{PO}_{4} / \mathrm{Li}$ & $50 \mu \mathrm{Ah} \cdot \mathrm{cm}^{-2} \cdot \mu \mathrm{m}^{-1}$ & [38] \\
\hline STMicroelectronics & $\mathrm{LiCoO}_{2} / \mathrm{LiPON} / \mathrm{Li}$ & $700 \mu \mathrm{Ah} /$ discharge at $5 \mathrm{~mA}$ & [39] \\
\hline Excellatron & $\mathrm{LiCoO}_{2}-\mathrm{LiMnO}_{2}-\mathrm{LiPON}-\mathrm{Sn}_{3} \mathrm{~N}_{4}$ & $0.3 \mu \mathrm{m}$ thick $/ 0.1 \mathrm{mAh} / 2000$ cycles & [35] \\
\hline Enfucell & $\mathrm{MnO}_{2}$-based cell & voltage rating $>3 \mathrm{~V}$ & [33] \\
\hline GS Caltex & $\mathrm{n} / \mathrm{a}$ & $300 \mu \mathrm{m}$ thick/3.9 V/ 8000 cycles & [40] \\
\hline
\end{tabular}


A sequential PLD technique was applied for the fabrication of a rechargeable thin-film lithium battery $\left(2-\mu \mathrm{m}\right.$ thick, area of $\left.0.23 \mathrm{~cm}^{2}\right)$ with partially crystallized LCO as the cathode, an $\mathrm{Li}_{6.1} \mathrm{~V}_{0.61} \mathrm{Si}_{0.39} \mathrm{O}_{5.36}$ (LVSO) glassy electrolyte, and $\mathrm{SnO}$ film anode [41]. The ablation beam produced by a Q-switched Nd:YAG laser $(\lambda=266 \mathrm{~nm}$, repetition rate of $10 \mathrm{~Hz})$ was used at the fluence of $3.5 \mathrm{~mJ} \cdot \mathrm{cm}^{-2}$. A single phase LCO film was obtained by post annealing at $600{ }^{\circ} \mathrm{C}$ for $1 \mathrm{~h}$ in air and the amorphous LVSO film exhibited an ionic conductivity of ca. $10^{-7} \mathrm{~S} \cdot \mathrm{cm}^{-1}$ at room temperature. Such a Li microbattery cycled at $44 \mu \mathrm{A} \cdot \mathrm{cm}^{-2}$ in the voltage range of 0.7 to $3.0 \mathrm{~V}$ delivered a capacity of $9.5 \mathrm{Ah} \cdot \mathrm{cm}^{-2}$. After 100 cycles, the capacity retention was $45 \%$ of that of the first cycle. Characteristics of solid-state lithium microbatteries fabricated by the PLD technique reported in the literature are listed in Table 3. Most of the microcells use $\mathrm{LiCoO}_{2}$ as the positive electrode, providing a nominal voltage of $\sim 3.9 \mathrm{~V}$ vs. $\mathrm{Li}^{+} / \mathrm{Li}$. Thus, among the fabricated all-solid-state thin-film lithium batteries, the electrochemical chain of $\mathrm{Li}-\mathrm{In} / 80 \mathrm{Li}_{2} \mathrm{~S}-20 \mathrm{P}_{2} \mathrm{~S}_{5} / \mathrm{LiCoO}_{2}$ with an average potential of $3.5 \mathrm{~V}$ exhibits the best performance in terms of energy density.

Sakuda et al. reported the construction of an SSLMB based on an LCO positive electrode with an SE coating, a highly conductive $80 \mathrm{Li}_{2} \mathrm{~S}-20 \mathrm{P}_{2} \mathrm{~S}_{5}$ solid electrolyte, and an Li-In alloy as the anode [42]. Such a microbattery delivered a specific capacity of $95 \mathrm{mAh} \cdot \mathrm{g}^{-1}$ at a current density of $0.13 \mathrm{~mA} \cdot \mathrm{cm}^{-2}$. By using LCO thin films prepared from a $\mathrm{Li}_{y} \mathrm{CoO}_{\delta}$ target containing $15 \% \mathrm{Li}_{2} \mathrm{O}$, Xia et al. fabricated thin-film microbatteries by the successive deposition of an $\mathrm{LCO}$ cathode on a $\mathrm{Pt} / \mathrm{Ti} / \mathrm{SiO}_{2}$ (amorphous)/Si composite substrate and amorphous $\mathrm{Si}$ anode [12]. Recently, the analysis by impedance spectroscopy of the microcell $\mathrm{Li} / \mathrm{LiPON} / \mathrm{Li}_{4} \mathrm{Ti}_{5} \mathrm{O}_{12}$ (nominal voltage of $1.5 \mathrm{~V}$ ), in which $\mathrm{LiPON}$ is an amorphous lithium phosphorus oxynitride (i.e., nitrogen-modified $\mathrm{Li}_{3} \mathrm{PO}_{4}$ ), has clarified the debate on the interface stability with lithium; it was clearly shown that LiPON forms a well-conducting solid electrolyte interface (SEI) layer [43]. Despite the low ionic conductivity $\left(1 \mu \mathrm{S} \cdot \mathrm{cm}^{-1}\right)$ and the rather large contribution to the internal cell resistance, LiPON can be used as a solid electrolyte film with a thickness of $\sim 1 \mu \mathrm{m}$ or less. Therefore, use of the $\mathrm{LiPON}-\mathrm{LiCoO} 2$ system is very popular in the construction of thin-film lithium microbatteries [26].

Table 3. Solid-state lithium microbatteries fabricated by the PLD technique.

\begin{tabular}{ccc}
\hline Electrochemical Chain & Characteristics & Ref. \\
\hline $\mathrm{Li} / \mathrm{Li}_{3} \mathrm{PO}_{4} / \mathrm{LiCoO}_{2}$ & $9.5 \mu \mathrm{Ah} \cdot \mathrm{cm}^{-2}$ & {$[14]$} \\
$\mathrm{Li} / \mathrm{Li}_{4} \mathrm{SiO}_{4} / \mathrm{LiCoO}_{2}$ & $10 \mu \mathrm{Ah} \cdot \mathrm{cm}^{-2}$ & {$[44]$} \\
$\mathrm{SnO} / \mathrm{Li}_{6.1} \mathrm{~V}_{0.61} \mathrm{Si}_{0.39} \mathrm{O}_{5.36} / \mathrm{LiCoO}_{2}$ & $9.5 \mathrm{Ah} \cdot \mathrm{cm}^{-2}$ at $44 \mu \mathrm{A} \cdot \mathrm{cm}^{-2}$ & {$[41]$} \\
$\mathrm{In} / 80 \mathrm{Li}_{2} \mathrm{~S}-20 \mathrm{P}_{2} \mathrm{~S}_{5} / \mathrm{LiCoO}_{2}$ & $95 \mathrm{mAh} \cdot \mathrm{g}^{-1}$ at $0.13 \mathrm{~mA} \cdot \mathrm{cm}^{-2}$ & {$[42]$} \\
$\mathrm{Li} / \mathrm{Li}_{3} \mathrm{PO}_{4} / \mathrm{LiMnPO}_{4}$ & $12 \mathrm{mAh} \cdot \mathrm{g}^{-1}$ & {$[45]$} \\
$\mathrm{Li} / \mathrm{LiPON} / \mathrm{Li}_{4} \mathrm{Ti}_{5} \mathrm{O}_{12}$ & $32 \mu \mathrm{Ah} \cdot \mathrm{cm}^{-2}$ at $3.5 \mu \mathrm{A} \cdot \mathrm{cm}^{-2}$ & {$[43]$} \\
\hline
\end{tabular}

\section{Positive Electrode PLD Films}

The main parameter for a microbattery is the delivered specific capacity. Rather than being expressed as the conventional unit of $\mathrm{mAh} \cdot \mathrm{g}^{-1}$, due to the uncertainty in the film density, technologists prefer the stored charge, $Q$ (expressed in $\mu$ Ah or in coulomb), per film surface area and the film thickness, i.e., $\mu \mathrm{Ah} \cdot \mathrm{cm}^{-2} \cdot \mu \mathrm{m}^{-1}$ of $\mathrm{mC} \cdot \mathrm{cm}^{-2} \cdot \mu \mathrm{m}^{-1}$. The relation between the gravimetric capacity, $Q_{m}$, of the material and the volumetric capacity of a film, $Q_{f}$, is given by:

$$
Q_{f}=0.36 d Q_{m}
$$

where $Q_{f}$ is expressed in $\mathrm{mC} \cdot \mathrm{cm}^{-2} \cdot \mu \mathrm{m}^{-1}, Q_{m}$ in $\mathrm{mAh} \cdot \mathrm{g}^{-1}$, and $d$ is the density of the material in $\mathrm{g} \cdot \mathrm{cm}^{-3}$. Table 4 summarizes the energetic quantities for the studied cathode compounds. 
Table 4. Characteristics of the oxide materials used as a positive electrode in Li batteries. $\Delta x_{\mathrm{m}}$ is the quantity of electrons transferred (or Li uptake).

\begin{tabular}{|c|c|c|c|c|}
\hline TMO Material & Density $\left(\mathrm{g} / \mathrm{cm}^{3}\right)$ & $C_{m}\left(\mathrm{mAh}^{-1}\right)$ for $\Delta x_{\mathrm{m}}$ & $C_{f}\left(\mu \mathrm{A} \cdot \mathrm{cm}^{-2} \cdot \mu \mathrm{m}^{-1}\right)$ & $C_{f}\left(\mathrm{mC} \cdot \mathrm{cm}^{-2} \cdot \mu \mathrm{m}^{-1}\right)$ \\
\hline $\mathrm{V}_{2} \mathrm{O}_{5}$ & 3.35 & $294\left(\Delta x_{\mathrm{m}}=2\right)$ & 98.5 & 354 \\
\hline $\mathrm{MoO}_{3}$ & 4.69 & $279\left(\Delta x_{m}=2\right)$ & 130.8 & 471 \\
\hline $\mathrm{LiCoO}_{2}$ & $5.03^{a}$ & $137\left(\Delta x_{\mathrm{m}}=0.5\right)$ & 68.9 & 248 \\
\hline $\mathrm{LiNi}_{0.5} \mathrm{Co}_{0.5} \mathrm{O}_{2}$ & $4.90^{\mathrm{a}}$ & $274\left(\Delta x_{\mathrm{m}}=1\right)$ & 134.2 & 483 \\
\hline $\mathrm{LiMn}_{2} \mathrm{O}_{4}$ & $4.32^{\mathrm{a}}$ & $148\left(\Delta x_{\mathrm{m}}=1\right)$ & 64.0 & 274 \\
\hline
\end{tabular}

a after Ozuku, T.; Ueda, A. J. Electrochem. Soc. 1994, 141, 2972.

\section{1. $\mathrm{LiCoO}_{2}(\mathrm{LCO})$}

Having a lamellar structure, $\mathrm{LiCoO}_{2}$ (LCO) is the prototypal positive electrode material commonly used in Li-ion batteries that yields a practical specific capacity of $135 \mathrm{mAh} \cdot \mathrm{g}^{-1}$ in the voltage range from $\sim 3.8 \mathrm{~V}$ (fully lithiated state) to $\sim 4.2 \mathrm{~V}$ (charge state at $\mathrm{Li}_{0.5} \mathrm{CoO}_{2}$ ) [46]. Since the early work in 1996 by Berkeley's group [47], numerous studies have been devoted to the growth of $\mathrm{LiCoO}_{2}$ thin films prepared by the PLD technique due in large to their high electrochemical performances. Further investigations of dense and well-defined PLD films described the phase evolution during $\mathrm{Li}$ extraction and the kinetics of $\mathrm{Li}^{+}$ions in the host lattice, which eventually found applications in the fabrication of the cathode element in microbattery stacks [48]. The two crystal forms, HT- and LT- $\mathrm{LiCoO}_{2}$ phases, with the rock-salt (rhombohedral, $R-3 m$ space group) and spinel (cubic, $F d 3 m$ space group) structure, respectively, have been synthesized by pulsed-laser deposition. It was pointed out that the crystallographic texture for LCO films differs from one deposit technique to another, i.e., PLD versus sputtering, which influences the electrochemical properties due to the diffusion plane orientation [49]. Julien et al. stated that well-crystallized PLD-grown LCO thin films with a single layered structure can be obtained at substrate temperatures $\left(T_{\mathrm{s}}\right)$ as low as $300^{\circ} \mathrm{C}$ [3].

The first growth of single phase LCO films by the PLD method was realized by Antaya et al. [4]. Films deposited on unheated stainless-steel substrates were amorphous but crystallized readily with heat treatment in air above $500{ }^{\circ} \mathrm{C}$. Later, Striebel et al. [47] demonstrated the promise of PLD-grown films as cathodes for rechargeable lithium cells. Crystalline (003)-textured LCO films with thicknesses ranging from 0.2 to $1.5 \mu \mathrm{m}$ were prepared without postdeposition treatment, which displayed a specific capacity of films of $62 \mu \mathrm{Ah} \cdot \mathrm{cm}^{2} \cdot \mu \mathrm{m}^{-1}$ and an Li diffusion coefficient of $1 \times 10^{-10} \mathrm{~cm}^{2} \cdot \mathrm{s}^{-1}$. Highly dense LCO films were first elaborated by the PLD process using a KrF laser under oxygen flow rates of $30 \mathrm{sccm}$ and the pressure was maintained at $260 \mathrm{~Pa}$ on (200)-textured F-doped $\mathrm{SnO}_{2}$ on fa used silica substrate maintained at $T_{\mathrm{s}}=700{ }^{\circ} \mathrm{C}$ [49]. As-prepared LCO thin films were (001) textured and had a density of $85 \%$ of the single crystal. The charge-discharge profile of the films was typical of the LCO bulk and presented an $\sim 18 \%$ capacity loss for a single cycle to $4.15 \mathrm{~V}$. In the potential range of 4.14 to $4.19 \mathrm{~V}$, the measured chemical diffusion coefficients ranged from $1.7 \times 10^{-12}$ to $2.6 \times 10^{-9} \mathrm{~cm}^{2} \cdot \mathrm{s}^{-1}$ for as-deposited films and films annealed at $700{ }^{\circ} \mathrm{C}$, respectively. Structural analysis of nanostructured LCO films prepared with PLD has been conducted by several research groups. Julien et al. $[3,8,50]$ analyzed changes of the stoichiometry (i.e., the absence of the $\mathrm{Co}_{3} \mathrm{O}_{4}$ amorphous phase) as a function of the growth conditions using Raman spectroscopy. The inclusion of $\mathrm{Co}_{3} \mathrm{O}_{4}$ impurity is detected by analysis of the Raman intensity of the $A_{1 \mathrm{~g}}$ modes. Impurity-free films exhibit a specific capacity as high as $195 \mathrm{mC} \cdot \mathrm{cm}^{-2} \cdot \mu \mathrm{m}^{-1}$ for polycrystalline films grown from an Li-rich target (i.e., excess of $15 \%$ $\mathrm{Li}_{2} \mathrm{O}$ ). The work by Okada et al. revealed that a decrease of the amount of inclusions can be obtained by a lower laser fluence and lower $T_{\mathrm{S}}$ [51]. Figure 2 presents the relationship between the impurity inclusions and growth conditions of PLD-grown LCO films established from spectroscopic Raman data. In this figure, the $\mathrm{Co}_{3} \mathrm{O}_{4}$ phase is grown under the conditions of high $P_{\mathrm{O}_{2}}$, i.e., above the gray dashed line. 


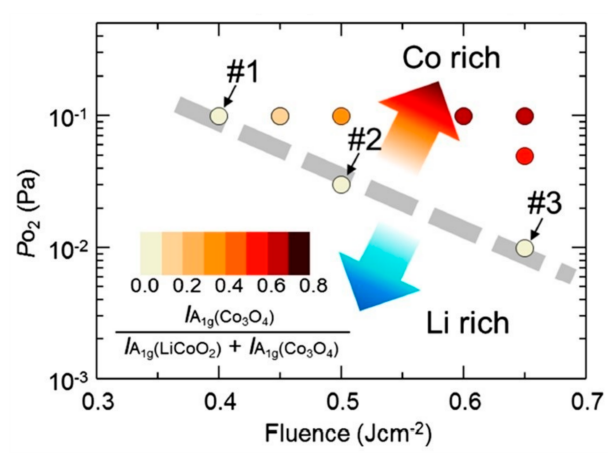

Figure 2. The relationship between impurity inclusions and growth conditions of PLD-grown LCO films established from spectroscopic Raman data (Reproduced with permission from [51]. Copyright 2017 AIP Publishing).

Ohnishi et al. $[52,53]$ stated that suppression of the $\mathrm{Co}_{3} \mathrm{O}_{4}$ spinel phase can be ensured by the growth under a relatively low oxygen partial pressure. Zhang et al. [54] discussed the effect of the deposition conditions on the structure and morphology. The advantages of the preferential orientation of LCO films prepared by PLD has been discussed by numerous groups with the conclusion that dense uniaxial textured (003)-oriented films are obtained by a well-chosen substrate [6,53,55-59]. However, Xia et al. [59] stated that the fast transport of $\mathrm{Li}^{+}$ions is obtained for LCO films with a random orientation, in contrast with the results obtained with films having (003)-preferred orientation. Contrastingly, Nishio et al. claimed an excellent electrochemical performance for epitaxially grown LCO (77-nm thick) with a (104)-orientation on a (100) $\mathrm{Nb}: \mathrm{SrTiO}_{3}$ substrate that exhibited a discharge capacity of $26 \mathrm{mAh} \cdot \mathrm{g}^{-1}$ even at high rates up to 100C [60]. Huo et al. stated that the film orientation is strongly dependent on the thickness and size of grains and demonstrated that films structured with parallel (003) planes are grown for thicknesses up to $300 \mathrm{~nm}$ [11]. Liu et al. showed that under certain PLD conditions, such as a high repetition rate of $35 \mathrm{~Hz}$ and low oxygen partial pressure of $P_{\mathrm{O}_{2}}=1 \mathrm{~Pa}$, LCO films tend to grow LCO films with a random orientation [61].

Epitaxial LCO thin films deposited on (001) $-\mathrm{Al}_{2} \mathrm{O}_{3}$ substrates remained in a single phase in a narrow range, $250 \leq T_{\mathrm{s}} \leq 300^{\circ} \mathrm{C}$, whereas secondary phases appeared at $T_{\mathrm{s}}>300^{\circ} \mathrm{C}$, i.e., $\mathrm{Co}_{2} \mathrm{O}_{3}, \mathrm{Co}_{3} \mathrm{O}_{4}$, and $\mathrm{LiCo}_{2} \mathrm{O}_{4}$ [5]. Xia et al. established that thin LCO films can be easily grown with a (003) orientation because of the lowest surface energy for the (003) plane, while the minimized strain energy in thick LCO films allows preferential (101) and (104) textures. It seems that this last type of orientation favors the electrochemical performance of the LCO cathode [12]. The reduction of the laser fluence results in a decrease of the surface roughness of LCO films. With post annealing at $400{ }^{\circ} \mathrm{C}$ and optimized deposition conditions, LCO films exhibit an initial discharge capacity of $36 \mu \mathrm{Ah} \cdot \mathrm{cm}^{-2} \cdot \mu \mathrm{m}^{-1}$ and a cycleability of $94 \%$ [57]. Composition control was monitored to prepare stoichiometric LCO films using an Li-enriched target with a high-rate growth via an increase of the laser fluence to $0.29 \mathrm{~J} \cdot \mathrm{cm}^{-2}$ and an adjustment of the $P_{\mathrm{O}_{2}}$ to scatter the excess lithium. Ohnishi et al. showed that by using a $\mathrm{Li}_{1.1} \mathrm{CoO}_{2+\delta}$ target, the deposition of stoichiometric LCO with the highest crystallinity can be realized at the rate of $0.06 \AA$ per pulse at the $P_{\mathrm{O}_{2}}$ of $0.1 \mathrm{~Pa}$ and $T_{\mathrm{s}}=800^{\circ} \mathrm{C}$ (Figure 3) $[52,62]$.

Recently, Nishio et al. claimed that a high deposition rate of $1.2 \AA \cdot \mathrm{s}^{-1}$ tends to form oxygen-deficient LCO films due to the destabilization of $\mathrm{Co}^{3+}$ cations and showed that post-annealing in air cancels the impurity phase [63]. Funayama et al. studied the effects of mechanical stress applied to LCO films ( $200 \mathrm{~nm}$ thick) deposited on Li-glass ceramic by the PLD method at $600{ }^{\circ} \mathrm{C}$ under a $20 \mathrm{~Pa}$ oxygen partial pressure for $1 \mathrm{~h}$. Due to the lattice volume change, the generated electromotive force was $6.1 \times 10^{-12} \mathrm{~V} \cdot \mathrm{Pa}^{-1}$ [64]. The electrode behavior shows an increase of the discharge capacity from 10 to $40 \mathrm{mAh} \cdot \mathrm{g}^{-1}$ at a $2 \mathrm{C}$ rate with an increase of the $T_{\mathrm{s}}$ from 600 to $750{ }^{\circ} \mathrm{C}$, whereas a $T_{\mathrm{s}}=800{ }^{\circ} \mathrm{C}$ worsens the performance. Studies of the physico-chemistry of PLD-grown LCO thin films report the structural, surface morphology, optical, and electrical properties [65-67]. 

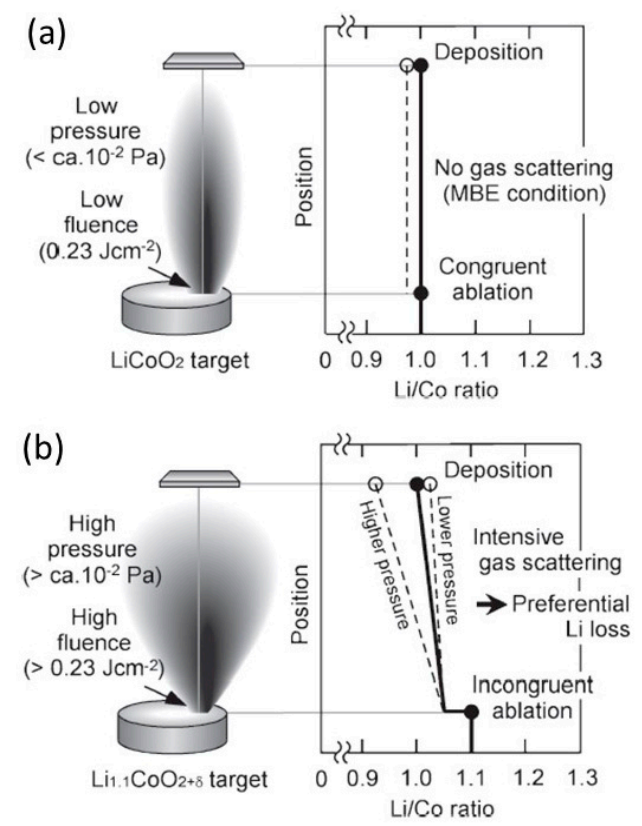

Figure 3. Schematic representation of the fast-laser ablation growth according to the $\mathrm{Li} / \mathrm{Co}$ ratio variation of the plume for a stoichiometric (a) and Li-enriched target (b). (Reproduced with permission from [62]. Copyright 2012 IOP Publishing).

The electrochemical properties, i.e., thermodynamics and kinetics, of lithium intercalation in PLD LCO thin films have been widely investigated by the structure-electrochemistry relationship [59,68-70]; structural evolution upon charge-discharge cycles [71]; effect of doping by $\mathrm{Ti}, \mathrm{Al}$, and $\mathrm{Mg}$ [49,72-74]; characterization of the electrode/electrolyte interface [75]; and lithium-ion kinetics vs. basal plane orientation [76-80]. Highly (003)-oriented impurity-free LCO thin films grown by PLD on a stainless-steel substrate display an initial discharge capacity of $52.5 \mu \mathrm{Ah} \cdot \mathrm{cm}^{-2} \cdot \mu \mathrm{m}^{-1}$ and a capacity loss of $0.18 \%$ per cycle at a moderate current density of $12.7 \mu \mathrm{A} \cdot \mathrm{cm}^{-2}$. These films show a very small lattice expansion upon charge, i.e., $0.09 \AA$ for a charge of $4.2 \mathrm{~V}$ [81]. Figure 4 shows the typical electrochemical features of PLD LCO thin films grown on an Si wafer maintained at different temperatures. Both the specific discharge capacity and the mid-voltage increased with increasing $T_{\mathrm{s}}$. For a film deposited at $T_{\mathrm{s}}=300{ }^{\circ} \mathrm{C}$ under $P_{\mathrm{O}_{2}}=15 \mathrm{~Pa}$, the discharge capacity reached a value $\sim 140 \mathrm{mC} \cdot \mathrm{cm}^{-2} \cdot \mu \mathrm{m}^{-1}$.

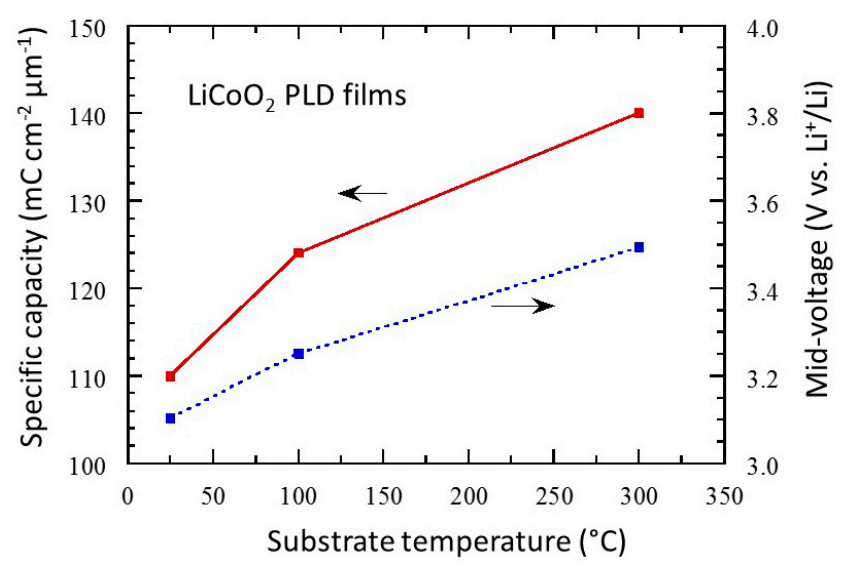

Figure 4. Electrochemical features of PLD-grown LCO thin films: specific discharge capacity and discharge mid-voltage vs. substrate temperature. 
The electrochemical behavior of doped LCO thin films show that the voltage plateau at $3.65 \mathrm{~V}$ disappears in the charge curve of $\mathrm{LiTi}_{0.05} \mathrm{Co}_{0.95} \mathrm{O}_{2}$ due to the doping effect, which cancels the semiconductor-metal-like transition of the $\mathrm{LCO}$ framework [81]. The Al-doped $\mathrm{LCO}$ film $\left(\mathrm{LiCo}_{0.5} \mathrm{Al}_{0.5} \mathrm{O}_{2}\right)$ exhibits a steady increase in the voltage vs. Li extraction with the absence of a voltage plateau as observed in stoichiometric LCO films; however, such films suffered from a limited capability and an upper bound of the diffusion coefficient of $\operatorname{Li}\left(D^{*}=9 \times 10^{-13} \mathrm{~cm}^{2} \cdot \mathrm{s}^{-1}\right)$ was observed [49]. Recent studies report on the improved electrochemical behavior of surface-modified LCO films using lithium tantalate $(\mathrm{LTaO})$ and lithium niobite $(\mathrm{LNbO})$. Coating with $\mathrm{LNbO}$ preserves the $\mathrm{LCO}$ surface and decreases the interfacial resistance, which indicates fast lithium transport [82]. LCO films modified by amorphous tungsten oxide (LWO) fabricated by PLD show a high capacity retention of $Q_{\mathrm{r}}=80 \%$ at a high rate of $20 \mathrm{C}$, against $Q_{\mathrm{r}}=0 \%$ for bare LCO films cycled at the same C-rate. A slight increase of the superficial diffusion coefficient of $\mathrm{Li}^{+}$ions from $2.2 \times 10^{-13}$ and $3.0 \times 10^{-13} \mathrm{~cm}^{2} \cdot \mathrm{s}^{-1}$ was also observed, owing to the surface modification [83-86]. Note that LWO as well as LNBO are lithium ion conductors, which act as an efficient buffer between the electrolyte and LCO cathode. The structural degradation of cycled LCO films was investigated by Raman spectroscopy over 400 cycles, showing microstructural modification due to nanocrystallization and phase separation [87].

All-solid-state lithium microbatteries (SSLMB) using $\mathrm{LiCoO}_{2}$ films have been developed using various inorganic solid electrolyte (SE) films, i.e., $\mathrm{LiPON}, \mathrm{Li}_{2} \mathrm{~S}-\mathrm{P}_{2} \mathrm{~S}_{5}$, and amorphous $\mathrm{Li}_{3} \mathrm{PO}_{4}$. The thin-film battery with an electrochemical chain $\mathrm{Li} /$ amorphous $\mathrm{Li}_{3} \mathrm{PO}_{4} / \mathrm{LCO} / \mathrm{Pt}$ shows a columnar-like LCO cathode (see the cross-sectional SEM image in Figure 5a) [88]. The excellent electrochemical performance is displayed in Figure 5b. This microcell exhibited an increase in capacity of up to $240 \mu \mathrm{Ah} \cdot \mathrm{cm}^{-2}$ when increasing the LCO thickness to $6.7 \mu \mathrm{m}$, which is $54 \%$ of the theoretical specific capacity of LCO $\left(69 \mu \mathrm{Ah} \cdot \mathrm{cm}^{-2} \cdot \mu \mathrm{m}^{-1}\right)$. Shiraki et al. fabricated an SSLMB with an epitaxial LCO thin-film cathode (200 nm thick) by using PLD with a polycrystalline $\mathrm{Li}_{1.1} \mathrm{CoO}_{2}$ target ablated at a laser fluence of $1 \mathrm{~J} \cdot \mathrm{cm}^{-2}$, LiPON solid electrolyte ( $2 \mu \mathrm{m}$ thick), and Li film as the anode (0.5 $\mu \mathrm{m}$ thick) [89]. The authors reported cyclic voltammograms with six redox peaks, which drastically changed upon cycling but did not display the galvanostatic charge-discharge profile of the SSLMB.
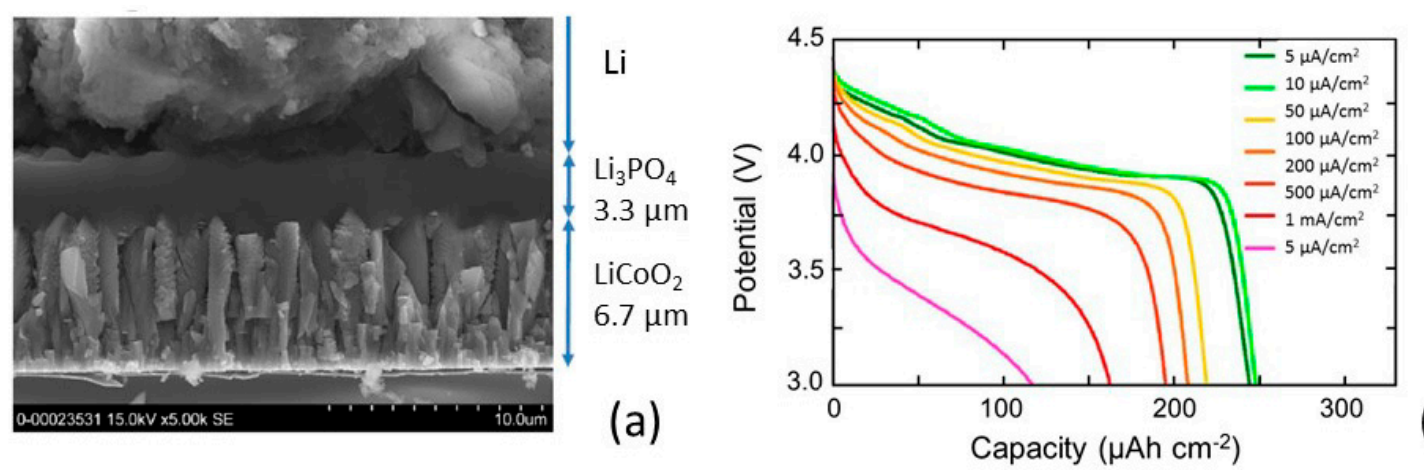

(b)

Figure 5. (a) SEM image cross-section of a $\mathrm{Li} /$ amorphous $\mathrm{Li}_{3} \mathrm{PO}_{4} / \mathrm{LCO}$ thin-film microbatteries.

(b) Discharge curves for various current densities in the voltage range of 3.0 to $4.5 \mathrm{~V} \mathrm{vs.} \mathrm{Li}^{+} / \mathrm{Li}$.

(Reproduced with permission from [88]. Copyright 2014 Elsevier).

\section{2. $\mathrm{LiNiO}_{2}(\mathrm{LNO})$}

PLD-grown thin films of lithium nickel oxide (LNO), i.e., $\mathrm{Li}_{x} \mathrm{Ni}_{1-x} \mathrm{O}$ and stoichiometric $\mathrm{LiNiO}_{2}$, are applied as electrochromic and/or battery electrodes. In an early work, Rubin et al. established the complex relationship of the surface morphology and chemical composition of $\mathrm{Li}_{x} \mathrm{Ni}_{1-x} \mathrm{O}$ thin films vs. the deposition oxygen partial pressure, substrate temperature, and substrate-target distance as well [90]. LNO films produced at $T_{\mathrm{s}}<600^{\circ} \mathrm{C}$ immediately absorb $\mathrm{CO}_{2}$ and $\mathrm{H}_{2} \mathrm{O}$ when exposed to air, whereas they show long-term stability for $T_{\mathrm{s}}=600^{\circ} \mathrm{C}$. LNO film with a composition of $\mathrm{Li}_{0.5} \mathrm{Ni}_{0.5} \mathrm{O}$ (cubic rock-salt $F d-3 m$ structure instead of the rhombohedral $R-3 m$ structure for $\mathrm{LiNiO}_{2}$ ) was obtained under 
a deposition atmosphere of $P_{\mathrm{O}_{2}}=60$ mTorr. This film (150-nm thick) showed excellent electrochemical reversibility as an electrochromic item in the range of 1.0 to $3.4 \mathrm{~V} \mathrm{vs}$. $\mathrm{Li}^{+} / \mathrm{Li}$. An electrochromic device using $\mathrm{WO}_{3}$ as the opposite electrode and PEO/LiTFSI as the solid polymer electrolyte $(250-\mu \mathrm{m}$ thick) showed an optical transmission range of $\approx 70 \%$ at $550 \mathrm{~nm}$. Bouessay et al. optimized the PLD conditions to prepare $\mathrm{NiO}$ films, i.e., $P_{\mathrm{O}_{2}}=0.1 \mathrm{mbar}$ and $T_{\mathrm{s}}=25{ }^{\circ} \mathrm{C}$, and analyzed the electrochromic reversibility associated with the $\mathrm{Ni}^{3+} / \mathrm{Ni}^{2+}$ redox couple [91]. Using a laser fluence of 1 to $2 \mathrm{~J} \cdot \mathrm{cm}^{-2}$, which corresponded to an ablation rate of $0.9 \AA \cdot \mathrm{s}^{-1}, \mathrm{NiO}$ films with a cubic rock-salt structure $(F m-3 m$ space group) were formed. Porous PLD NiO films were prepared using nickel foil as the target in a low oxygen atmosphere $\left(P_{\mathrm{O}_{2}}=50 \mathrm{~Pa}\right)[92,93]$ and were applied as the electrode for supercapacitors, showing a high specific capacitance of $835 \mathrm{~F} \cdot \mathrm{g}^{-1}$ at a $1 \mathrm{~A} \cdot \mathrm{g}^{-1}$ current density.

Similarly to LCO, the PLD growth of stoichiometric $\mathrm{LiNiO}_{2}$ with an $\alpha-\mathrm{NaFeO}_{2}$ layered structure requests an $\mathrm{Li}$-enriched target, i.e., $\mathrm{LiNiO}_{2}+15 \% \mathrm{Li}_{2} \mathrm{O}$. López-Iturbe and coworkers attempted to avoid Li loss by using an Ar atmosphere of $P_{\mathrm{Ar}}=10 \mathrm{mTorr}$ and laser fluence of $15 \mathrm{~J} \cdot \mathrm{cm}^{-2}$ [94], while Rao et al. introduced pure oxygen $\left(P_{\mathrm{O}_{2}}=0.1\right.$ Torr $)$ in the PLD chamber and ablated the target at a laser fluence of $10 \mathrm{~J} \cdot \mathrm{cm}^{-2}$ [95]. The LNO films prepared at $T_{\mathrm{s}}=700^{\circ} \mathrm{C}$ exhibited an initial discharge capacity of $175 \mathrm{mC} \cdot \mathrm{cm}^{-2} \cdot \mathrm{mm}^{-1}$. Yuki et al. used, as the oxygen evolution reaction (OER), electrocatalysts, which were prepared LNO films from a target composed of $\mathrm{Li}_{2} \mathrm{O}$ and $\mathrm{NiO}_{2}$ sintered at $1000{ }^{\circ} \mathrm{C}$ for $8.5 \mathrm{~h}$ in air ablated by a Nd:YAG laser operating at $532 \mathrm{~nm}$ [96]. Recently, PLD $\mathrm{Li}_{x} \mathrm{Ni}_{2-x} \mathrm{O}_{2}$ thin films with $0.15 \leq x \leq 0.45$ deposited on a glass substrate under a pressure of $0.1 \mathrm{~Pa}$ and annealed at $350{ }^{\circ} \mathrm{C}$ were grown by PLD with an $\mathrm{LiNiO}_{2}$ structure. The films appeared to be entirely made of particles even in the cross-section (grain size of $95 \mathrm{~nm}$ for $x=0.45$ ). The average surface roughness estimated from the AFM measurements decreased with an increasing $x$, reaching a value of $0.615 \mathrm{~nm}$ for $x=0.45$ [97].

\section{3. $\mathrm{LiNi}_{1-y} \mathrm{Co}_{y} \mathrm{O}_{2}(\mathrm{NCO})$}

The $\mathrm{LiNi}_{1-y} \mathrm{Co}_{y} \mathrm{O}_{2}(0<y<1)$ system with a layered $\alpha-\mathrm{NaFeO}_{2}$ structure belongs to a $\mathrm{LiCoO}_{2}-\mathrm{LiNiO}_{2}$ solid solution with a higher reversible capacity than LCO and better cycleability than LNO. Among these substituted oxides, Ni-rich $\mathrm{LiNi}_{0.8} \mathrm{Co}_{0.2} \mathrm{O}_{2}$ (NCO) has been identified as one the most attractive cathodes [98]. In this context, several works investigated the growth of NCO thin films using pulsed-laser deposition. Dense PLD NCO films grown at $T_{\mathrm{s}}>400^{\circ} \mathrm{C}$ exhibited a gravimetric density of $4.8 \mathrm{~g} \cdot \mathrm{cm}^{-3}$ [99]. Ramana et al. grew NCO films deposited on an Ni foil substrate at temperatures of $25 \leq T_{\mathrm{s}} \leq 500{ }^{\circ} \mathrm{C}$ under $P_{\mathrm{O}_{2}}=6$ to $18 \mathrm{~Pa}$ from Li-rich ceramic $\left(15 \mathrm{~mol} \% \mathrm{Li}_{2} \mathrm{O}\right.$ excess to avoid $\mathrm{NiO}$ or $\mathrm{Co}_{3} \mathrm{O}_{4}$ impurity phases) [100]. At $T_{\mathrm{s}} \leq 300^{\circ} \mathrm{C}$, the PLD film showed the highest intensity of the (00l) reflection, which indicates that the $c$-axis was normal to the film surface. The XRD (003) diffraction peak at $2 \theta=18.5^{\circ}$ corresponds to an interplanar spacing of $0.145 \mathrm{~nm}$. Phase diagram mapping (Figure 6) was proposed to highlight the effect of the growth temperature on the microstructure of PLD $\mathrm{LiNi}_{0.8} \mathrm{Co}_{0.2} \mathrm{O}_{2}$ films. Galvanostatic titration carried out at a rate of $C / 30$ in the potential range of 2.5 to $4.2 \mathrm{~V}$ showed a discharge capacity of $82 \mu \mathrm{Ah} \cdot \mathrm{cm}^{-2} \mu \mathrm{m}^{-1}$, which compares with the theoretical value of $136 \mu \mathrm{Ah} \cdot \mathrm{cm}^{-2} \cdot \mu \mathrm{m}^{-1}\left(490 \mathrm{mC} \cdot \mathrm{cm}^{-2} \cdot \mu \mathrm{m}^{-1}\right)$ [101].

Hirayama et al. fabricated NCO films using the standard PLD conditions $(\Phi=100-220 \mathrm{~mJ}$, $P_{\mathrm{O}_{2}}=3.3 \mathrm{~Pa}$, target composition $\mathrm{Li} / \mathrm{Ni}(\mathrm{Co})=1.3$, and $\left.T_{\mathrm{s}}=600-650{ }^{\circ} \mathrm{C}\right)$ at a deposition rate of $0.3 \mathrm{~nm} \cdot \mathrm{min}^{-1}$ on an oriented $\mathrm{SrTiO}_{3}$ (STO) substrate. Microstructural analysis shows a misfit of ca. $5 \%$ and roughness of 1 to $3 \mathrm{~nm}$ for the film grown with an in-plane orientation at $T_{\mathrm{s}}=600{ }^{\circ} \mathrm{C}$. AFM imaging revealed the surface modification for films cycled in the voltage range of 2 to $5 \mathrm{~V}$ [102]. PLD NCO films ( $0.62 \mu \mathrm{m}$ thick) were electrochemically characterized by galvanostatic titration (GITT), cyclic voltammetry (CV), and electrochemical impedance spectroscopy (EIS). Films grown at $T_{\mathrm{S}}=600{ }^{\circ} \mathrm{C}$ under $P_{\mathrm{O}_{2}}=13 \mathrm{~Pa}$ with a laser fluence of $\Phi=450 \mathrm{~mJ}$ per pulse exhibited an average specific capacity of $\sim 60 \mu \mathrm{Ah} \cdot \mathrm{cm}^{-2} \cdot \mu \mathrm{m}^{-1}$ and the $\mathrm{Li}^{+}$diffusion coefficient varied from $3 \times 10^{-13}$ to $2 \times 10^{-10} \mathrm{~cm}^{2} \cdot \mathrm{s}^{-1}$. After 100 cycles, the electrode showed a capacity retention of 85\% [103]. The kinetics of the Li-ion intercalation in PLD NCO films grown on an Nb-doped STO substrate at $T_{\mathrm{s}}=600^{\circ} \mathrm{C}$ under $P_{\mathrm{O}_{2}}=3.3 \mathrm{~Pa}$ were investigated by EIS [104]. Nyquist plots showed changes of the electrode impedance as a function 
of the Li extraction/insertion with a larger value at a potential of $4.2 \mathrm{~V}$. Baskaran et al. prepared NCO films on Pt and Si substrates heated at $T_{\mathrm{s}}=500{ }^{\circ} \mathrm{C}$ under a low oxygen partial pressure of $0.21 \mathrm{~Pa}$ [105]. The 40-min deposited films (120-nm thick) displayed a specific discharge capacity of $69.6 \mu \mathrm{Ah} \mathrm{cm}^{-2} \cdot \mu \mathrm{m}^{-1}\left(145 \mathrm{mAh} \cdot \mathrm{g}^{-1}\right)$ after 10 cycles. Based on these results, a Li-ion microbattery was fabricated with a $\mathrm{LNCO} / \mathrm{Li}_{3.4} \mathrm{~V}_{0.6} \mathrm{Si}_{0.4} \mathrm{O}_{4}(\mathrm{LVSO}) / \mathrm{SnO}$ configuration with a thickness of $\sim 1.5 \mu \mathrm{m}$. Such a microcell delivered a capacity of $16.1 \mu \mathrm{Ah} \cdot \mathrm{cm}^{-2} \cdot \mu \mathrm{m}^{-1}$ after 20 cycles.

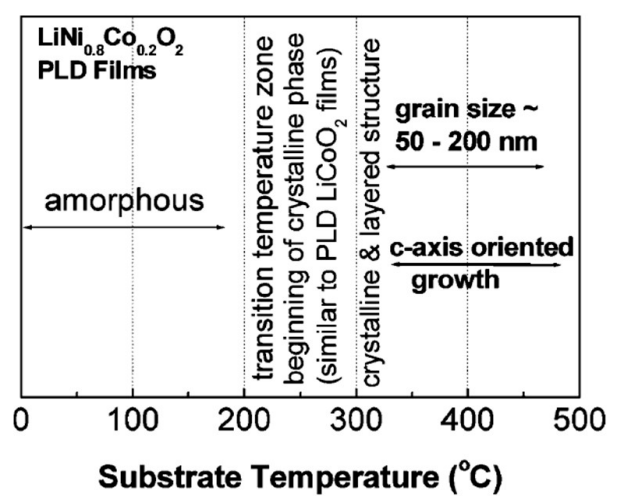

Figure 6. Phase diagram of microstructure development in PLD $\mathrm{LiNi}_{0.8} \mathrm{Co}_{0.2} \mathrm{O}_{2}$ films as a function of the growth temperature. (Reproduced with permission from [100]. Copyright 2006 American Chemical Society).

\section{4. $\mathrm{LiNi}_{1-y} \mathrm{Mn}_{y} \mathrm{O}_{2}$ (NMO)}

The substitution of $\mathrm{Mn}$ for $\mathrm{Ni}$ has been demonstrated to be beneficial for $\mathrm{LiNiO}_{2}$ cathode materials. $\mathrm{LiNi}_{0.5} \mathrm{Mn}_{0.5} \mathrm{O}_{2}$ (NMO) thin films were prepared on stainless steel and gold substrates from an Li-enriched target with an $\mathrm{Li} /(\mathrm{Ni}+\mathrm{Mn})$ ratio of 1.5 in the $\mathrm{NiO}+\mathrm{MnO}_{2}$ mixture. Under standard conditions $\left(\Phi=2 \mathrm{~J} \cdot \mathrm{cm}^{-2}, T_{\mathrm{s}}=550{ }^{\circ} \mathrm{C}\right.$, and $\left.P_{\mathrm{O}_{2}}=266 \mathrm{~Pa}\right)$, impurity-free and (001)-textured PLD films (300-500 nm thick) were obtained after an annealing process at $650{ }^{\circ} \mathrm{C}$ [106]. Galvanostatic charge-discharge tests showed that NMO films deposited on stainless steel displayed an electrochemical response, with a large voltage plateau between 2.5 and $3 \mathrm{~V}$ attributed to the presence of spinel phases (i.e., $\mathrm{LiMn}_{2} \mathrm{O}_{4}$ and $\mathrm{LiNi}_{0.5} \mathrm{Mn}_{1.5} \mathrm{O}_{4}$ ), while $\mathrm{NMO}$ films prepared on $\mathrm{Au}$ substrate showed the typical fingerprint of the $\mathrm{LiMO}_{2}$ layered compound with a single plateau at ca. $3.7 \mathrm{~V}$. The analysis of the kinetics from $\mathrm{CV}$ measurements in the 2.5 to 4.5 voltage range led to a diffusion coefficient of the $\mathrm{Li}^{+}$-ions of $D^{*}=3.13 \times 10^{-13} \mathrm{~cm}^{2} \cdot \mathrm{s}^{-1}$ for the Li insertion and $7.44 \times 10^{-14} \mathrm{~cm}^{2} \cdot \mathrm{s}^{-1}$ for the Li extraction. GITT results showed that $D^{*}$ is highly dependent on the electrode potential in the range of $10^{-12}$ to $10^{-16} \mathrm{~cm}^{2} \cdot \mathrm{s}^{-1}$ [107]. Sakamoto et al. addressed the growth of epitaxial PLD NMO films with an orientation of the basal layered plane (BLP) that depends on the $\mathrm{SrTiO}_{3}$ (STO) substrate plane: The BLP is parallel to the $S T O(110)$ substrate, while the BLP is perpendicular to the $S T O(111)$ substrate. The relationship between the lattice parameters and applied voltage highlights the charge-discharge processes for both orientations [108]. In a second article, Sakamoto et al. examined the structural properties of the surface and bulk of $\mathrm{LiNi}_{0.5} \mathrm{Mn}_{0.5} \mathrm{O}_{2}$ epitaxial thin films during an electrochemical reaction using in situ X-ray scattering [109]. In normal conditions, the two-dimensional diffusion of Li during (de)intercalation proceeds for the (110) plane. However, 3D-diffusion activity can be observed for a high degree of cation mixing $\left(\mathrm{Ni}^{2+}\right.$ in $\mathrm{Li}(3 a)$ sites $)$.

\section{5. $\mathrm{Li}(\mathrm{Ni}, \mathrm{Co}, \mathrm{Al}) \mathrm{O}_{2}(\mathrm{NCA})$}

The growth of $\mathrm{LiNi}_{0.8} \mathrm{Co}_{0.15} \mathrm{Al}_{0.05} \mathrm{O}_{2}$ (NCA) has been envisaged because Al-doping provides excellent structural and thermal stability for the electrode with the suppression of phase transitions. NCA thin films were prepared on Ni substrates at $T_{\mathrm{s}}=500^{\circ} \mathrm{C}$ by PLD with an energy and laser-pulse repetition rate of $300 \mathrm{~mJ}$ and $10 \mathrm{~Hz}$, respectively, under $P_{\mathrm{O}_{2}}=18 \mathrm{~Pa}$. The PLD target (i.e., pellet pressed at 1.5 to $5.0 \times 10^{3} \mathrm{~kg} \cdot \mathrm{cm}^{-2}$ ), optimized by using bulk NCA Li-enriched with $15 \mathrm{~mol} \% \mathrm{Li}_{2} \mathrm{O}$ as the 
precursor, was sintered at $800{ }^{\circ} \mathrm{C}$ for $24 \mathrm{~h}$ [110]. The Li//NCA microcells delivered an initial specific capacity of $92 \mu \mathrm{Ah} \cdot \mathrm{cm}^{-2} \cdot \mu \mathrm{m}^{-1}$. The kinetics of $\mathrm{Li}^{+}$ions in PLD films measured by the GITT method in the voltage range of 2.50 to $4.25 \mathrm{~V}$ vs. $\mathrm{Li}^{+} / \mathrm{Li}$ revealed a diffusion coefficient of $4 \times 10^{-11} \mathrm{~cm}^{2} \cdot \mathrm{s}^{-1}$ with a maximum of $1 \times 10^{-10} \mathrm{~cm}^{2} \cdot \mathrm{s}^{-1}$ for the composition of $\mathrm{Li}_{0.7} \mathrm{Ni}_{0.8} \mathrm{Co}_{0.15} \mathrm{Al}_{0.05} \mathrm{O}_{2}$. Figure 7 displays the specific capacity of $\mathrm{Li} / / \mathrm{LiNi}_{0.8} \mathrm{Co}_{0.15} \mathrm{Al}_{0.05} \mathrm{O}_{2}$ cells as a function of the substrate temperature. PLD films were grown onto various substrates at $25 \leq T_{\mathrm{s}} \leq 500{ }^{\circ} \mathrm{C}$ under a controlled $\mathrm{O}_{2}$ atmosphere $\left(P_{\mathrm{O}_{2}}=50 \mathrm{mTorr}\right)$. NCA thin films prepared onto Ni foil at $T_{\mathrm{s}}=500{ }^{\circ} \mathrm{C}$ exhibited the best specific discharge capacity of $100 \mu \mathrm{A} \cdot \mathrm{cm}^{-2} \cdot \mu \mathrm{m}^{-1}$.

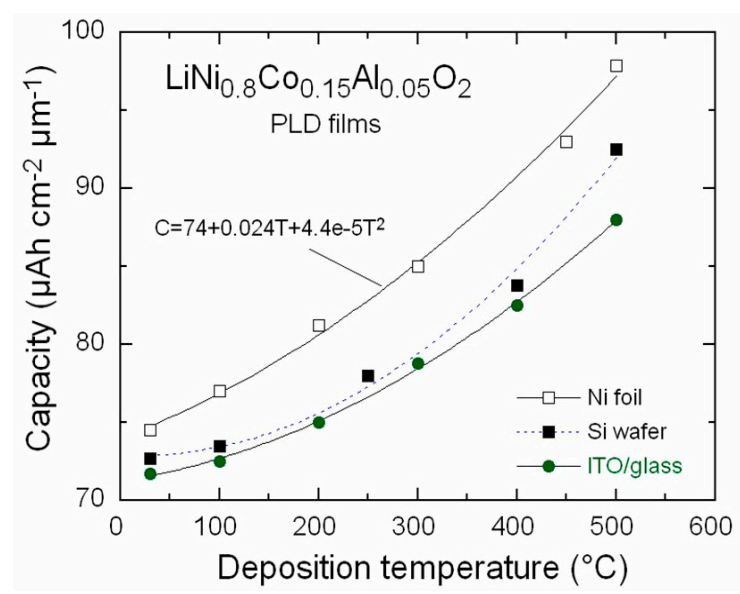

Figure 7. The specific capacity of $\mathrm{LiNi}_{0.8} \mathrm{Co}_{0.15} \mathrm{Al}_{0.05} \mathrm{O}_{2}$ thin films deposited onto Ni foil, Si wafer, and ITO-coated glass as a function of the substrate temperature.

\section{6. $\mathrm{Li}(\mathrm{Ni}, \mathrm{Mn}, \mathrm{Co}) \mathrm{O}_{2}(\mathrm{NMC})$}

Lithiated nickel-manganese-cobalt oxides, $\mathrm{LiNi}_{1-y-z} \mathrm{Mn}_{y} \mathrm{Co}_{z} \mathrm{O}_{2}$ (NMC), is a complex $\mathrm{LiNiO}_{2}-$ $\mathrm{LiMnO}_{2}-\mathrm{LiCoO}_{2}$ solid solution, which displays the same structure as rock salt, $\alpha-\mathrm{NaFeO}_{2}$, with a valence state of cations as $\mathrm{Ni}^{2+}, \mathrm{Mn}^{4+}$, and $\mathrm{Co}^{3+}$. $\mathrm{LiNi}_{1 / 3} \mathrm{Co}_{1 / 3} \mathrm{Mn}_{1 / 3} \mathrm{O}_{2}$ (NMC333) thin film electrodes were prepared by pulsed laser deposition on a $\mathrm{Pt} / \mathrm{Ti} / \mathrm{SiO}_{2} / \mathrm{Si}$ substrate (where the $150-\mathrm{nm}$ thick $\mathrm{Pt}$ and the 100-nm thick Ti films act as the current collector and buffer layer, respectively) at room temperature under a $P_{\mathrm{O}_{2}}$ of $6.6 \mathrm{~Pa}$. The deposition rate was about $4.4 \mathrm{~nm} \cdot \mathrm{min}^{-1}$. Impurity-free NMC333 films were obtained using an Li-enriched target $\left(15 \%\right.$ excess $\left.\mathrm{Li}_{2} \mathrm{O}\right)$. The charge-discharge profiles strongly depended on the film morphology that was tuned by increasing the annealing temperature from 400 to $500^{\circ} \mathrm{C}$. The best electrochemical features were obtained for annealing at $450^{\circ} \mathrm{C}$, showing a discharge plateau of about 3.7 and 3.6 V [111]. Epitaxial and highly textured $\mathrm{LiNi}_{0.5} \mathrm{Mn}_{0.3} \mathrm{Co}_{0.2} \mathrm{O}_{2}(\mathrm{NMC532})$ thin film cathodes were deposited by a one-step PLD process [112]. Using a laser fluence of $\Phi=6 \mathrm{~J} \cdot \mathrm{cm}^{-2}$, $T_{\mathrm{S}}=750{ }^{\circ} \mathrm{C}$, and an Li-enriched target $\left(20 \% \mathrm{Li}_{2} \mathrm{CO}_{3}\right.$ excess), the films were deposited on silicon (111), stainless steel (SS), and c-cut sapphire (0001) substrates. It was stated that highly dense and epitaxial films with a strong (003) reflection peak intensity are achieved at high $T_{\mathrm{s}}$. Films grown on an Au-SS substrate delivered $125 \mathrm{mAh} \cdot \mathrm{g}^{-1}$ at $0.5 \mathrm{C}$ and demonstrated a $72 \%$ capacity retention after 100 cycles. Furthermore, 3D-electrode architectures were fabricated, and are applicable to power hearing aids. Structured NMC333 film electrodes (50-80 $\mu \mathrm{m}$ thick) were prepared by laser printing using a pulsed laser $(\lambda=355 \mathrm{~nm})$ at a fluence of 50 to $100 \mathrm{~mJ} \cdot \mathrm{cm}^{-2}$. Such films exhibit a stable discharge capacity at a low C-rate (0.1C), but for a current density of $1 \mathrm{C}$, the electrode reached $40 \%$ of the initial capacity [113]. Recently, Abe et al. elucidated the deterioration mechanism of pristine $\mathrm{ZrO}_{2}$-coated NMC333 thin films prepared by PLD on a (110)STO substrate maintained at two temperatures of 25 and $700{ }^{\circ} \mathrm{C}$; the oxygen pressure ranged from 3.3 to $10 \mathrm{~Pa}$ [114]. Characterization was performed by cyclic voltammetry, in situ X-ray diffraction, and in situ neutron reflectometry. As a result, $\mathrm{ZrO}_{2}$ coating suppressed the low activity of the spinel phase formed at the surface and hence improved the cycleability of the thin film electrode. 


\subsection{Li-Rich Layered Oxides}

The growth of Li-rich layered oxide $\mathrm{Li}_{1.2} \mathrm{Mn}_{0.55} \mathrm{Ni}_{0.15} \mathrm{Co}_{0.1} \mathrm{O}_{2}$ on SRO/STO(100) and SRO/STO(111) substrate (where SRO and STO are $\mathrm{SrRuO}_{3}$ and $\mathrm{SrTiO}_{3}$, respectively) heated at $T_{\mathrm{s}}=600{ }^{\circ} \mathrm{C}$ was reported by Bendersky et al. [115]. The transmission electron microscopy (TEM) images recorded using a high-angle annular dark field (HAADF) mode showed a predominant $\mathrm{Li}_{2}(\mathrm{Mn}, \mathrm{Ni}, \mathrm{Co}) \mathrm{O}_{3}$ monoclinic phase. Johnston-Peck et al. confirmed the growth of monoclinic Li-rich thin films ( $\mathrm{C} 2 / \mathrm{m}$ space group) using a target with the composition of $\mathrm{Li}_{1.2} \mathrm{Mn}_{0.55} \mathrm{Ni}_{0.15} \mathrm{Co}_{0.1} \mathrm{O}_{2}$ and displayed the $\mathrm{CV}$ response with a non-aqueous electrolyte at a scan rate of $0.1 \mathrm{mV} \cdot \mathrm{s}^{-1}$ [116]. Yan et al. intended to develop a PLD thin film electrode using an Li-rich layer structured oxide with a composition of $\mathrm{Li}_{1.2} \mathrm{Mn}_{0.54} \mathrm{Ni}_{0.13} \mathrm{Co}_{0.13} \mathrm{O}_{2}$ (or written as $0.55 \mathrm{Li}_{2} \mathrm{MnO}_{3} \cdot 0.45 \mathrm{LiNi}_{1 / 3} \mathrm{Co}_{1 / 3} \mathrm{Mn}_{1 / 3} \mathrm{O}_{2}$ ) [117]. Films deposited at $T_{\mathrm{s}}=650{ }^{\circ} \mathrm{C}$ under $P_{\mathrm{O}_{2}}=46 \mathrm{~Pa}$ and annealed at $800^{\circ} \mathrm{C}$ showed the best electrochemical performance with an initial specific discharge capacity of $70 \mu \mathrm{Ah} \cdot \mathrm{cm}^{-2} \cdot \mu \mathrm{m}^{-1}$. However, the differential capacity curves, $\mathrm{d} Q / \mathrm{d} V$, indicated that the layered structure gradually changed to the spinel phase during the charge-discharge cycling.

\section{8. $\mathrm{Li}_{2} \mathrm{MO}_{3}(\mathrm{M}=\mathrm{Mn}, \mathrm{Ru})$}

Pulsed-laser deposited $\mathrm{Li}_{2} \mathrm{MnO}_{3}$ thin films at various thicknesses $(12<\delta<48 \mathrm{~nm})$ were grown using a $\mathrm{KrF}$ excimer laser on $\mathrm{Nb}: \mathrm{SrTiO}_{3}(111)$ substrates from an $\mathrm{Li}$-rich $\mathrm{Li}_{3.2} \mathrm{MnO}_{3}$ target. With synthetic conditions $\left(T_{\mathrm{s}}=650{ }^{\circ} \mathrm{C}, P_{\mathrm{O}_{2}}=75 \mathrm{~Pa}\right.$, and $\left.\Phi=0.8-1.1 \mathrm{~J} \cdot \mathrm{cm}^{-2}\right)$ and a laser frequency of $f=1$ to $5 \mathrm{~Hz}, \mathrm{PLD} \mathrm{Li} 2 \mathrm{MnO}_{3}(111)$ films exhibited a single-phase with the $\mathrm{C} 2 / m$ symmetry. The results of ICP analysis gave a composition of $\mathrm{Li}_{1.90} \mathrm{Mn}^{\mathrm{IV}} \mathrm{O}_{2.95}$, which indicates lithium and oxygen vacancies. The highest discharge capacity of $300 \mathrm{mAh} \cdot \mathrm{g}^{-1}$ was delivered after 50 cycles by a 12.6-nm thick film [118]. PLD epitaxial $\mathrm{Li}_{2} \mathrm{RuO}_{3}$ thin films were successfully prepared with a (010) and (001) orientation on STO(110) and (111) substrates heated at $T_{\mathrm{S}}=500$ to $550^{\circ} \mathrm{C}$ under $P_{\mathrm{O}_{2}}=3.3 \mathrm{~Pa}$. The initial charge-discharge capacities calculated using a theoretical density of $5.15 \mathrm{~g} \cdot \mathrm{cm}^{-3}$ were 120 and $105 \mathrm{mAh} \cdot \mathrm{g}^{-1}$ at a $0.5 \mathrm{C}$ rate for the (010) and (001) orientation, respectively $[119,120]$.

\section{9. $\mathrm{LiMn}_{2} \mathrm{O}_{4}(\mathrm{LMO})$}

Since the early report in 1996 [47], numerous studies have been devoted to $\mathrm{LiMn}_{2} \mathrm{O}_{4}$ (LMO) thin films grown by laser ablation. A spinel structure ( $F d 3 m$ space group) was successfully prepared using different PLD conditions and applied as a positive electrode in thin-film lithium microbatteries (see, for example, [121]). Most prior works focused on the fundamental properties of PLD-grown LMO cathode films, aiming to deposit the highly structured and porous morphology required for a good operating electrode [7,122-136]. Morcrette et al. analyzed PLD film composition as a function of $T_{\mathrm{s}}$ and $P_{\mathrm{O}_{2}}$ using the Rutherford backscattering method and nuclear reaction analysis [122]. A stoichiometric LMO film was obtained at $T_{\mathrm{s}}=500{ }^{\circ} \mathrm{C}$ and $P_{\mathrm{O}_{2}}=20 \mathrm{~Pa}$, while the $\mathrm{Li} / \mathrm{Mn}$ ratio decreased with $T_{\mathrm{s}}$ and increased with $P_{\mathrm{O}_{2}}$. The film of $\mathrm{Li}_{0.6} \mathrm{Mn}_{2} \mathrm{O}_{3}$ (20\% oxygen loss) was obtained under vacuum. The $\mathrm{Mn}_{3} \mathrm{O}_{4}+\mathrm{MnO}$ and $\mathrm{Mn}_{3} \mathrm{O}_{4}+\mathrm{LiMn}_{2} \mathrm{O}_{4}$ mixed phases were successively grown in the range of $0.01 \leq P_{\mathrm{O}_{2}} \leq 1 \mathrm{~Pa}$. Julien et al. defined the conditions of the disposition of LMO films grown on $\mathrm{Si}$ substrates. Impurity-free well-crystallized samples with a crystallite size of $300 \mathrm{~nm}$ were obtained at $T_{\mathrm{s}}$ as low as $300{ }^{\circ} \mathrm{C}$ and $P_{\mathrm{O}_{2}}=10 \mathrm{~Pa}$ using an Li-enriched target $\left(15 \% \mathrm{Li}_{2} \mathrm{O}\right.$ excess) to avoid $\mathrm{Li}$ deficiency in the film [123]. The electrochemical features of the Li cell showed a specific capacity as high as $120 \mathrm{mC} \cdot \mathrm{cm}^{-2} \cdot \mu \mathrm{m}^{-1}$ in the voltage range of 3.0 to $4.2 \mathrm{~V} \mathrm{vs.} \mathrm{Li}^{+} / \mathrm{Li}$, which was attributed to the high degree of film crystallinity $[7,123]$. Simmen et al. studied the relationship between $\mathrm{Li}_{1+x} \mathrm{Mn}_{2} \mathrm{O}_{4-\delta}$ thin films and Li excess in the target and concluded that a film deposited from a composite target of $\mathrm{Li}_{1.03} \mathrm{Mn}_{2} \mathrm{O}_{4-\delta}+7.5 \mathrm{~mol} \% \mathrm{Li}_{2} \mathrm{O}$ was the best, exhibiting a discharge capacity of $42 \mu \mathrm{Ah} \cdot \mathrm{cm}^{-2} \cdot \mu \mathrm{m}^{-1}$ [127]. Various substrates were successfully used for the epitaxial growth of $\mathrm{LiMn}_{2} \mathrm{O}_{4}$ (LMO) spinel thin films, such as $\mathrm{Pt}, \mathrm{Si}, \mathrm{Au}, \mathrm{MgO}, \mathrm{Al}_{2} \mathrm{O}_{3}$, and $\mathrm{SrTiO}_{3}$. Gao et al. [128] reported a detailed mechanism of the epitaxial LMO film/substrate (current collector) interface formation. A coherent hetero-interface was formed with the substrate but a tetragonal Jahn-Teller distortion was 
observed, induced by oxygens' non-stoichiometry and the lattice misfit strain. PLD epitaxial LMO thin films were deposited on oriented $\mathrm{Nb}: \mathrm{SrTIO}_{3}$ substrates maintained at $950{ }^{\circ} \mathrm{C}$ from a sintered target with $100 \mathrm{wt} . \%$ excess $\mathrm{Li}_{2} \mathrm{O}$ with different surface morphologies and orientations, such as (100)-oriented pyramidal, (110)-oriented rooftop, or (111)-oriented flat structure. The pyramidal-type LMO was cycled at a 3.3C rate, demonstrating a specific capacity of $90 \mathrm{mAh} \cdot \mathrm{g}^{-1}$ after 1000 cycles [129]. Using oriented substrates, i.e., (111) Nb:SrTiO ${ }_{3}$ (STO) and (001) $\mathrm{Al}_{2} \mathrm{O}_{3}$ single crystal, $\mathrm{LMO}$ films were grown with the (111) orientation under the following synthesis conditions: Li-enriched target ( $\mathrm{Li} / \mathrm{Mn}=0.6)$, $T_{\mathrm{s}}=650{ }^{\circ} \mathrm{C}$, and $P_{\mathrm{O}_{2}}=30 \mathrm{~Pa}$ [130]. Electrochemical tests emphasized the interactions between the films and substrate, and showed a plateau voltage at 3.6 to $3.8 \mathrm{~V}$ for LMO/STO and 3.8 to $4.1 \mathrm{~V}$ for LMO/alumina. Canulescu et al. [131] investigated the mechanisms of laser-plume expansion during the PLD of LMO films under $P_{\mathrm{O}_{2}}$ ranging between $10^{-4}$ and $20 \mathrm{~Pa}$. The Li deficiency occurs as a result of the different behavior of the species at elevated $T_{\mathrm{s}}$. Hussain et al. [132,133] obtained highly oriented $\mathrm{LiMn}_{2} \mathrm{O}_{4}$ thin films on oriented $\mathrm{Si}$ substrates heated in the range of $100 \leq T_{\mathrm{s}} \leq 600{ }^{\circ} \mathrm{C}$ under $P_{\mathrm{O}_{2}}=10 \mathrm{~Pa}$ and with a laser fluence of $\Phi=10 \mathrm{~J} \cdot \mathrm{cm}^{-2}$. Grains with a spherical shape (around $230 \mathrm{~nm}$ in diameter) changed to a flake-like structure at $T_{\mathrm{s}}=600^{\circ} \mathrm{C}$ (Figure 8a). The grain size varied almost linearly with the substrate temperature (Figure $8 \mathrm{~b}$ ).

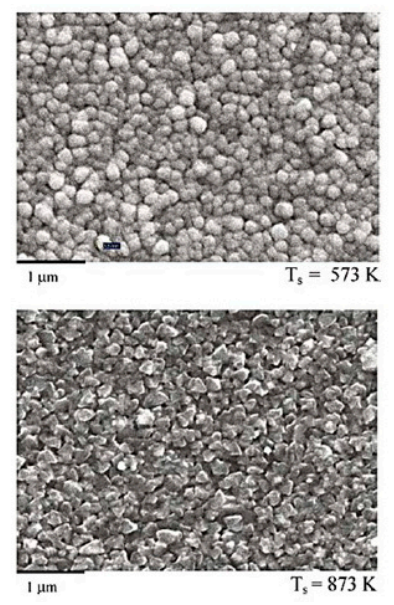

(a)

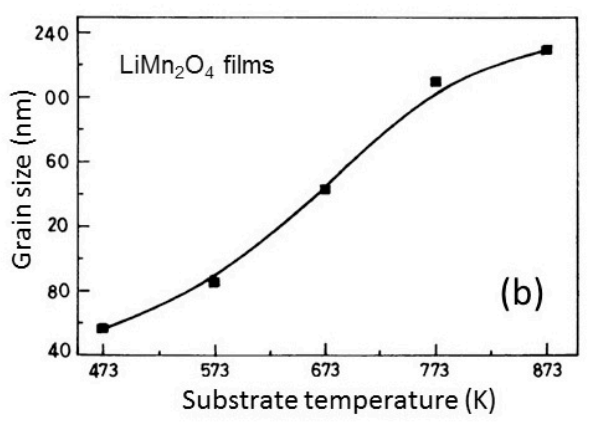

Figure 8. (a) SEM images of $\mathrm{LiMn}_{2} \mathrm{O}_{4}$ films deposited at $T_{\mathrm{S}}=300{ }^{\circ} \mathrm{C}$ and $T_{\mathrm{S}}=600{ }^{\circ} \mathrm{C}$. (b) The grain size of PLD thin films as a function of $T_{\mathrm{s}}$. (Reproduced with permission from [133]. Copyright 2007 Springer).

By applying an elevated-temperature PLD technique, Tang et al. [134] studied the influence of the substrate temperature $\left(T_{\mathrm{s}}\right)$ and the oxygen partial pressure $\left(P_{\mathrm{O}_{2}}\right)$ on LMO film crystallinity. LMO thin films deposited on $\mathrm{Si}(001) / 0.2 \mu \mathrm{m}-\mathrm{SiO}_{2}$ substrates at $575^{\circ} \mathrm{C}$ under $13 \mathrm{~Pa}$ oxygen had a flat and smooth surface and exhibited mainly a (111) out-of-plane preferred texture (Figure 9a). Such films of the $300 \mathrm{~nm}$ thickness showed a very dense cross-section (density $\sim 4.3 \mathrm{~g} \cdot \mathrm{cm}^{-3}$ ) (see Figure $9 \mathrm{~b}$ ) [135]. The effect of stoichiometric deviations on the electrochemical performance of an LMO thin-film cathode was investigated by Morcrette et al. [136], while the kinetics of $\mathrm{Li}^{+}$ions in the LMO thin-film framework were documented by Yamada and coworkers [137]. A high-activation barrier of $50 \mathrm{~kJ} \cdot \mathrm{mol}^{-1}$ for Li-ion transfer was identified at the electrode/electrolyte interface for films deposited at $T_{\mathrm{s}}=700{ }^{\circ} \mathrm{C}$ and $P_{\mathrm{O}_{2}}=27 \mathrm{~Pa}$. Albrecht et al. [138] reported the minimum crystallization temperature of spinel LMO thin films in a narrow annealing temperature range of around $700{ }^{\circ} \mathrm{C}$. Electrochemical tests carried out with the galvanostatic cycling with the potential limits (GCPL) method proved that Li-ions are (de-)intercalated in different tetrahedral sites for which the processes occur at potentials that are slightly shifted by $U \approx 100 \mathrm{mV}$, which is similar to the previous results by Julien et al. [7]. 


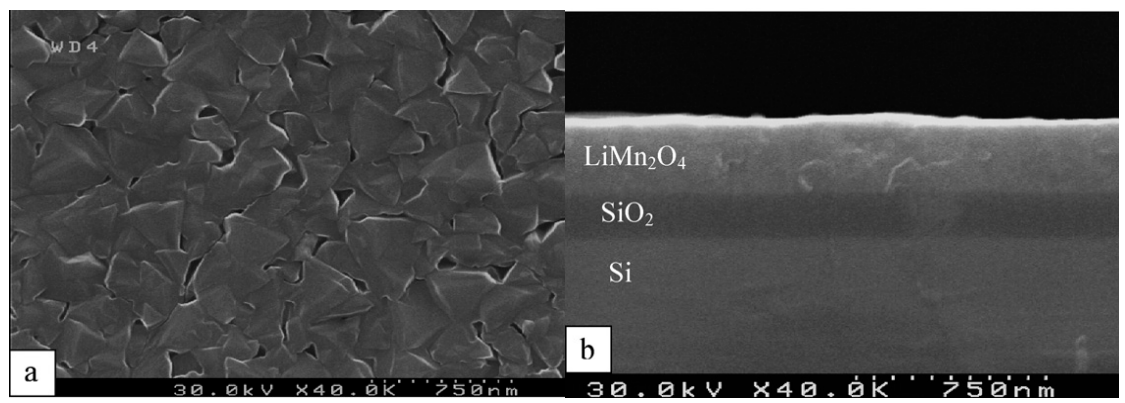

Figure 9. (a) Surface morphology and (b) cross-sectional picture of PLD-grown LMO thin film deposited on an $\mathrm{Si}(001)$ substrate covered by a $0.2 \mu \mathrm{m} \mathrm{SiO}$ layer at $575{ }^{\circ} \mathrm{C}$ under a $13 \mathrm{~Pa}$ oxygen partial pressure. (Reproduced with permission from [135]. Copyright 2008 Elsevier).

Studies of the structure and electrochemical reactivity of heteroepitaxial $\mathrm{LiMn}_{2} \mathrm{O}_{4} / \mathrm{La}_{0.5} \mathrm{Sr}_{0.5} \mathrm{CoO}_{3}$ (LMO/LSCO) bilayer thin films deposited on crystalline $\mathrm{SrTiO}_{3}$ substrates show that $\mathrm{LSCO}$ reduced the lattice misfit strain with the substrate and favored a lower LMO surface roughness. However, a decrease of the electrical conductivity occurred during the electrochemical test (after first cycle) due to the lattice oxygen loss at the outermost layer $(40 \mathrm{~nm})$ [139]. Tang et al. reported a comparative investigation of the structures, morphologies, and properties of Li insertion for LMO films with different crystallizations. At $T_{\mathrm{s}}=400^{\circ} \mathrm{C}$, LMO films consisted of nanocrystallites $<100 \mathrm{~nm}$ in size with rough surfaces that exhibited a discharge capacity of $61 \mu \mathrm{Ah} \cdot \mathrm{cm}^{2} \cdot \mu \mathrm{m}^{-1}$ with a capacity loss of $0.032 \%$ per cycle up to 500 cycles, while for $T_{\mathrm{s}}=600^{\circ} \mathrm{C}$ and $P_{\mathrm{O}_{2}}=10 \mathrm{~Pa}$, highly crystallized films showed an initial discharge capacity of $54.3 \mu \mathrm{Ah} \cdot \mathrm{cm}^{2} \cdot \mu \mathrm{m}^{-1}$ [134]. The intrinsic properties of PLD-grown LMO have been investigated by several techniques. Electrical measurements of LMO films showed that the conductivity is sensitive to $T_{\mathrm{s}}$, as the activation energy that followed the Mott's rule increased with $T_{\mathrm{s}}$ up to $E_{\mathrm{a}}=0.64 \mathrm{eV}$ at $T_{\mathrm{s}}=600{ }^{\circ} \mathrm{C}$ [133]. Singh et al. characterized the crystallinity and texture of LMO films deposited at $T_{\mathrm{s}}=650^{\circ} \mathrm{C}$. Here, (111)-oriented films were grown on a doped Si substrate, while films deposited on a stainless-steel substrate exhibited a (001) orientation [140]. The thermo-power (or Seebeck coefficient) of PLD LMO films was reported to be $70 \mu \mathrm{V} \cdot \mathrm{K}^{-1}$ [141].

PLD LMO films were subjected to an overcharge $\left(5 \mathrm{~V}\right.$ vs. $\left.\mathrm{Li}^{+} / \mathrm{Li}\right)$, which did not modify the structure and preserved the well-resolved voltage peaks at 4.1 and $4.2 \mathrm{~V}$, while an overdischarge (2 V vs. $\mathrm{Li}^{+} / \mathrm{Li}$ ) led to a loss of capacity due to the structural disorder associated with the tetragonal transition, i.e., Jahn-Teller distortion [142]. Singh patented the fabrication of PLD Li $i_{1-x} M_{y} \mathrm{Mn}_{2-2 z} \mathrm{O}_{4}$ films, where $M$ is a doping element $(M=\mathrm{Al}, \mathrm{Ni}, \mathrm{Co}, \mathrm{Cr}, \mathrm{Mg}$, etc.) and $x, y$, and $z$ vary from 0.0 to 0.5 [143]. These defective spinel structures enhanced the oxygen content as compared to $\mathrm{LiMn}_{2} \mathrm{O}_{4}$ crystal. In particular, the oxygen-rich $\mathrm{Li}_{1-\delta} \mathrm{Mn}_{2-\delta} \mathrm{O}_{4}$ films were superior cathode films, leading to excellent rechargeable battery performances. It is claimed that a high discharge rate of $25 \mathrm{C}$ produces only a $25 \%$ capacity loss and a specific capacity $>150 \mathrm{mAh} \cdot \mathrm{g}^{-1}$ remains after 300 cycles. Rao et al. reported the preparation of well-crystallized LMO films at a high substrate temperature of $T_{\mathrm{s}}=700{ }^{\circ} \mathrm{C}$ and $P_{\mathrm{O}_{2}}=13 \mathrm{~Pa}$ that delivered a capacity of $133 \mathrm{mC} \cdot \mathrm{cm}^{-2} \cdot \mu \mathrm{m}^{-1}$ at a very slow $\mathrm{C} / 100$ rate [144]. Several workers reported the evolution of the thin-film electrode/electrolyte interface, as the planar form of the film is the ideal geometry for such investigations [145-148]. Room temperature impedance measurements were carried out to identify the formation of the solid electrolyte interface (SEI) layer on a PLD LMO film cathode and the degradation mechanism during cycling in an aprotic electrolyte containing $\mathrm{LiPF}_{6}$ salt. A reversible disproportionation reaction was suggested with the formation of the $\mathrm{Li}_{2} \mathrm{Mn}_{2} \mathrm{O}_{4}$ and $\lambda-\mathrm{MnO}_{2}$ phases at the surface [146]. Using epitaxial-film model electrodes, Hirayama studied the surface reaction and the formation of the SEI layer and the interfacial structural reconstruction during an initial battery process using in situ surface X-ray diffraction and reflectometry [147]. TEM images confirmed the surface reconstruction that occurred during the first charge, i.e., when a potential was applied. After 10 cycles, the SEI layer was observed on both the (111) and (110) surfaces and Mn dissolution appeared at the (110) surface [148]. Inaba et al. [149] investigated the surface morphology evolution of PLD LMO thin films 
grown on a PT substrate at $T_{\mathrm{S}}=600^{\circ} \mathrm{C}$ by electrochemical scanning tunneling microscopy (STM) with voltage cycling in the range of 3.5 to $4.25 \mathrm{~V}$. The original LMO grains of $400 \mathrm{~nm}$ in size coexisted with small particles 120 to $250 \mathrm{~nm}$ in size, which appeared after 20 cycles and decreased to $\sim 70 \mathrm{~nm}$ after 75 cycles through a kind of dissolution/precipitation process. LMO thin-film electrodes with a grain size of $<100 \mathrm{~nm}$ deposited on a stainless steel substrate at $T_{\mathrm{s}}=40{ }^{\circ} \mathrm{C}$ under a $26 \mathrm{~Pa}$ oxygen partial pressure displayed an excellent capacity of $62.4 \mu \mathrm{Ah} \cdot \mathrm{cm}^{-2} \cdot \mu \mathrm{m}^{-1}$ when cycled at a $20 \mu \mathrm{A} \cdot \mathrm{cm}^{-2}$ current density in the voltage range of 3.0 to $4.5 \mathrm{~V}$. A very low capacity fading was recorded for up to 500 cycles at $55^{\circ} \mathrm{C}$. $\mathrm{Li}^{+}$-ion diffusion coefficients evaluated from EIS measurements were around $2.7 \times 10^{-12} \mathrm{~cm}^{2} \cdot \mathrm{s}^{-1}$ for an electrode charged at $4.0 \mathrm{~V}$ and $2.4 \times 10^{-11} \mathrm{~cm}^{2} \cdot \mathrm{s}^{-1}$ for $4.2 \mathrm{~V}$ [150]. Xie et al. [151] investigated the $\mathrm{Li}^{+}$-ion transport in LMO thin films ( $100 \mathrm{~nm}$ thick) grown on Au substrates at $600{ }^{\circ} \mathrm{C}$ at a deposition rate of $0.14 \mathrm{~nm} \cdot \mathrm{min}^{-1}$. The chemical diffusion coefficients determined by the EIS, GITTm, and PITT methods were in the range of $10^{-14}$ to $10^{-11} \mathrm{~cm}^{2} \cdot \mathrm{s}^{-1}$ in the voltage range of 3.9 to $4.2 \mathrm{~V}$. Table 5 lists some typical results on the kinetics of $\mathrm{Li}^{+}$ions in pulsed-laser deposited $\mathrm{LMO}$ thin films.

Table 5. Diffusion coefficients of $\mathrm{Li}^{+}$ions in PLD LMO thin film frameworks.

\begin{tabular}{ccccc}
\hline Growth Conditions & $\left.\boldsymbol{T}_{\mathbf{s}}{ }^{\circ}{ }^{\circ} \mathbf{C}\right)$ & Method & $\begin{array}{c}\text { Diffusion Coefficient } \\
\left(\mathbf{c m}^{-2} \cdot \mathbf{s}^{-\mathbf{1}} \mathbf{c}\right.\end{array}$ & Ref. \\
\hline$P_{\mathrm{O}_{2}}=13 \mathrm{~Pa}$ & 800 & GITT & $2.5 \times 10^{-11}$ & {$[47]$} \\
$P_{\mathrm{O}_{2}}=13 \mathrm{~Pa}, P=10^{8} \mathrm{~W} \cdot \mathrm{cm}^{-2}$ & 300 & GITT & $10^{-11}-10^{-12}$ & {$[7]$} \\
$P_{\mathrm{O}_{2}}=30 \mathrm{~Pa}, \Phi=1.0 \mathrm{~mJ} \cdot \mathrm{cm}^{-2}$ & 600 & EIS/PITT/GITT & $10^{-11}-10^{-14}$ & {$[151]$} \\
$P_{\mathrm{O}_{2}}=26 \mathrm{~Pa}, P$ pulse $=160 \mathrm{~mJ}$ & 400 & PITT & $10^{-10}-10^{-12}$ & {$[152]$} \\
$P_{\mathrm{O}_{2}}=20 \mathrm{~Pa}, \Phi=1.1 \mathrm{~mJ} \cdot \mathrm{cm}^{-2}$ & 500 & Li radiotracer & $1.4 \times 10^{-10}\left(300^{\circ} \mathrm{C}\right)$ & {$[153]$} \\
$P_{\mathrm{O}_{2}}=0.2 \mathrm{~Pa}, \Phi=3.5 \mathrm{~mJ} \cdot \mathrm{cm}^{-2}$ & 350 & Li radiotracer & $1.8 \times 10^{-12}\left(350^{\circ} \mathrm{C}\right)$ & {$[154]$} \\
$P_{\mathrm{O}_{2}}=10 \mathrm{~Pa}, \Phi=2.0 \mathrm{~mJ} \cdot \mathrm{cm}^{-2}$ & 650 & Chronoamperometry & $8.4 \times 10^{-10}$ & {$[155]$} \\
\hline
\end{tabular}

The electrochemical behavior of Li-rich spinel $\mathrm{Li}_{1.1} \mathrm{Mn}_{1.9} \mathrm{O}_{4}$ thin films grown by PLD on an $\mathrm{Au}$ substrate was reported by several workers $[156,157]$. The best performance was reported at a discharge current density of the 36C-rate for LMO films deposited for $30 \mathrm{~min}$ in $P_{\mathrm{O}_{2}}=30 \mathrm{~Pa}$ and $T_{\mathrm{s}}=600{ }^{\circ} \mathrm{C}$ with an Nd:YAG laser (266 nm) adjusted to an energy fluence of $1 \mathrm{~J} \cdot \mathrm{cm}^{-2}$ [156]. Nanocrystalline LMO films with grains less than $100 \mathrm{~nm}$ were deposited on a stainless-steel substrate at $T_{\mathrm{s}}=400{ }^{\circ} \mathrm{C}$ and $P_{\mathrm{O}_{2}}=26 \mathrm{~Pa}$ using a PLD pulse power of $100 \mathrm{~mJ}$ at the frequency of $10 \mathrm{~Hz}$. The film cycled over 100 cycles delivered a specific capacity of $118 \mathrm{mAh} \cdot \mathrm{g}^{-1}$ at a current density of $100 \mathrm{~A} \cdot \mathrm{cm}^{-2}$ [157]. Using reflectometry measurements, Hirayama et al. [158] studied the structural modifications at the electrode/electrolyte interface of a lithium cell, in which the LMO electrodes were prepared as epitaxial films by the PLD method with different orientations. The respective orientation of the LMO film corresponded to that of the substrate plane, i.e., the (111), (110), and (100) planes of the $\mathrm{SrTiO}_{3}$ substrate. No density change was observed for the (110) and (100) planes, whereas a defect layer was detected in the (111) plane. $\mathrm{ZrO}_{2}$-modified $\mathrm{LiMn}_{2} \mathrm{O}_{4}$ thin films prepared via PLD consisting of amorphous $\mathrm{ZrO}_{2}$ formed on the grain boundary and the outer layer of the LMO matrix [159]. The high capacity retention of $82 \%$ after 130 cycles of films of $x \mathrm{ZrO}_{2}-(1-x) \mathrm{LiMn}_{2} \mathrm{O}_{4}(x=0.025)$ monitored at the $4 \mathrm{C}$ rate was attributed to the decrease of the charge transfer resistance $\left(R_{\mathrm{ct}}\right)$.

Epitaxial $\mathrm{LiMn}_{2} \mathrm{O}_{4} / \mathrm{La}_{0.5} \mathrm{Sr}_{0.5} \mathrm{CoO}_{3}$ (LMO/LSCO) bilayer thin films with sub-nano flat interfaces were deposited on (111)-oriented STO substrates at $T_{\mathrm{s}}=650{ }^{\circ} \mathrm{C}$ in $P_{\mathrm{O}_{2}}=4 \mathrm{~Pa}$. After the first charge-discharge cycle, the decrease of the electrical conductivity of the LSCO buffer layer due to lattice oxygen loss induced capacity fading [139]. The PLD growth of a multilayer LMO thin film electrode demonstrated the compensation of lithium loss during deposition [160]. Such a sample prepared in the PLD conditions $\left(T_{\mathrm{s}}=650{ }^{\circ} \mathrm{C}, \Phi=530 \mathrm{~mJ} \cdot \mathrm{cm}^{-2}\right.$, and $\left.P_{\mathrm{O}_{2}}=1.3 \mathrm{~Pa}\right)$ showed the typical two pairs of voltammetry peaks at 0.82 and $1.02 \mathrm{~V}$ vs. $\mathrm{Ag} / \mathrm{AgCl}$ in an aqueous cell. Kim et al. [161] prepared a $\mathrm{Li}_{0.17} \mathrm{La}_{0.61} \mathrm{TiO}_{3} / \mathrm{LiMn}_{2} \mathrm{O}_{4}$ (LLTO/LMO) hetero-epitaxial electrolyte/electrode by PLD with an energy fluence of $\Phi=1.7 \mathrm{~J} \cdot \mathrm{cm}^{-2}$ in a $P_{\mathrm{O}_{2}}=6.6 \mathrm{~Pa}$ atmosphere. The typical herostructure is composed of a 17.5-nm thick LMO, 7-nm thick interfacial layer, and 26.5-nm thick LLTO deposited on a (111)-oriented 
STO substrate. Voltammograms of the first and second cycles displayed redox peaks around $3.8 \mathrm{~V}$ attributed to an oxygen-deficient LMO and around 4.0 and $4.2 \mathrm{~V}$, which are the typical redox voltages of the LMO spinel. Suzuli et al. [162] prepared multi-layer epitaxial $\mathrm{LiMn}_{2} \mathrm{O}_{4} / \mathrm{SrRuO}_{3}(\mathrm{LMO} / \mathrm{SRO})$ thin film electrodes deposited for $30 \mathrm{~min}$ via PLD on (111)STO substrates heated at $650{ }^{\circ} \mathrm{C}$ using an $\mathrm{Li}_{1.2} \mathrm{Mn}_{2} \mathrm{O}_{4}$ target in $P_{\mathrm{O}_{2}}=6.6 \mathrm{~Pa}$. The $\mathrm{LMO}(33 \mathrm{~nm}) / \mathrm{SRO}(38 \mathrm{~nm})$ film exhibited a discharge capacity of $125 \mathrm{mAh} \cdot \mathrm{g}^{-1}$ with the typical plateau regions of LMO in the charge-discharge reaction. Yim et al. substituted Sn for Mn in PLD LMO thin films [163]. The $\mathrm{LiSn}_{x / 2} \mathrm{Mn}_{2-x} \mathrm{O}_{4}$ films were prepared on a $\mathrm{Pt} / \mathrm{Ti} / \mathrm{SiO}_{2} / \mathrm{Si}(100)$ substrate in the conditions of $T_{\mathrm{s}}=450{ }^{\circ} \mathrm{C}, P_{\mathrm{O}_{2}}=26.7 \mathrm{~Pa}, \Phi=4.6 \mathrm{~J} \cdot \mathrm{cm}^{-2}, 10 \mathrm{~Hz}$ pulse frequency, and $4 \mathrm{~cm}$ target-substrate distance. XPS and EXAFS measurements showed that $\mathrm{Sn}^{2+}$ cations replace $\mathrm{Mn}^{3+}$ ions, which resulted in an increase of the valence of $\mathrm{Mn}$ in the spinel lattice. A high specific capacity of $\sim 120 \mathrm{mAh} \cdot \mathrm{g}^{-1}$ and cycleability with a capacity retention $>81 \%$ at the $4 \mathrm{C}$ rate after 90 cycles was attributed to the Mn-deficient structure. A multi-layer PLD process was utilized to deposit LMO films (90 nm thick) on Si-based substrates coated with Pt as the current collector [164]. A reversible capacity of $2.6 \mu \mathrm{Ah} \cdot \mathrm{cm}^{-2}$ (corresponding to a specific capacity of $\approx 28 \mu \mathrm{Ah} \cdot \mathrm{cm}^{-2} \cdot \mu \mathrm{m}^{-1}$ or $66 \mathrm{mAh} \cdot \mathrm{g}^{-1}$ assuming a dense film with $4.3 \mathrm{~g} \cdot \mathrm{cm}^{-3}$ ) was reached at an extremely high current density of $1889 \mu \mathrm{A} \cdot \mathrm{cm}^{-2}$ (equivalent to the $348 \mathrm{C}$ rate) with a capacity retention of $86 \%$ over 3500 cycles. A significant non-diffusion-controlled contribution (pseudocapacitive-like) was evidenced by cyclic voltammetry; however, the two typical voltage plateaus in the GCD of LMO (around $4 \mathrm{~V}$ ) indicates that the faradaic redox reaction is the main process. For an easy comparison, Table 6 lists the electrochemical properties of PLD-prepared LMO thin film electrodes.

Table 6. Electrochemical properties of PLD-prepared LMO thin film electrodes. $J$ is the current density, $\delta$ is the film thickness, and $\Delta C_{c}$ is the capacity fading per cycle.

\begin{tabular}{cccc}
\hline $\begin{array}{c}\text { PLD Conditions } \\
\boldsymbol{T}_{\mathrm{s}} / \boldsymbol{P}_{\mathbf{O}_{2} / \boldsymbol{\Phi}}\end{array}$ & Specific Capacity & Electrochemical Parameters & Ref. \\
\hline $300^{\circ} \mathrm{C} / 13 \mathrm{~Pa} / 0.5 \mathrm{~J} \cdot \mathrm{cm}^{-2}$ & $120 \mathrm{mC} \cdot \mathrm{cm}^{-2} \cdot \mu \mathrm{m}^{-1}$ & $J=5 \mu \mathrm{A} \cdot \mathrm{cm}^{-2} ; \delta=200 \mathrm{~nm} ; \Delta C_{\mathrm{c}}=0.14 \%$ & {$[7]$} \\
$25^{\circ} \mathrm{C} / 0.2 \mathrm{~Pa} / 3.5 \mathrm{~mJ} \cdot \mathrm{cm}^{-2}$ & $1.6 \mu \mathrm{Ah} \cdot \mathrm{cm}^{-2}$ & $J=4.4 \mu \mathrm{A} \cdot \mathrm{cm}^{-2} ; \delta=100 \mathrm{~nm} ; \Delta C_{\mathrm{c}}=0.4 \%$ & {$[121]$} \\
$500^{\circ} \mathrm{C} / 20 \mathrm{~Pa} / 2 \mathrm{~J}$ & $\mathrm{n} / \mathrm{a}$ & $\Delta C_{\mathrm{c}}=0.05 \% / \mathrm{cycle}$ & {$[122]$} \\
$500^{\circ} \mathrm{C} / 20 \mathrm{~Pa} / 4.3 \mathrm{~J} \cdot \mathrm{cm}^{-2}$ & $42 \mu \mathrm{Ah} \cdot \mathrm{cm}^{-2} \cdot \mu \mathrm{m}^{-1}$ & $J=13 \mu \mathrm{A} \cdot \mathrm{cm}^{-2}(1 \mathrm{C}) ; \delta=0.3 \mu \mathrm{m} ; \Delta C_{\mathrm{c}}=0.025 \%$ & {$[127]$} \\
$13 \mathrm{~Pa} / 2.3 \mathrm{~J} \cdot \mathrm{cm}^{-2}$ & $130 \mathrm{mAh} \cdot \mathrm{g}^{-1}$ & $I=5 \mu \mathrm{A}(3.3 \mathrm{C}) ; \delta=110 \mathrm{~nm} ; \Delta C_{\mathrm{c}}=0.14 \%$ & {$[129]$} \\
$575^{\circ} \mathrm{C} / 13 \mathrm{~Pa} / 160 \mathrm{~mJ}$ & $111 \mathrm{mAh} \cdot \mathrm{g}^{-1}$ & $J=50 \mu \mathrm{A} \cdot \mathrm{cm}^{-2} ; \delta=0.3 \mu \mathrm{m} ; \Delta C_{\mathrm{c}}=1.5 \%$ & {$[135]$} \\
$600^{\circ} \mathrm{C} / 30 \mathrm{~Pa} / 1 \mathrm{~J} \cdot \mathrm{cm}^{-2}$ & $96 \mathrm{mAh} \cdot \mathrm{g}^{-1}$ & $J=6 \mu \mathrm{A} \cdot \mathrm{cm}^{-2} ; \delta=100 \mathrm{~nm} ;$ & {$[151]$} \\
$600^{\circ} \mathrm{C} / 30 \mathrm{~Pa} / 1 \mathrm{~J} \cdot \mathrm{cm}^{-2}$ & $170 \mathrm{mC} \mathrm{cm}^{-2} \cdot \mu \mathrm{m}^{-1}$ & $I=1 \mathrm{~mA}(180 \mathrm{C}) ; \delta=120 \mathrm{~nm}$ & {$[156]$} \\
$400^{\circ} \mathrm{C} / 26 \mathrm{~Pa} / 160 \mathrm{~mJ}^{-2}$ & $142 \mathrm{mAh} \cdot \mathrm{g}^{-1}$ & $J=20 \mu \mathrm{A} \cdot \mathrm{cm}^{-2} ; \delta=0.4 \mu \mathrm{m} ; \Delta C_{\mathrm{c}}=0.06 \%$ & {$[157]$} \\
$450^{\circ} \mathrm{C} / 26.7 \mathrm{~Pa} / 4.6 \mathrm{~J} \cdot \mathrm{cm}^{-2}$ & $120 \mathrm{mAh} \cdot \mathrm{g}^{-1}$ & $J=330 \mathrm{~mA} \cdot \mathrm{g}^{-1} ; \delta=140 \mathrm{~nm} ; \Delta C_{\mathrm{c}}=0.2 \%$ & {$[163]$} \\
$650{ }^{\circ} \mathrm{C} / 2.6 \mathrm{~Pa} / 457 \mathrm{~mJ} \cdot \mathrm{cm}^{-2}$ & $26 \mu \mathrm{Ah} \cdot \mathrm{cm}^{-2} \cdot \mu \mathrm{m}^{-1}$ & $J=1.88 \mathrm{~mA} \cdot \mathrm{cm}^{-2}(348 \mathrm{C}) ; \delta=90 \mathrm{~nm}$ & {$[164]$} \\
\hline
\end{tabular}

\subsection{0. $\mathrm{LiNi}_{0.5} \mathrm{Mn}_{1.5} \mathrm{O}_{4}(\mathrm{LNM})$}

$\mathrm{LiNi}_{x} \mathrm{Mn}_{2-x} \mathrm{O}_{4}$ is a substituted oxide spinel that operates at high voltages $>4.5 \mathrm{~V}$ upon Li extraction. Substituted spinel films of $\mathrm{Li}_{x} \mathrm{Mn}_{2-y} M_{y} \mathrm{O}_{4}$ where $M=\mathrm{Ni}$, Co and $0 \leq y \leq 0.25$ as-prepared with a crystalline morphology ( $0.3 \mu \mathrm{m}$ thick) showed the typical features of high-voltage electrodes without carbon additive or binder materials in the range of 2.0 to $5.8 \mathrm{~V} \mathrm{vs.} \mathrm{Li}^{+} / \mathrm{Li}$ [165]. Cyclic voltammetry showed that: (i) PLD LiMn ${ }_{1.9} \mathrm{Ni}_{0.1} \mathrm{O}_{4}$ films charged at $5.7 \mathrm{~V}$ do not show capacity fading; (ii) $\mathrm{LiMn}_{2} \mathrm{O}_{4}$ and $\mathrm{LiMn}_{1.75} \mathrm{Co}_{0.25} \mathrm{O}_{4}$ films present a good stability to 5.6 and $5.4 \mathrm{~V} \mathrm{vs.} \mathrm{Li}^{+} / \mathrm{Li}$, respectively; and (iii) below $3 \mathrm{~V}$ the films exhibit the typical Jahn-Teller distortion. The compound, $\mathrm{LiNi}_{0.5} \mathrm{Mn}_{1.5} \mathrm{O}_{4}$ (LNM), is more interesting because of the oxidation state of cations: $\mathrm{Ni}^{2+}$ can be oxidized twice (i.e., $2 \mathrm{e}^{-}$ transfer) during charge while $\mathrm{Mn}^{4+}$ is electrochemically inactive. Xia et al. showed that laser-ablated LNM films 0.3 to $0.5 \mu \mathrm{m}$ thick deposited on a stainless steel substrate heated at $600{ }^{\circ} \mathrm{C}$ under an oxygen partial pressure of $26 \mathrm{~Pa}$ exhibit excellent capacity retention (i.e., $\sim 120 \mathrm{mAh} \cdot \mathrm{g}^{-1}$ after 50 cycles) in the voltage range of 3 to $5 \mathrm{~V}$ vs. $\mathrm{Li}^{+} / \mathrm{Li}$ [166]. Well-crystallized oxygen deficient $\mathrm{LiMn}_{1.5} \mathrm{Ni}_{0.5} \mathrm{O}_{4-\delta}$ films deposited by PLD at a controlled fluence of $\Phi=2 \mathrm{~J} \cdot \mathrm{cm}^{-2}, T_{\mathrm{s}}=600{ }^{\circ} \mathrm{C}$, and $P_{\mathrm{O}_{2}}=26 \mathrm{~Pa}$ for $40 \mathrm{~min}$ exhibited a stepwise voltage profile near $4.7 \mathrm{~V}$ and a small plateau in the $4 \mathrm{~V}$ region. These 
disordered spinel structures had a stable specific capacity of $55 \mu \mathrm{A} \mathrm{h} \mathrm{cm}{ }^{-2} \cdot \mu \mathrm{m}^{-1}$ in the voltage range of 3 to $5 \mathrm{~V}$ vs. $\mathrm{Li}^{+} / \mathrm{Li}$. The good rate capability was due to the high kinetics for $\mathrm{Li}$ diffusion in the range of $10^{-12}$ to $10^{-10} \mathrm{~cm}^{2} \mathrm{~s}^{-1}$ measured by the potentiostatic intermittent titration technique (PITT). These values are comparable to that of layered LCO $[167,168]$. Epitaxial LNM films were grown on single-crystal oriented $\mathrm{SrTiO}_{3}(\mathrm{STO})$ substrates from an Li-enriched target with $\mathrm{Li} /(\mathrm{Ni}+\mathrm{Mn})=$ 0.6. The film orientation, i.e., (100)-, (110)-, and (111)-oriented, were the replica of those of the STO substrates [169]. Depending on the film orientation and thickness, the discharge profiles exhibited two to three plateaus around $3.9,4.5$, and $4.7 \mathrm{~V} \mathrm{vs.} \mathrm{Li}^{+} / \mathrm{Li}$, which were attributed to the $\mathrm{Mn}^{3+} / \mathrm{Mn}^{4+}$, $\mathrm{Ni}^{2+} / \mathrm{Ni}^{3+}$, and $\mathrm{Ni}^{3+} / \mathrm{Ni}^{4+}$ redox couples, respectively. Note that the emergence of the $\mathrm{Mn}^{3+} / \mathrm{Mn}^{4+}$ redox couple was due to the introduced oxygen vacancies [170].

Other 5-V class cathode thin films include $\mathrm{LiCoMnO}_{4}$. PLD LiCoMnO films prepared under standard conditions (i.e., $T_{\mathrm{S}}=500{ }^{\circ} \mathrm{C}, P_{\mathrm{O}_{2}}=20-100 \mathrm{~Pa}$, and $\Phi=2 \mathrm{~J} \cdot \mathrm{cm}^{-2}$ ) had a composition of Li:Co:Mn $=0.99: 0.98: 1$. These films were tested in the voltage range of 3.0 to $5.5 \mathrm{~V} \mathrm{vs.} \mathrm{Li}^{+} / \mathrm{Li}$ in SSMB consisting of $\mathrm{Li} / \mathrm{Li}_{3} \mathrm{PO}_{4} / \mathrm{LiCoMnO}$ fabricated on $\mathrm{Pt} / \mathrm{Cr} / \mathrm{SiO}_{2}$ substrates [171]. Cyclic voltammetry showed that the higher capacity in the 5-V region was obtained for the film grown under $P_{\mathrm{O}_{2}}=100 \mathrm{~Pa}$ (Figure 10). A specific discharge capacity of $90 \mathrm{mAh} \cdot \mathrm{g}^{-1}$ remained after 20 cycles. Epitaxial $\mathrm{Li}_{0.92} \mathrm{Co}_{0.65} \mathrm{Mn}_{1.35} \mathrm{O}_{4}$ film with a cubic spinel structure was grown on a $\mathrm{SrTiO}_{3}(111)$ single-crystal substrate using a layer-by-layer technique, which consisted of repeating a $\mathrm{Li}_{1.2} \mathrm{Mn}_{2} \mathrm{O}_{4} / \mathrm{Li}_{1.4} \mathrm{CoO}_{2}$ deposition process at $T_{\mathrm{s}}=650{ }^{\circ} \mathrm{C}$ and $P_{\mathrm{O}_{2}}=6.6 \mathrm{~Pa}$ using a $\mathrm{KrF}$ excimer laser $(\lambda=248 \mathrm{~nm})$ [172]. For a film area of $0.7 \mathrm{~mm}^{2}$, thickness of $33.4 \mathrm{~nm}$, and density of $4.38 \mathrm{~g} \mathrm{~cm}^{-3}$, the specific discharge capacity was $340 \mathrm{~mA} \cdot \mathrm{g}^{-1}$ at the second cycle. A capacity retention of $80 \%$ was observed after 20 cycles.

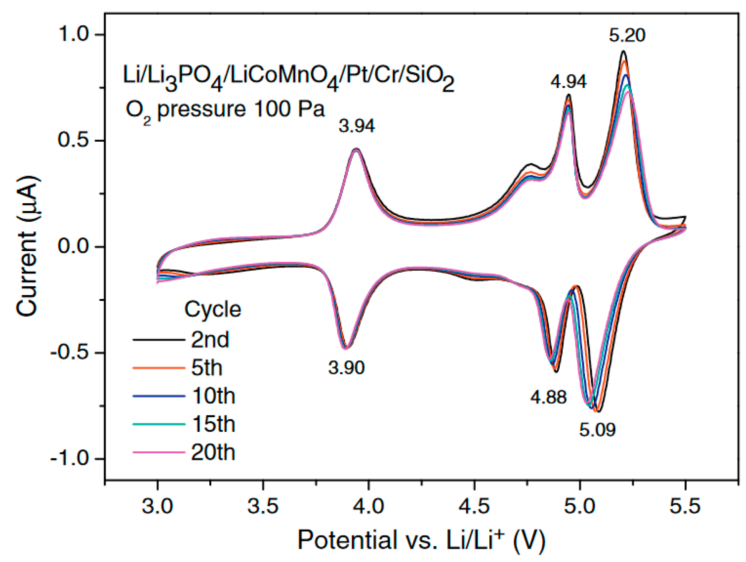

Figure 10. Cyclic voltammogram recorded at a $0.5 \mathrm{mV} \cdot \mathrm{s}^{-1}$ scan rate of a $\mathrm{Li}_{2} / \mathrm{Li}_{3} \mathrm{PO}_{4} / \mathrm{LiCoMnO}_{4}$ thin film battery. The $\mathrm{LiCoMnO}_{4}$ film cathode was grown under $P_{\mathrm{O}_{2}}=100 \mathrm{~Pa}$. (Reproduced with permission from [171]. Copyright 2014 Elsevier).

\subsection{1. $\mathrm{MnO}_{2}$}

Due to its environmental compatibility and low cost, manganese oxides are promising candidate materials for supercapacitor applications using neutral aqueous solution as the electrolyte (i.e., $0.5 \mathrm{~mol} \cdot \mathrm{L}^{-1}$ $\mathrm{K}_{2} \mathrm{SO}_{4}$ ) [173]. Xia et al. prepared a dense $\mathrm{Mn}_{3} \mathrm{O}_{4}$ spinel thin film grown by PLD, which transformed to nanoporous $\mathrm{MnO}_{x}$ after electrochemical lithium insertion/extraction. After 2000 cycles, the $\mathrm{MnO}_{x}$ film deposited at $T_{\mathrm{s}}=600{ }^{\circ} \mathrm{C}$ under $P_{\mathrm{O}_{2}}=26 \mathrm{~Pa}$ demonstrated a specific capacitance of $193 \mathrm{~F} \cdot \mathrm{g}^{-1}$ at a current density of $5 \mathrm{~A} \cdot \mathrm{g}^{-1}$ [174]. The fundamental aspects of the redox reaction were investigated on amorphous $\mathrm{MnO}_{x}$ and crystalline $\mathrm{Mn}_{2} \mathrm{O}_{3}$ films prepared by PLD onto $\mathrm{Si}$ and (316)-stainless steel substrates [175]. Using standard conditions $\left(\Phi=2-3 \mathrm{~J} \cdot \mathrm{cm}^{-2}, P_{\mathrm{O}_{2}}=13 \mathrm{~Pa}, T_{\mathrm{s}}=200-500{ }^{\circ} \mathrm{C}\right)$ Co-doped $\mathrm{MnO}_{x}$ films were grown from a hybrid $\mathrm{Co}_{3} \mathrm{O}_{4} / \mathrm{Mn}_{3} \mathrm{O}_{4}$ target. Non-doped and 3\% Co-doped amorphous films (i.e., $\mathrm{MnO}_{x}$

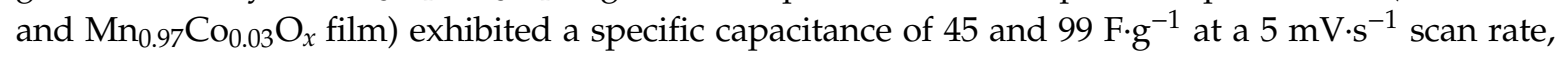
respectively. The $\mathrm{V}_{2} \mathrm{O}_{5} / \mathrm{Mn}_{3} \mathrm{O}_{4}$ target was used to prepare PLD-grown V-doped $\mathrm{MnO}_{x}$ thin films with a 
$\mathrm{V}$ content in the range of 3.3 to $10 \mathrm{~atm}$. \%. The specific capacitance of the crystalline PLD $\mathrm{Mn}_{2} \mathrm{O}_{3}$ film reached the value of $290 \mathrm{~F} \cdot \mathrm{g}^{-1}$ at a $1 \mathrm{mV} \cdot \mathrm{s}^{-1}$ scan rate, while the $10 \mathrm{~atm}$. \% V-doped film $\left(\mathrm{Mn}_{0.9} \mathrm{~V}_{0.1} \mathrm{O}_{2}\right)$ had a higher specific current value [176].

\subsection{2. $\mathrm{LiMPO}_{4}(\mathrm{M}=\mathrm{Fe}, \mathrm{Mn})$ Olivines}

$\mathrm{LiFePO}_{4}$ (LFP) thin-film electrodes have been successfully fabricated by pulsed-laser deposition [156,177-179]. It was shown that, due to the film thickness and carbon content, the electrochemical performances are very sensitive, i.e., electronic conductivity and Li-ion diffusion. Iriyama et al. reported the PLD growth of olivine structured LFP thin films and their electrochemical properties characterized by cyclic voltammetry and charge-discharge tests $[180,181]$. The typical olivine features were evidenced by CV measurements in the range of 2.0 and $5.0 \mathrm{~V} \mathrm{vs.} \mathrm{Li}^{+} / \mathrm{Li}$, i.e., a single couple of anodic and cathodic peaks at $\sim 3.4 \mathrm{~V}$. Song et al. synthesized PLD LFP films with a low carbon content $(<1 \mathrm{wt} . \%)$ on stainless steel substrates utilizing an Ar atmosphere [182]. The 75-nm thick films showed reversible cycling of more than $80 \mathrm{mAh} \cdot \mathrm{g}^{-1}$ after 60 cycles. Furthermore, 156-nm thick films grown using a target-substrate distance reduced to $5 \mathrm{~cm}$ had a layered surface texture and delivered more than $120 \mathrm{mAh} \cdot \mathrm{g}^{-1}$ with a good capacity retention. LFP thin films with a needle-like morphology were prepared by an off-axis PLD technique [183]. The effect of the substrate on the structure and morphology was examined by Palomares et al. for PLD film deposited under argon gas kept at a pressure of $8 \mathrm{~Pa}$ [184]. Stainless steel was demonstrated to be the best substrate for the single-phase olivine (Pnma space group) with a temperature set at $500{ }^{\circ} \mathrm{C}$.

$\mathrm{LiFePO}_{4}$ deposited by pulsed-laser deposition proved to be effective as a thin film electrode. Tang et al. stated that a well-crystallized pure olivine phase was grown using optimized deposition parameters $\left(T_{\mathrm{s}}=500^{\circ} \mathrm{C}, P_{\mathrm{Ar}}=20-30 \mathrm{~Pa}\right.$, pulse power of $120 \mathrm{~mJ}$, pulse frequency of $\left.10 \mathrm{~Hz}, \lambda=248 \mathrm{~nm}\right)$ [185]. An electrochemical capacity of $38 \mu \mathrm{Ah} \mathrm{cm}^{-2} \cdot \mu \mathrm{m}^{-1}$ at the $\mathrm{C} / 20$ rate $\left(36 \mu \mathrm{Ah} \cdot \mathrm{cm}^{-2} \cdot \mu \mathrm{m}^{-1}\right.$ at a rate of $\left.\mathrm{C} / 4\right)$ was measured at $25^{\circ} \mathrm{C}$. High substrate temperatures $\left(500 \leq T_{\mathrm{s}} \leq 700{ }^{\circ} \mathrm{C}\right)$ favored the presence of $\mathrm{Fe}^{3+}$ impurities, i.e., $\mathrm{Li}_{3} \mathrm{Fe}_{2}\left(\mathrm{PO}_{4}\right)_{3}$ and $\mathrm{Fe}_{4}\left(\mathrm{P}_{2} \mathrm{O}_{7}\right)_{3}$. In a second article, the same group analyzed the kinetics of $\mathrm{Li}^{+}$ions in PLD LFP films using CV, GITT, and EIS measurements [179]. CV data provided average $D^{*}$ values of $10^{-14} \mathrm{~cm}^{2} \cdot \mathrm{s}^{-1}$, while $D^{*}$ deduced from both GITT and EIS techniques was in the range of $10^{-14}$ to $10^{-18} \mathrm{~cm}^{2} \cdot \mathrm{s}^{-1}$. A maximum $D^{*}$ value was observed at $x=0.5$ for $\mathrm{Li}_{x} \mathrm{FePO}_{4}$. Lu et al. prepared different composite thin films, i.e., $\mathrm{LiFePO}_{4}-\mathrm{Ag}$ and $\mathrm{LiFePO}_{4}-\mathrm{C}$, with the aim of enhancing the electronic conductivity $[177,178]$. It was found that films grown with $2 \mathrm{~mol} \%$ carbon and annealed at $600{ }^{\circ} \mathrm{C}$ for $6 \mathrm{~h}$ had an improved coulombic efficiency. Well-crystallized olivine-type structure LFP films were obtained by PLD coupled with high temperature annealing of $650{ }^{\circ} \mathrm{C}$. The first discharge capacity was $27 \mathrm{mAh} \cdot \mathrm{g}^{-1}$ with a retention of only $49 \%$ after 100 cycles. The low reversible capacity and poor cycling performance was attributed to the existence of an $\mathrm{Fe}_{2} \mathrm{O}_{3}$ impurity produced by the high temperature treatment and poor intrinsic conductivity [186]. Sauvage et al. published several reports on the electrochemical properties of PLD LFP thin films grown in different configurations [187-190]. First, it was shown that well-crystallized and homogeneous 300-nm thick LFP films deposited on Pt-capped Si substrates have intrinsic $\mathrm{Li}$ insertion properties evaluated both in aqueous and non-aqueous electrolytes, i.e., voltage plateau at $3.42 \mathrm{~V}$ vs. $\mathrm{Li}^{+} / \mathrm{Li}$ [187]. Second, the influence of the film thickness was studied in the range of 12 to $600 \mathrm{~nm}$ [188]. Third, the effect of the texture on the electrochemical performance was analyzed for PLD films deposited on a polycrystalline $\alpha-\mathrm{Al}_{2} \mathrm{O}_{3}$ substrate coated with a 20-nm thick Pt layer from an $\mathrm{LiFePO}_{4}$ pellet as the target. The standard PLD conditions were used (i.e., $\left(\Phi=2 \mathrm{~J} \cdot \mathrm{cm}^{-2}, P_{\mathrm{Ar}}=8 \mathrm{~Pa}\right.$, $T_{\mathrm{S}}=600^{\circ} \mathrm{C}$ ) [189]. Finally, the electrochemical stability of LFP films was analyzed as a function of the exposition to the most common lithium salt and for different current collectors (i.e., $\mathrm{Si}, \mathrm{Pt}, \mathrm{Ti}, \mathrm{Al}$, and (304)-stainless steel) [190]. A 270-nm thick film tested by CV at a $2 \mathrm{mV} \cdot \mathrm{s}^{-1}$ scanning rate in $1 \mathrm{~mol} \cdot \mathrm{L}^{-1}$ $\mathrm{LiClO}_{4}$ in EC/DMC solution delivered a specific capacity of $1.52 \mu \mathrm{Ah} \mathrm{cm}{ }^{-2}$ after 150 cycles. Recently, Raveendran et al. reported the properties of $\mathrm{FeSe}$ and $\mathrm{LiFeO}_{2} / \mathrm{FeSe}$ bi-layers prepared by PLD as cathode materials [191]. Mangano-olivine $\mathrm{LiMnPO}_{4}$ (LMP) thin films were fabricated on Pt-coated $\mathrm{SiO}_{2}$ glass substrates using PLD parameters, e.g., $\Phi=1.58 \mathrm{~J} \cdot \mathrm{cm}^{-2}, T_{\mathrm{s}}=400-700{ }^{\circ} \mathrm{C}$, and $P_{\mathrm{Ar}}=2-100 \mathrm{~Pa}$ [45]. LMP 
films (50-nm thick, $0.09 \mathrm{~cm}^{2}$ area) were applied in $\mathrm{Li} / \mathrm{Li}_{3} \mathrm{PO}_{4} / \mathrm{LiMnPO}_{4}$ microbatteries for 500 cycles.

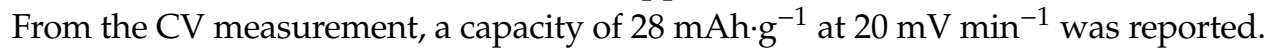

\subsection{3. $\mathrm{V}_{2} \mathrm{O}_{5}$}

Another candidate material for the cathodes of microbatteries is $\mathrm{V}_{2} \mathrm{O}_{5}$, in which about $1 \mathrm{~mol} \mathrm{of} \mathrm{\textrm {Li } ^ { + }}$ ions can be inserted and extracted without the phase transformation of $\mathrm{V}_{2} \mathrm{O}_{5}$, leading to a theoretical specific capacity of $147 \mathrm{mAh} \cdot \mathrm{g}^{-1}$. Due to its stable layered structure and its ability to accommodate large amounts of $\mathrm{Li}$ ions, $\mathrm{V}_{2} \mathrm{O}_{5}$ has been widely studied for the development of electrochromic displays, color memory devices, and lithium-battery cathodes [192]. Extensive works have evidenced the advantages of PLD for the preparation of $\mathrm{V}_{2} \mathrm{O}_{5}$ films with a good reproducible stoichiometry similar to the target material [193-207]. The first work related to the growth of $\mathrm{V}_{2} \mathrm{O}_{5}$ thin film by PLD as an electrode for a thin-film lithium battery was reported by the National Renewable Energy Labs (USA) [193] followed by Julien's group [194,195]. A major advantage of laser ablation deposits is that it is possible to prepare thin layers of crystallized $\mathrm{V}_{2} \mathrm{O}_{5}$ under oxygen at a relatively low temperature of $200{ }^{\circ} \mathrm{C}$ [193]. The growth mechanism of PLD V $\mathrm{O}_{5}$ thin films has been proposed by Ramana and coworkers [196]. It was reported that the grain size, surface roughness, and global morphology are highly sensitive to the nature and temperature of the substrate for films deposited in an oxygen partial pressure of $P_{\mathrm{O}_{2}}=13 \mathrm{~Pa}$. The functional influence of the growth temperature on the grain size for films deposited onto various substrates was also evidenced. Two main features should be pointed out: (i) The exponential variation of the grain size over the substrate temperature range of 25 to $500{ }^{\circ} \mathrm{C}$; (ii) the variation is dependent on the substrate material, which is larger for the $\mathrm{Si}(00)$ wafer. McGraw et al. reported that pulsed-laser deposited $\mathrm{V}_{2} \mathrm{O}_{5}$ films can be grown on a number of low-cost substrates, including $\mathrm{SnO}_{2}$-coated glass, on which highly textured (001) films are obtained at $T_{\mathrm{s}}=500{ }^{\circ} \mathrm{C}$ under $P_{\mathrm{O}_{2}}$ in the range of 0.2 to $0.5 \mathrm{~Pa}[52,197,198]$. PLD thin films of $\mathrm{V}_{2} \mathrm{O}_{5}$ were prepared for applications in lithium batteries using a ceramic $\mathrm{V}_{2} \mathrm{O}_{5}$ target and a $\mathrm{KrF}$ laser of a wavelength of $248 \mathrm{~nm}$. Depending on the temperature of the substrates and the oxygen pressure during deposition, amorphous or crystallized layers are obtained. PLD-grown amorphous films exhibited a low capacity loss of $\sim 2 \%$ over 100 discharge-charge cycles in the voltage range 4.1 to $1.8 \mathrm{~V}$ compared to $20 \%$ for crystalline film $[45,199]$. Thin layers of $\mathrm{V}_{2} \mathrm{O}_{5}$ were also prepared using a $\mathrm{V}_{2} \mathrm{O}_{3}$ target [200]. By making deposits at $200{ }^{\circ} \mathrm{C}$ with the same $\mathrm{V}_{2} \mathrm{O}_{3}$ target, amorphous layers were obtained in the absence of oxygen and layers crystallized in the presence of oxygen. Madhuri et al. [201] reported the successful crystallization of laser-ablated $\mathrm{V}_{2} \mathrm{O}_{5}$ thin films at $T_{\mathrm{s}}=20{ }^{\circ} \mathrm{C}$. These films were grown in the orthorhombic structure and exhibited a predominant (001) orientation. The growth of crystalline thin dense films without post-deposition annealing was claimed and the good electrochemical performance of PLD films was demonstrated. Iida et al. [202] addressed the electrochromic properties of $\mathrm{V}_{2} \mathrm{O}_{5}$ films deposited onto ITO glass as a function of the PLD parameters. The film recrystallization occurred in the range of 400 $\leq T_{\mathrm{s}} \leq 500{ }^{\circ} \mathrm{C}$ and the best morphology was obtained for $P_{\mathrm{O}_{2}}=13.3 \mathrm{~Pa}$. McGraw et al. deposited thin films of $\mathrm{V}_{2} \mathrm{O}_{5}$ for applications in lithium batteries using a ceramic $\mathrm{V}_{2} \mathrm{O}_{5}$ target and a $\mathrm{KrF}$ laser, with a wavelength of $248 \mathrm{~nm}$. Depending on the temperature of the substrates and the oxygen pressure during deposition, amorphous or crystallized layers were obtained $[193,199]$. Thin layers of $\mathrm{V}_{2} \mathrm{O}_{5}$ were also prepared using a $\mathrm{V}_{2} \mathrm{O}_{3}$ target. By making deposits at $200{ }^{\circ} \mathrm{C}$ with the same $\mathrm{V}_{2} \mathrm{O}_{3}$ target, amorphous layers were obtained in the absence of oxygen and layers crystallized in the presence of oxygen. Stoichiometric amorphous $\mathrm{V}_{2} \mathrm{O}_{5}$ films can be grown onto substrates maintained at low temperatures $\left(T_{\mathrm{s}}<100{ }^{\circ} \mathrm{C}\right)$ using a sintered $\mathrm{V}_{2} \mathrm{O}_{5}$ target. Ramana et al. revealed that stoichiometric $\mathrm{V}_{2} \mathrm{O}_{5}$ films can be grown with a layered structure onto amorphous glass substrates at temperatures as low as $200{ }^{\circ} \mathrm{C}$ and an oxygen partial pressure of 100 mTorr [203]. The onset of crystallization occurred at $200^{\circ} \mathrm{C}$ with an activation energy of 0.43 to $n 0.55 \mathrm{eV}$ [204]. Correlations between the growth conditions, microstructure, and optical properties were investigated for $\mathrm{V}_{2} \mathrm{O}_{5}$ thin films deposited over a wide substrate temperature range of 30 to $500{ }^{\circ} \mathrm{C}$ by Rutherford backscattering spectrometry (RBS), X-ray photoelectron spectroscopy (XPS), scanning electron microscopy (SEM), and UV-vis-NIR 
spectral measurements. As shown in Figure 11, the film grain size follows a power law of the substrate temperature and the optical energy bandgap decreases from 2.47 to $2.12 \mathrm{eV}$ with the increase of $T_{\mathrm{s}}$ from 30 to $500{ }^{\circ} \mathrm{C}$ [205]. Bowman and Gregg investigated the effect of the applied strain on the resistance of $\mathrm{V}_{2} \mathrm{O}_{5}$ thin films grown from both metallic vanadium and a ceramic $\mathrm{V}_{2} \mathrm{O}_{5}$ target using a laser fluence of $\sim 3.0$ and $\sim 1.5 \mathrm{~J} \mathrm{~cm}^{-2}$, respectively [208]. Deng et al. compared the growth of $\mathrm{V}_{2} \mathrm{O}_{5}$ films using femtosecond (f-PDL) and nanosecond (n-PDL) pulsed laser deposition using SEM, XRD, and Raman spectroscopy. Prior to annealing, f-PLD films showed a rougher texture and nano-crystalline character, while n-PLD films were much smoother and predominantly amorphous [209].

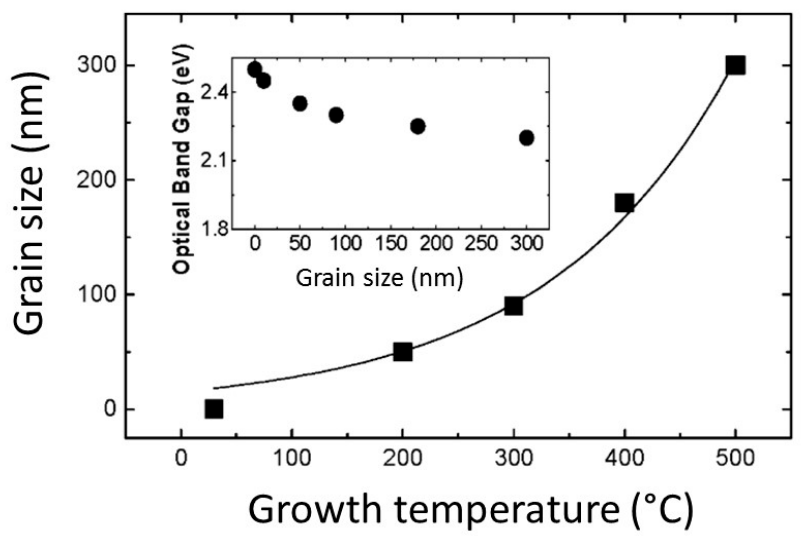

Figure 11. Variation of the grain size in $\mathrm{V}_{2} \mathrm{O}_{5}$ thin films as a function of the substrate temperature. (Reproduced with permission from [205]. Copyright 2005 American Chemical Society).

The PLD growth conditions were refined by an analysis of the surface properties for the production of high-quality $\mathrm{V}_{2} \mathrm{O}_{5}$ films. The investigations were carried out by AFM, SEM, FTIR, and XRD. AFM measurements showed a surface roughness of $\sim 12 \mathrm{~nm}$ with a Gaussian-like height distribution of surface grains for films deposited at $T_{\mathrm{s}}=200{ }^{\circ} \mathrm{C}$ under $P_{\mathrm{O}_{2}}=10 \mathrm{~Pa}$ [210]. The local structure of $0.3-\mu \mathrm{m}$ thick films grown on $\mathrm{Si}(100)$ substrates was characterized by Raman spectroscopy [211]. The influence of the deposition temperature on the microstructure was investigated by an examination of the rigid layer-like mode at $145 \mathrm{~cm}^{-1}$, which showed a frequency shift with increasing $T_{\mathrm{S}}$. The ability of the $\mathrm{V}_{2} \mathrm{O}_{5}$ thin film lattice to accommodate $\mathrm{Li}^{+}$ions was also investigated by Raman spectroscopy. The appearance of the $\delta$ - and $\gamma$-phases of $\mathrm{Li}_{x} \mathrm{~V}_{2} \mathrm{O}_{5}$ gave additional insight into the structural changes of lithiated films. From the photoluminescence spectra, lida et al. evidenced a blue shift of the vanadyl $\mathrm{V}=\mathrm{O}$ peak upon $\mathrm{Li}^{+}$insertion for different electric charge in the range of $0 \leq Q \leq 20{\mathrm{mC} \mathrm{of} \mathrm{Li}^{+}}^{\text {[212] }}$. From X-ray diffraction and Raman spectroscopy data, Shibuya et al. derived a $P_{\mathrm{O}_{2}}-T_{\mathrm{s}}$ phase diagram for $\mathrm{V}-\mathrm{O}$ films grown on $\mathrm{Si}(100)$ substrates (Figure 12). The composition of $\mathrm{V}-\mathrm{O}$ films was as follows: (i) $\mathrm{A} \mathrm{VO}_{2}$ monoclinic phase was formed at $T_{\mathrm{s}} \geq 450{ }^{\circ} \mathrm{C}$ and $P_{\mathrm{O} 2}$ in the range of 5 to $20 \mathrm{mTorr}$; (ii) a $\mathrm{V}_{2} \mathrm{O}_{5}$ orthorhombic phase was obtained under oxidative conditions, i.e., at high $P_{\mathrm{O}_{2}}$; (iii) a $\mathrm{V}_{6} \mathrm{O}_{13}$ phase was grown under $P_{\mathrm{O}_{2}}$ between oxidative and reductive conditions; and (iv) metastable $\mathrm{V}_{4} \mathrm{O}_{9}$ and $\mathrm{VO}_{2}$ (B) phases were formed for lower $T_{\mathrm{s}}\left(\leq 400{ }^{\circ} \mathrm{C}\right)$ and lower $P_{\mathrm{O}_{2}}$ ( $\leq 30$ mTorr) [213].

$\mathrm{V}_{2} \mathrm{O}_{5}$ thin films have been widely used as electrochromic electrodes but few reports are devoted to PLD-grown films. Fang et al. obtained thin films deposited on $\mathrm{In}_{2} \mathrm{O}_{3}: \mathrm{SnO}_{2}$ (ITO)-coated glass and (111)Si wafer from a $\mathrm{V}_{2} \mathrm{O}_{5}$ target using an $\mathrm{XeCl}$ laser with a wavelength of $308 \mathrm{~nm}$ for applications in electrochromic devices [214,215]. Electrochromic tests over 60,000 cycles showed that a significant change in the optical density (bleached and colored states) was evaluated to be 0.13 at $\lambda=600 \mathrm{~nm}$ for as-prepared films at $T_{\mathrm{s}}=200{ }^{\circ} \mathrm{C}$. Crystallized c-axis oriented $\mathrm{V}_{2} \mathrm{O}_{5}$ films were obtained under oxygen and at a substrate temperature of $200^{\circ} \mathrm{C}$. The durability without long-term degradation of the electrochromic $\mathrm{V}_{2} \mathrm{O}_{5}$ films was tested over 8000 cycles in the voltage range of 1.2 to $1.4 \mathrm{~V}$ [216]. Ti-doped $\mathrm{V}_{2} \mathrm{O}_{5}$ thin films prepared by the pulsed laser ablation technique at $T_{\mathrm{s}}=200{ }^{\circ} \mathrm{C}$ and $\Phi=2 \mathrm{~J} \cdot \mathrm{cm}^{-2}$ were studied as the electrode for an electrochromic display that exhibits a neutral brownish blue color. 
The long-term durability was verified over 8000 cycles of a voltage cycled in the range from -1.0 to $+1.0 \mathrm{~V}$ vs. SCE showing a charge of $35 \mathrm{mC} \cdot \mathrm{cm}^{-2}$. The good cycleability was attributed to the layered structure of PLD crystalline films with a parallel orientation to the substrate, suitable for $\mathrm{Li}^{+}$-ions transport [215]. PLD thin films of the system, $\mathrm{WO}_{3}-\mathrm{V}_{2} \mathrm{O}_{5}$, were prepared with a laser fluence of 1 to $2 \mathrm{~J} \cdot \mathrm{cm}^{-2}$ on $\mathrm{SnO}_{2} / \mathrm{F}$-coated glass substrates at $T_{\mathrm{s}}=25^{\circ} \mathrm{C}$ under $P_{\mathrm{O}_{2}}=0.1 \mathrm{mbar}$. Such films with low $\mathrm{V}$ contents cycled in the protonic medium. The true color neutrality is the main advantage of $\mathrm{V}$-based $\mathrm{WO}_{3}$ thin films; however, the cell capacity and coloration efficiency decrease with an increase of the $\mathrm{V}$ content [217]. The orthorhombic $\mathrm{V}_{2} \mathrm{O}_{5}$ phase is also applied as electrodes for sensors. Huotari reported that pure PLD films were obtained at $\Phi=2.6 \mathrm{~J} \mathrm{~cm}^{-2}, T_{\mathrm{s}}=400{ }^{\circ} \mathrm{C}$, and $P_{\mathrm{O}_{2}}=1.0 \mathrm{~Pa}$ with a post-annealing treatment at $400^{\circ} \mathrm{C}$ for $1 \mathrm{~h}$ in normal ambient conditions [218]. The efficient response to $\mathrm{NH}_{3}$ at part-per-billion levels. indicates these films use as possible sensing materials for ammonia gas [219].

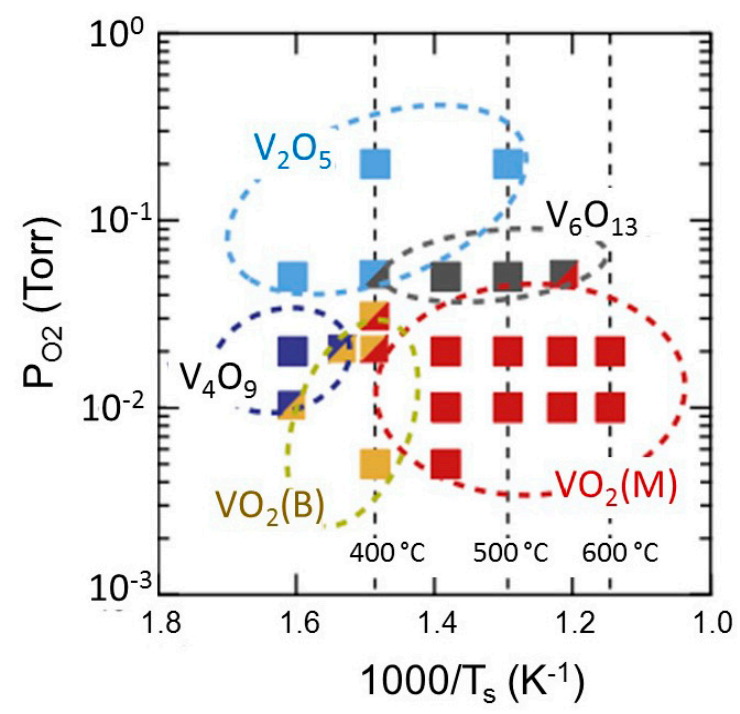

Figure 12. $P_{\mathrm{O}_{2}}$ vs. 1000/T shase diagram for films of vanadium oxides laser-pulse deposited on silicon substrates. (Reproduced with permission from [213]. Copyright 2015 AIP Publishing).

The electrochemical properties of $\mathrm{V}_{2} \mathrm{O}_{5}$ thin-film cathode material have been widely studied in cells with aprotic electrolytes (typically $\mathrm{LiClO}_{4}$ dissolved in propylene carbonate). The electrochemical charge-discharge profiles of PLD $\mathrm{V}_{2} \mathrm{O}_{5}$ films were also found to be dependent on $T_{\mathrm{s}}$, exhibiting a marked difference for $\mathrm{V}_{2} \mathrm{O}_{5}$ films grown at $T_{\mathrm{s}}<20{ }^{\circ} \mathrm{C}$ when compared to those grown at $T_{\mathrm{s}} \geq 200^{\circ} \mathrm{C}$. The effect of the substrate temperature and hence the microstructure on the kinetics of the lithium intercalation process in $\mathrm{V}_{2} \mathrm{O}_{5}$ films is remarkable. The applicability of the grown PLD $\mathrm{V}_{2} \mathrm{O}_{5}$ films in lithium microbatteries indicates that PLD $\mathrm{V}_{2} \mathrm{O}_{5}$ films in the temperature range of 200 to $400{ }^{\circ} \mathrm{C}$ offer better electrochemical performance than films grown at other temperatures due to their excellent structural quality and stability $[25,220]$. As an experimental fact, pulsed laser deposited $\mathrm{V}_{2} \mathrm{O}_{5}$ thin films exhibit a higher initial voltage than the crystalline material, i.e., $\sim 4.1$ vs. $\sim 3.5 \mathrm{~V}\left(\mathrm{Li}^{+} / \mathrm{Li}\right)$. For instance, $\mathrm{V}_{2} \mathrm{O}_{5}$ thin-film cathodes, deposited from a $\mathrm{V}_{6} \mathrm{O}_{13}$ target at a fluence of $\sim 12 \mathrm{~J} \mathrm{~cm}^{-2}$ on $\mathrm{SnO}_{2}$-coated glass at $T_{\mathrm{s}}=200{ }^{\circ} \mathrm{C}$, were efficient for $\mathrm{Li}^{+}$-ion incorporation. In (h00)-textured films, the specific capacity reached values between $50 \%$ and $80 \%$ of the theoretical value. On the other hand, amorphous films display a stable capacity corresponding to $1.2 \mathrm{~F} \mathrm{~mol}^{-1}$ in the voltage range of 4.1 to $1.5 \mathrm{~V}$. Prior textured $\mathrm{V}_{2} \mathrm{O}_{5}$ films discharged beyond the threshold to $2.0 \mathrm{~V} \mathrm{vs}$. $\mathrm{Li}^{+} / \mathrm{Li}$ showed an immediate and continuous capacity fading and a quasi-total amorphization after 10 cycles $[193,197]$. The chemical diffusion coefficient of $\mathrm{Li}^{+}$ions, $D^{*}$, measured by PITT was found to be in the range of $1.7 \times 10^{-12}$ to $5.8 \times 10^{-15}$ $\mathrm{cm}^{2} \cdot \mathrm{s}^{-1}$ in crystalline $\mathrm{V}_{2} \mathrm{O}_{5}$ films, which compares well to the value found in $\mathrm{Li}_{x} \mathrm{~V}_{2} \mathrm{O}_{5}$ phases, whereas $D^{*}$ displayed a smooth and continuous decrease as the Li content increased in amorphous films [198]. 
In an attempt to apply PLD $\mathrm{V}_{2} \mathrm{O}_{5}$ films in SSMB, a thin-film microbattery was constructed using a glassy $\mathrm{Li}_{1.4} \mathrm{~B}_{2.5} \mathrm{~S}_{0.1} \mathrm{O}_{4.9}$ electrolyte film with an ionic conductivity of $5 \times 10^{-6} \mathrm{~S} \cdot \mathrm{cm}^{-1}$ at $25{ }^{\circ} \mathrm{C}$ and an $\mathrm{Li}$ anode film. This $\mathrm{Li} / \mathrm{Li}_{1.4} \mathrm{~B}_{2.5} \mathrm{~S}_{0.1} \mathrm{O}_{4.9} / \mathrm{V}_{2} \mathrm{O}_{5}$ cell delivered a capacity of $\sim 400 \mathrm{mC} \cdot \mathrm{cm}^{-2} \cdot \mu \mathrm{m}^{-1}$ at a current density of $15 \mu \mathrm{A} \cdot \mathrm{cm}^{-2}$ [221]. $\mathrm{Ag}_{0.3} \mathrm{~V}_{2} \mathrm{O}_{5}$ and LiPON thin films with a smooth surface were grown by PLD in an $\mathrm{N}_{2}$ and $\mathrm{O}_{2}$ atmosphere, respectively. The Li/LiPON/Ag $\mathrm{Ag}_{0.3} \mathrm{~V}_{2} \mathrm{O}_{5} \mathrm{SSMB}$ displayed good cycleability at a current density of $7 \mu \mathrm{A} \cdot \mathrm{cm}^{-2}$ in the voltage window of 1.0 to $3.5 \mathrm{~V}$. The specific capacity was maintained at $40 \mu \mathrm{Ah} \cdot \mathrm{cm}^{-2} \cdot \mu \mathrm{m}^{-1}$ after 100 cycles [222]. Recently, amorphous vanadium oxide a- $\mathrm{VO}_{x}$ PLD films (650 nm thick) were grown on stainless steel substrates from a $\mathrm{V}_{2} \mathrm{O}_{5}$ PLD-target under $P_{\mathrm{O}_{2}}$ in the range of 0 to $30 \mathrm{~Pa}$. Films prepared under $P_{\mathrm{O}_{2}}=13 \mathrm{~Pa}$ had a smooth surface and bore an $\mathrm{O} / \mathrm{V}$ atomic ratio of 2.13 with a higher atomic percentage of $\mathrm{V}^{5+}$ than that of $\mathrm{V}^{4+}$. Electrochemical tests carried out in Li cells with $1 \mathrm{~mol} \cdot \mathrm{L}^{-1} \mathrm{LiPF}_{6}$ in ethylene carbonate (EC) and diethyl carbonate (DEC) (1:1 by volume) as the electrolyte showed a reversible specific capacity as high as $300 \mathrm{mAh} \cdot \mathrm{g}^{-1}$ at the $\mathrm{C} / 10$ current rate and a capacity retention of $90 \%$ after 100 cycles [223]. Such studies were initiated by Zhang et al. in 1997 to obtain $\mathrm{VO}_{x}$ films PLD grown at $200^{\circ} \mathrm{C}$ and exhibiting a specific capacity of $340 \mathrm{mAh} \cdot \mathrm{g}^{-1}$ at a current density of $0.1 \mathrm{~mA} \cdot \mathrm{cm}^{-2}$ and a capacity loss $<2 \%$ at the end of 100 cycles [201]. A summary of the electrochemical properties of PLD-grown vanadium oxide thin film electrodes is given in Table 7.

Table 7. Electrochemical properties of PLD-prepared vanadium oxide thin film electrodes. $J$ is the current density, $\delta$ is the film thickness, and $\Delta C_{C}$ is the capacity fading per cycle.

\begin{tabular}{|c|c|c|c|}
\hline $\begin{array}{l}\text { PLD Conditions } \\
\qquad T_{\mathrm{s}} / P_{\mathrm{O}_{2}} / \Phi\end{array}$ & Specific Capacity & Electrochemical Parameters & Ref. \\
\hline $200^{\circ} \mathrm{C} / 2.6 \mathrm{~Pa} / 12 \mathrm{~J} \cdot \mathrm{cm}^{-2}$ & $200 \mathrm{mAh} \cdot \mathrm{g}^{-1}$ & Capacity loss of $<2 \%$ over 200 cycles & [193] \\
\hline $300{ }^{\circ} \mathrm{C} / 133 \mathrm{~Pa} / 0.1 \mathrm{~J} \cdot \mathrm{cm}^{-2}$ & $235 \mathrm{mC} \mathrm{cm}{ }^{-2} \cdot \mu \mathrm{m}^{-1}$ & $J=5 \mu \mathrm{A} \cdot \mathrm{cm}^{-2} ; \Delta C_{\mathrm{c}}=1.1 \%$ & [195] \\
\hline $100^{\circ} \mathrm{C} / 6 \mathrm{~Pa} / 200 \mathrm{~mJ}$ & $240 \mathrm{mAh} \cdot \mathrm{g}^{-1}$ & $0.1 \mathrm{C}$ current rate; $\delta=650 \mathrm{~nm} ; \Delta C_{\mathrm{c}}=0.1 \%$ & [223] \\
\hline $200^{\circ} \mathrm{C}$ & $340 \mathrm{mAh} \cdot \mathrm{g}^{-1}$ & Capacity loss $<2 \%$ after 100 cycles & [201] \\
\hline $200{ }^{\circ} \mathrm{C} / 10 \mathrm{~Pa} / 2 \mathrm{~J} \cdot \mathrm{cm}^{-2}$ & $340 \mathrm{mC} \mathrm{cm}-2 \cdot \mu \mathrm{m}^{-1}$ & $\delta=100 \mathrm{~nm} ; 8000$ cycles (electrochromic) & [216] \\
\hline
\end{tabular}

\subsection{4. $V_{6} \mathrm{O}_{13}$}

With the ability of vanadium cations (two $\mathrm{V}^{4+}$ every $\mathrm{V}^{5+}$ ) to be reduced, the mixed-valence vanadium oxide, $\mathrm{V}_{6} \mathrm{O}_{13}$, the structure of which is formed by alternated single and double layers of $\mathrm{VO}_{6}$ units, can insert reversibly about $6 \mathrm{~mol}$ of $\mathrm{Li}$, giving a specific capacity of $311 \mathrm{mAh} \cdot \mathrm{g}^{-1}$. It makes this compound a good candidate for the cathode material of rechargeable batteries [224]. $\mathrm{V}_{6} \mathrm{O}_{13}$ films were fabricated by the PLD technique using a pulsed $\mathrm{KrF}$ excimer laser $(\lambda=248 \mathrm{~nm}$, $20 \mathrm{~ns}$ pulse duration, $10 \mathrm{~Hz}$ frequency, and $4 \mathrm{~J} \cdot \mathrm{cm}^{-2}$ laser fluence). A (100)-oriented Si substrate was maintained at a temperature of $500{ }^{\circ} \mathrm{C}$. During the PLD process, the formation of crystalline $\mathrm{V}_{6} \mathrm{O}_{13}$ films (dark-bluish color) and the vanadium oxidation state (+2.166) was monitored by controlling the processing temperature and $\mathrm{O}_{2}$ partial pressure. The (002)-oriented $\mathrm{V}_{6} \mathrm{O}_{13}$ thin films $(50 \mathrm{~nm}$ thick) were obtained after a post annealing at $400{ }^{\circ} \mathrm{C}$ under an oxygen partial pressure of $100 \mathrm{~Pa}$ [221]. The discharge profiles for $\mathrm{Li} / / \mathrm{V}_{6} \mathrm{O}_{13}$ thin-film cells were recorded in the voltage range of 3.3 to $2.5 \mathrm{~V}$ at a current density of $5 \mu \mathrm{A} \mathrm{cm}^{-2}$ (Figure 13). A film as-grown at $T_{\mathrm{s}}=250^{\circ} \mathrm{C}$ exhibited a steady discharge curve with an insertion uptake of $6 \mathrm{Li}$ per $\mathrm{V}_{6} \mathrm{O}_{13}$ formula unit, whereas the cell voltage decay was faster for a film deposited at $T_{\mathrm{S}}=25^{\circ} \mathrm{C}$. However, the films deposited at $T_{\mathrm{S}}=250^{\circ} \mathrm{C}$ and annealed at $300^{\circ} \mathrm{C}$ in an Ar atmosphere displayed a stepped discharge profile with the appearance of a voltage plateau at ca. 3.02 and $2.85 \mathrm{~V}$ vs. $\mathrm{Li}^{+} / \mathrm{Li}$. 


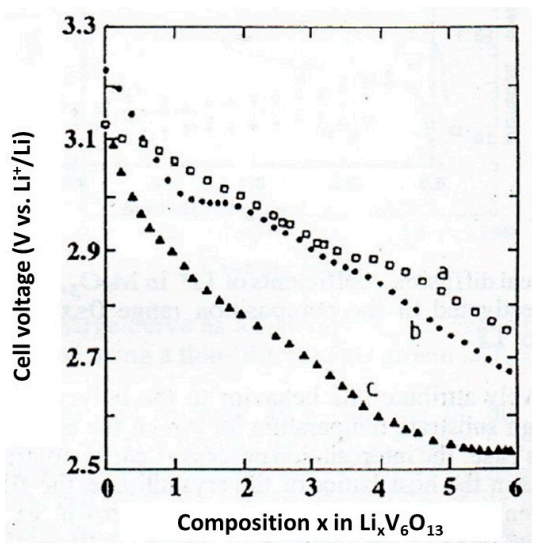

Figure 13. Discharge profiles vs. lithium uptake for $\mathrm{Li} / / \mathrm{V}_{6} \mathrm{O}_{13}$ thin-film microbatteries. Active cathode films were grown with: (a) $\mathrm{T}_{\mathrm{s}}=250{ }^{\circ} \mathrm{C}$, as-deposited; (b) $\mathrm{T}_{\mathrm{s}}=250{ }^{\circ} \mathrm{C}$, annealed at $300{ }^{\circ} \mathrm{C}$ in Ar; (c) $T_{\mathrm{s}}=25^{\circ} \mathrm{C}$, annealed at $300^{\circ} \mathrm{C}$ in Ar.

\subsection{5. $\mathrm{FeF}_{2}$}

Iron fluoride is a conversion-type cathode material with a high theoretical specific capacity of $571 \mathrm{mAh} \cdot \mathrm{g}^{-1}$. Several groups reported electronic additive-free $\mathrm{FeF}_{2}$ films grown by the PLD technique at low temperatures [225-228]. The electrochemical properties of $\mathrm{FeF}_{x}$ films were reported to be dependent on the substrate temperature. Using an $\mathrm{FeF}_{3}$ target, crystallized-like $\mathrm{FeF}_{2}$ film $\left(\mathrm{P}_{2} / \mathrm{mnm}\right.$ space group) was obtained at $T_{\mathrm{s}}=600^{\circ} \mathrm{C}$, while a mixed $\mathrm{FeF}_{3}-\mathrm{FeF}_{2}$ phase was grown at $T_{\mathrm{s}}=25^{\circ} \mathrm{C}$ and single $\mathrm{FeF}_{3}$ phase was prepared at $T_{\mathrm{s}}=-50{ }^{\circ} \mathrm{C}$ [226]. $\mathrm{FeF}_{x}$ deposited on stainless steel substrates under vacuum $\left(5 \times 10^{-5} \mathrm{~Pa}\right)$ exhibited a capacity of $\sim 600 \mathrm{mAh} \cdot \mathrm{g}^{-1}$ at a current density of $0.56 \mu \mathrm{A} \cdot \mathrm{cm}^{-2}$. Santos-Ortiz et al. reported the PLD growth of polycrystalline $\mathrm{FeF}_{2}$ thin films on oxide-etched $\mathrm{Si}(100)$ and glass substrates using standard conditions $\left(T_{\mathrm{s}}=400{ }^{\circ} \mathrm{C}, \Phi=8 \mathrm{~J} \cdot \mathrm{cm}^{-2}\right.$, growth rate of $\sim 6 \mathrm{~nm} \cdot \mathrm{min}^{-1}$ ) [227]. A 50-nm thick PLD FeF 2 film on stainless steel substrates held at $400{ }^{\circ} \mathrm{C}$ showed an initial specific discharge capacity of $167 \mathrm{mAh} \cdot \mathrm{g}^{-1}$ when cycled 200 times in the potential range of 1 to $4 \mathrm{~V}$ vs. $\mathrm{Li}^{+} / \mathrm{Li}$ at the $1 \mathrm{C}$ current rate [228].

\subsection{6. $\mathrm{MoO}_{3}$}

$\mathrm{MoO}_{3}$ is an attractive cathode material for microbattery technology from several standpoints: (i) The orthorhombic a-phase is a layered structure favorable for Li insertion between slabs; (ii) Mo has the highest +6 oxidation state, making the high structural stability; (iii) the lattice can be reversibly inserted up to $1.5 \mathrm{Li}$ per mole of oxide, yielding a specific capacity of $280 \mathrm{mAh} \cdot \mathrm{g}^{-1}$; and (iv) the capacity of the dense film can reach a value of $\approx 130 \mu \mathrm{Ah} \cdot \mathrm{cm}^{-2} \cdot \mu \mathrm{m}^{-1}$, almost twice the value for $\mathrm{LiCoO}_{2}$ [229]. In addition to the use as cathode batteries, $\mathrm{MoO}_{3}$ is a material applied in electrochromics, gas sensors, and electro-optics. For certain applications, high-quality films grown by PLD are required.

Currently, $\mathrm{PLD} \mathrm{MoO}$ thin films are grown using a $\operatorname{KrF}$ excimer laser $(\lambda=248 \mathrm{~nm})$ with a fluence of $2 \mathrm{~J} \mathrm{~cm}^{-2}$ (energy of $300 \mathrm{~mJ}$ per pulse) and deposited on various substrates heated in the range of $25 \leq T_{\mathrm{s}} \leq 500{ }^{\circ} \mathrm{C}$ under an atmosphere of $\mathrm{O}_{2}$ flow maintained at a pressure of $0.1 \leq P_{\mathrm{O}_{2}} \leq 20 \mathrm{~Pa}$. In the prior report, Julien et al. showed that the structure analyzed by optical spectroscopy strongly depends on $T_{\mathrm{s}}$ : For $T_{\mathrm{s}}<150{ }^{\circ} \mathrm{C}$, an amorphous phase is formed, the $\beta-\mathrm{MoO}_{3}$ phase grows at $T_{\mathrm{s}} \approx 200{ }^{\circ} \mathrm{C}$, and the layered $\alpha-\mathrm{MoO}_{3}$ phase appears at $T_{\mathrm{S}}=300{ }^{\circ} \mathrm{C}$ [230-233]. Al-Kuhaili et al. reported the growth of polycrystalline $\mathrm{MoO}_{3}$ films on unheated substrates using both $\mathrm{XeF}$ and $\mathrm{KrF}$ excimer lasers. By tuning the annealing temperature in the range of 300 to $500{ }^{\circ} \mathrm{C}$, both the grain size and surface roughness increased. Films formed using the XeF laser $(\lambda=351 \mathrm{~nm})$ and annealed at $400{ }^{\circ} \mathrm{C}$ have the best stoichiometry of $\mathrm{MoO}_{2.95}$ [233]. Analyzing the growth mechanism, Ramana and Julien concluded that the thermochemical reaction during ablation strongly influences the structural characteristics of PLD $\mathrm{MoO}_{3}$ films. Above $T_{\mathrm{s}}=400^{\circ} \mathrm{C}$, the formation of compositional defects induces structural disorder, i.e., $\alpha-\beta-\mathrm{MoO}_{3-x}$ phase mixture $[234,235]$. 
The applicability of PLD films to an Li microbattery was demonstrated by the best electrochemical features: A discharge capacity of $90 \mu \mathrm{Ah} \mathrm{cm}^{-2} \mu \mathrm{m}^{-1}$ was obtained for $T_{\mathrm{s}}=400{ }^{\circ} \mathrm{C}$, while only $53 \mu \mathrm{Ah} \cdot \mathrm{cm}^{-2} \cdot \mu \mathrm{m}^{-1}$ was delivered for $T_{\mathrm{s}}=200^{\circ} \mathrm{C}$ [236]. Puppala et al. investigated the microstructure and morphology of $\mathrm{PLD} \mathrm{MoO}_{3-x}$ thin films' growth for catalytic applications using a femtosecond laser (f-PLD) and a nanosecond excimer-laser (n-PLD). Substantially textured films with a partially crystalline phase prior to annealing were obtained by the f-PDL laser, while the n-PLD-grown $\mathrm{MoO}_{3-x}$ films were predominantly amorphous with a smooth surface [237]. Sunu et al. claimed that as-deposited PLD films $\left(T_{\mathrm{s}}=400{ }^{\circ} \mathrm{C}, \Phi=4-5 \mathrm{~J} \cdot \mathrm{cm}^{-2}\right.$, repetition rate of 15 to $20 \mathrm{~Hz}$, and $P_{\mathrm{O}_{2}}=500 \mathrm{~Pa}$ ) are suboxide-like, i.e., mixture of $\eta-\mathrm{Mo}_{4} \mathrm{O}_{11}$ and $\chi-\mathrm{Mo}_{4} \mathrm{O}_{11}$, which transformed to $\mathrm{MoO}_{3}$ after annealing at $500{ }^{\circ} \mathrm{C}$ in air for $5 \mathrm{~h}$ [238]. Several works reported the PLD growth of films $\left(\mathrm{MoO}_{3}\right)_{1-x}\left(\mathrm{~V}_{2} \mathrm{O}_{5}\right)_{x}$ with $0.0 \leq x \leq 0.3$ prepared at room temperature under an oxygen pressure of $13.3 \mathrm{~Pa}$. The effect of the $\mathrm{V}_{2} \mathrm{O}_{5}$ content on the coloring switching properties for thermochromic, gasochromic, photochromic, and electrochromic applications was investigated $[239,240]$. Contrary to pure $\mathrm{MoO}_{3}$, the electrochromism of $\mathrm{MoO}_{3}-\mathrm{V}_{2} \mathrm{O}_{5}$ films showed that the Mo oxidation state (+6) did not change considerably upon $\mathrm{Li}^{+}$insertion, while $\mathrm{V}^{5+}$ was reduced considerably to $\mathrm{V}^{4+}$ [239]. A similar improvement of the gas-sensing properties, i.e., the shortest response time and highest transmittance change, was observed for $\mathrm{V}_{2} \mathrm{O}_{5}$-doped $\mathrm{MoO}_{3}$ films under an $\mathrm{H}_{2}$ atmosphere [240].

\subsection{7. $\mathrm{WO}_{3}$}

Tungsten oxide $\left(\mathrm{WO}_{3}\right)$ belongs to the class of "chromogenic" materials, i.e., materials exhibiting coloration effects through electro-, photo-, gas-, laser-, and thermochromism processes, which requires the high homogeneity provided by the PLD technique. Preliminary studies of the growth of $\mathrm{WO}_{3}$ thin films by PLD were first attempted by Haro-Poniaowski et al. [233] in 1998. Later, Rougier et al. reported the PLD conditions for the growth of efficient $\mathrm{WO}_{3}$ films as electrochromics (EC) components [241]. The microstructure of films deposited on $\mathrm{SnO}_{2}: \mathrm{F}$ coated glass substrate is strongly sensitive to both the oxygen pressure and substrate temperature: (i) Crystallized films are formed for $T_{\mathrm{s}}=400{ }^{\circ} \mathrm{C}$ and $P_{\mathrm{O}_{2}}=10 \mathrm{~Pa}$; (ii) amorphous films are obtained for $P_{\mathrm{O}_{2}}=1 \mathrm{~Pa}$ at any $T_{\mathrm{s}}$; (iii) for $T_{\mathrm{s}}=25^{\circ} \mathrm{C}$ and $P_{\mathrm{O} 2}=1 \mathrm{~Pa}, \mathrm{WO}_{3}$ films are blue colored and conductive; and (iv) colorless insulator films are grown for $T_{\mathrm{S}}=25^{\circ} \mathrm{C}$ and $P_{\mathrm{O}_{2}}=10 \mathrm{~Pa}$, which display the best electrochromic properties. Qiu and $\mathrm{Lu}$ showed that oxygen deficient $\mathrm{WO}_{3-\delta}$ films with a deviated monoclinic structure were produced using PLD parameters as $2.5 \mathrm{~J} \cdot \mathrm{cm}^{-2}, P_{\mathrm{O}_{2}}=26 \mathrm{~Pa}$, and a target-Si(100) substrate distance of $d=5 \mathrm{~cm}$ [242]. Ramana et al. investigated the structural transformations of $\mathrm{PLD} \mathrm{WO}_{3}$ as a function of the annealing treatment. Using standard conditions $\left(\Phi=2 \mathrm{~J} \cdot \mathrm{cm}^{-2}, T_{\mathrm{s}}=300{ }^{\circ} \mathrm{C}, P_{\mathrm{O}_{2}}=13.3 \mathrm{~Pa}\right)$, films deposited on glass substrates (200-500 nm thick) showed an atomic ratio of $\mathrm{O} / \mathrm{W} \approx 2.96 \pm 0.05$. The monoclinic phase of the as-prepared film transformed to an orthorhombic phase at $350{ }^{\circ} \mathrm{C}$ and to a hexagonal phase at $500{ }^{\circ} \mathrm{C}[243,244]$. By varying the substrate temperature in the range of 150 to $800{ }^{\circ} \mathrm{C}$ and the oxygen pressure from 1 to $40 \mathrm{~Pa}$, Mitsugi et al. obtained $\mathrm{WO}_{3}$ films with a different microstructure: Amorphous, crystallized tetragonal, and triclinic phases [245]. Hussain et al. obtained amorphous, polycrystalline, and nanocrystalline $\mathrm{WO}_{3}$ phases, and iso-epitaxial $\mathrm{WO}_{3}(00 l)$ thin films deposited on single-crystal $\mathrm{SrTiO}_{3}$ substrates at $600{ }^{\circ} \mathrm{C}$ and under $P_{\mathrm{O}_{2}}=18 \mathrm{~Pa}$ [246]. Suda et al. deposited $\mathrm{PLD} \mathrm{WO}_{3}$ thin films on flexible ITO substrates. They showed that films, prepared at $T_{\mathrm{s}}<300{ }^{\circ} \mathrm{C}$, are amorphous and polycrystalline phases were obtained at $T_{\mathrm{s}}>400{ }^{\circ} \mathrm{C}$, while the crystallinity of the film on glass substrates was not dependent on $P_{\mathrm{O}_{2}}$ [247]. Films deposited at $400{ }^{\circ} \mathrm{C}$ were porous with a nanocrystalline triclinic structure and showed the best cycleability [216,248,249].

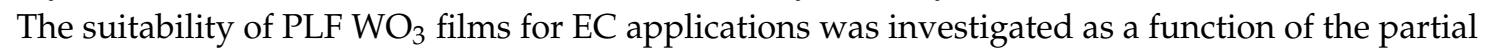
oxygen pressure during deposition. Studies of the texture and morphology of PLD 30-nm thick $\mathrm{WO}_{3}$ films deposited on $\mathrm{Si}(100)$ and $\mathrm{SrTiO}_{3}(100)$ substrates under an $\mathrm{O}_{2}$ background of 2.5 Pa showed that: (i) The laser fluence (in the range of 5 to $15 \mathrm{~J} \cdot \mathrm{cm}^{-2}$ ) strongly influences the texture, (ii) the films grown on STO are biaxially textured with a smooth surface, and (iii) films deposited on Si are granular [250]. The fabrication of $\mathrm{WO}_{3}$ thin films with color neutrality for applications as EC materials was realized by 
the deposition of films containing $20 \%$ of vanadium onto $\mathrm{SnO}_{2}: \mathrm{F}$ coated glasses at $T_{\mathrm{S}}=20{ }^{\circ} \mathrm{C}$ under $P_{\mathrm{O}_{2}}=10 \mathrm{~Pa}$. The blue color in the reduced state $(-0.4 \mathrm{~V})$ of the W-O-V films lost intensity and turned grey-blue (transmittance of 50\%) as the $\mathrm{V}$ concentration increased [251]. Highly transparent $\mathrm{WO}_{3}$ films exhibiting strong coloration and fast and full bleaching were prepared under PLD conditions $\left(\Phi=1 \mathrm{~J} \cdot \mathrm{cm}^{-2}, T_{\mathrm{s}}=250^{\circ} \mathrm{C}, P_{\mathrm{O}_{2}}=16 \mathrm{~Pa}\right.$, and $\left.d=40 \mathrm{~mm}\right)$ [252]. $\mathrm{WO}_{3}$ films were also prepared using similar PLD parameters for applications in gas sensors [253-255].

\section{Solid Electrolyte PLD Films}

For the development of solid-state thin film batteries, thin films of solid electrolytes with excellent performances, i.e., high ionic conductivity $\left(\sigma_{\mathrm{i}}\right)$, good stability against the lithium anode, large electrochemical window $(\Delta V)$, and poor electronic conductivity $\left(\sigma_{\mathrm{e}}\right)$, are currently required. To fulfill these requirements, the thin films of oxide-, phosphate-, or sulphide-based solid electrolytes were grown by the PLD technique [256-258]. The facile manufacture of such thin films is due to the easy control of the PLD chamber's atmosphere. Table 8 lists some typical solid electrolyte thin films prepared by PLD [41,259-264].

Table 8. Electrical properties of PLD-grown solid-electrolyte thin films.

\begin{tabular}{cccc}
\hline Electrolyte & Ionic Conductivity $\mathbf{( \mathbf { S ~ c m } ^ { \mathbf { - 1 } } )}$ & $\begin{array}{c}\text { Electronic Conductivity (S } \\
\mathbf{c m}\end{array}$ & Ref. \\
\hline $\mathrm{Li}_{3.3} \mathrm{PO}_{3.9} \mathrm{~N}_{0.17}(\mathrm{LiPON})$ & $1.6 \times 10^{-6}$ & $>10^{-14}$ & {$[259]$} \\
$\mathrm{Li}_{3.4} \mathrm{~V}_{0.6} \mathrm{Si}_{0.4} \mathrm{O}_{4}$ (LVSO) & $2.5 \times 10^{-7}$ & $7.4 \times 10^{-13}$ & {$[41]$} \\
$\mathrm{Li}_{3.25} \mathrm{Ge}_{0.25} \mathrm{P}_{0.75} \mathrm{~S}_{4}$ (thio-LISICON) & $2.2 \times 10^{-3}$ & $1.5 \times 10^{-7}$ & {$[260]$} \\
$\mathrm{Li}_{0.5} \mathrm{La}_{0.5} \mathrm{TiO}_{3}$ (LLTO) & $2.2 \times 10^{-5}$ & $3.5 \times 10^{-11}$ & {$[261]$} \\
$\mathrm{Li}_{2} \mathrm{O}-\mathrm{Si}_{2} \mathrm{O}$ (LSO) & $2.2 \times 10^{-4}\left(200^{\circ} \mathrm{C}\right)$ & - & {$[262]$} \\
$\beta-\mathrm{LiAlSiO}_{4}$ & $4.0 \times 10^{-7}\left(225^{\circ} \mathrm{C}\right)$ & - & {$[263]$} \\
$\mathrm{Li}_{6} \mathrm{BaLa}_{2} \mathrm{Ta}_{2} \mathrm{O}_{12}$ (garnet-type) & $2.0 \times 10^{-6}\left(25^{\circ} \mathrm{C}\right)$ & $2.9 \times 10^{-13}$ & {$[264]$} \\
\hline
\end{tabular}

\subsection{LiPON}

In the early 1990s, Bates et al. prepared $\mathrm{Li}_{3} \mathrm{PO}_{4}$ thin films using a sputter-deposition technique in the presence of $\mathrm{N}_{2}$ gas that resulted in a nitrogen-doped lithium phosphate (called LiPON) of a typical chemical composition, $\mathrm{Li}_{3.3} \mathrm{PO}_{3.9} \mathrm{~N}_{0.17}$ to $\mathrm{Li}_{2.9} \mathrm{PO}_{2.9} \mathrm{~N}_{0.7}$. The structure consists of doubly and triply coordinated nitrogen atoms, which form cross-links between the phosphate chains [20]. LiPON displays a high chemical stability and an ionic conductivity of $2 \times 10^{-6} \mathrm{~S} \cdot \mathrm{cm}^{-1}$ at $25^{\circ} \mathrm{C}$ [265]. The growth of LiPON thin films by pulsed-laser deposition is also realized in nitrogen partial pressure with a moderate laser power influence $[259,266]$.

Zhao et al. reported the growth LiPON thin films on three different substrates (i.e., Si wafer, $\mathrm{Au}$-coated $\mathrm{Si}$, and $\mathrm{Al}$-coated glass plate) by reactive PLD in an $\mathrm{N}_{2}$ gas atmosphere in the range of 50 to 200 mTorr using a $\mathrm{Li}_{3} \mathrm{PO}_{4}$ target. The target was ablated by the beam of a Nd:YAG laser at the fluence of 5 to $20 \mathrm{~mJ} \cdot \mathrm{cm}^{-2}$. The influence of the ambient $\mathrm{N}_{2}$ pressure and the laser fluence on the ionic conductivity was systemically examined and the best result of $1.6 \times 10^{-6} \mathrm{~S} \cdot \mathrm{cm}^{-1}$ with an activation energy of $0.58 \mathrm{eV}$ at $25^{\circ} \mathrm{C}$ was obtained for a film prepared under $200 \mathrm{mTorr}$ at $\Phi=15 \mathrm{~J} \cdot \mathrm{cm}^{-2}$. The mechanism of the nitridation of $\mathrm{Li}_{3} \mathrm{PO}_{4}$ was carried out by XPS measurements, showing that $\sigma_{\mathrm{i}}$ increases with the N/P ratio [259]. West et al. showed that a 17-nm thick layer of LiPON deposited at the solid electrolyte-electrode interface decreased the charge-transfer resistance from 4470 to $760 \mathrm{~cm}^{-2}$ in a Li/LiPON/LNM cell. The PLD amorphous films with $\sigma_{\mathrm{i}}=1.5 \times 10^{-8} \mathrm{~S} \cdot \mathrm{cm}^{-1}$ at $25^{\circ} \mathrm{C}$ were deposited from a crystalline $\mathrm{Li}_{2} \mathrm{PO}_{2} \mathrm{~N}$ target under the flow of $\mathrm{N}_{2}$ gas at $P_{\mathrm{N}_{2}}=1 \mathrm{~Pa}$ [267].

\section{2. $\mathrm{Li}_{x} \mathrm{La}_{2 / 3+y} \mathrm{TiO}_{3-d}(\mathrm{LLTO})$}

Solid electrolytes, such as lithium lanthanum titanium oxides, $\mathrm{Li}_{x} \mathrm{La}_{2 / 3+y} \mathrm{TiO}_{3-\delta}$ (LLTO), based on a perovskite-like structure can accept vacancies at the $\mathrm{Li}$ (or $\mathrm{La}$ ) and oxygen sites and show properties 
depending on the composition, with an electronic conductivity when $\mathrm{Ti}^{3+}$ cations (instead of $\mathrm{Ti}^{4+}$ ) are present and an ionic conductivity for Li-rich material. The typical growth of LLTO thin films fabricated by the laser ablation technique is obtained at deposition temperatures in the range of 600 to $800^{\circ} \mathrm{C}$ under a controlled oxygen pressure from 0.1 to $100 \mathrm{~Pa}$ [268]. LLTO films, such as $\mathrm{Li}_{3 x} \mathrm{La}_{(2 / 3)-x} \mathrm{TiO}_{3}$, exhibit a high ionic conductivity of up to $10^{-5} \mathrm{~S} \cdot \mathrm{cm}^{-1}$ when deposited with pulsed laser deposition [269-271]. $\mathrm{Li}_{0.5} \mathrm{La}_{0.5} \mathrm{TiO}_{3}$ (LLTO) PLD thin films, prepared at 400 to $600{ }^{\circ} \mathrm{C}$, are amorphous and show an ionic conductivity of $\sim 2 \times 10^{-5} \mathrm{~S} \cdot \mathrm{cm}^{-1}$ at room temperature. Contrary to crystalline films, the amorphous LLTO exhibits good stability in contact with lithium metal anodes. Half-cells based on $\mathrm{LiCoO}_{2}$ films covered with LLTO films deposited by pulsed laser deposition could be cycled for hundreds of cycles [269]. Furusawa et al. prepared amorphous LLTO films at $T_{\mathrm{s}}=25^{\circ} \mathrm{C}$ with a uniform thickness $(0.46-0.63 \mu \mathrm{m})$ using a laser energy of $180 \mathrm{~mJ}$ per pulse at $10 \mathrm{~Hz}$ [270]. The authors stated a controlled pressure of $\sim 10^{-6}$ Torr but did not mention the presence of $\mathrm{O}_{2}$ gas. The highest $\sigma_{\mathrm{i}}$ of $1.2 \times 10^{-3} \mathrm{~S} \cdot \mathrm{cm}^{-1}$ $\left(E_{\mathrm{a}}=0.35 \mathrm{eV}\right.$ ) obtained for $\mathrm{Li}_{0.5} \mathrm{La}_{0.5} \mathrm{TiO}_{3}$ films deposited on an Ag substrate was due to the absence of grain boundaries. Maqueda optimized the PLD growth parameters to prepare $\mathrm{La}_{0.57} \mathrm{Li}_{0.29} \mathrm{TiO}_{3}$ dense films at $T_{\mathrm{s}}=700{ }^{\circ} \mathrm{C}$ under $P_{\mathrm{O}_{2}}=15 \mathrm{~Pa}$ with smooth surfaces [271]. The obtained nano-crystalline films exhibited domains, which are cubic and tetragonal modifications of the perovskite phase. Transport measurements showed an ionic conductivity of $8.2 \times 10^{-4} \mathrm{~S} \cdot \mathrm{cm}^{-1}$ at $25^{\circ} \mathrm{C}$ with $E_{\mathrm{a}}=0.34 \mathrm{eV}$. Epitaxial $\mathrm{Li}_{0.33} \mathrm{La}_{0.56} \mathrm{TiO}_{3}$ solid electrolyte thin films were grown on $\mathrm{NdGaO}_{3}(110)$ by PLD at $T_{\mathrm{s}}$ higher than $900{ }^{\circ} \mathrm{C}$ under $P_{\mathrm{O}_{2}}=5 \mathrm{~Pa}$ [272]. These films showed a conductivity $\sigma_{\mathrm{i}}$ of $3.5 \times 10^{-5} \mathrm{~S} \cdot \mathrm{cm}^{-1}$ at $25^{\circ} \mathrm{C}$ with $E_{\mathrm{a}}=0.35 \mathrm{eV}$ (Figure 14).

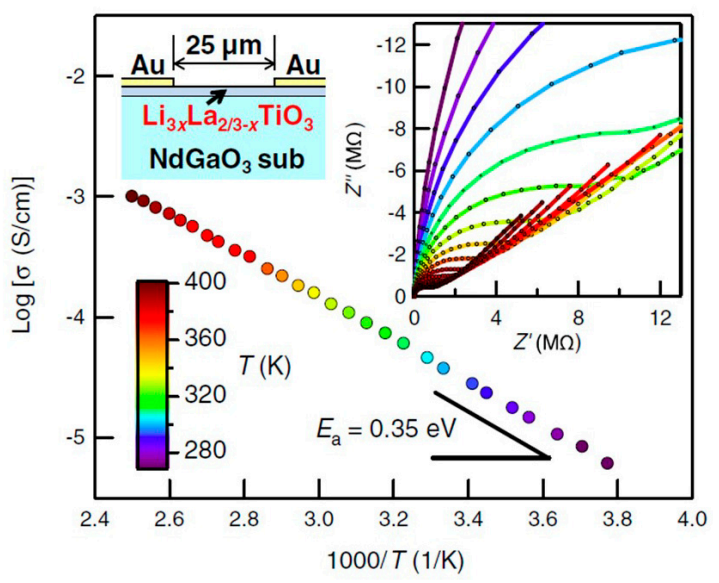

Figure 14. Temperature of the in-plane ionic for conductivity epitaxial $\mathrm{Li}_{0.33} \mathrm{La}_{0.56} \mathrm{TiO}_{3}$ solid electrolyte thin films (36-nm tick) deposited on $\mathrm{NdGaO}_{3}(110)$ by PLD at $T_{\mathrm{s}}$ higher than $900{ }^{\circ} \mathrm{C}$ under $P_{\mathrm{O}_{2}}=5 \mathrm{~Pa}$. (Reproduced with permission from [272]. Copyright 2012 Elsevier).

The influence of different substrates and excess lithium in the target on the microstructure and ionic conductivity of PLD LLTO thin films was examined by Aguesse et al. [273] Despite a large lattice mismatch of up to $+8.8 \%$ with the substrate, the epitaxial growth of LLTO is possible on different (001) oriented $\mathrm{LaAlO}_{3}, \mathrm{SrTiO}_{3}$, and $\mathrm{MgO}$ substrates using a sintered $\mathrm{Li}_{0.37} \mathrm{La}_{0.54} \mathrm{TiO}_{3}$ target and PLD parameters, such as $T_{\mathrm{s}}=750-880{ }^{\circ} \mathrm{C}, P_{\mathrm{O}_{2}}=4-20 \mathrm{~Pa}$, and laser fluence of $1.07 \mathrm{~J} \mathrm{~cm}^{-2}$. An ionic conductivity as high as $19.2 \times 10^{-3} \mathrm{mS} \cdot \mathrm{cm}^{-1}$ at $25^{\circ} \mathrm{C}$ was obtained for 170 -nm thick LLTO films grown on an STO substrate from an ablated $10 \mathrm{~mol} \%$ lithium excess target. PLD LLTO films with a $\sigma_{i}$ of $3 \times 10^{-4} \mathrm{~S} \cdot \mathrm{cm}^{-1}$ and $\sigma_{\mathrm{e}}$ of $5 \times 10^{-11} \mathrm{~S} \cdot \mathrm{cm}^{-1}$ were obtained by controlling the background $P_{\mathrm{O}_{2}}$ and $T_{\mathrm{s}}$. Amorphous LLTO films were utilized in SSMB cycled up to $4.8 \mathrm{~V} \mathrm{vs.} \mathrm{Li}^{+} / \mathrm{Li}$ with high voltage $\mathrm{LiNi}_{0.5} \mathrm{Mn}_{1.5} \mathrm{O}_{4}$ spinel cathode thin films [274].

Another class of LLTO electrolytes consists of Ti-based solid electrolytes with a garnet-like structure, first reported by Weppner et al. [275]. $\mathrm{Li}_{6} \mathrm{BaLa}_{2} \mathrm{Ta}_{2} \mathrm{O}_{12}$ thin films were deposited on an $\mathrm{MgO}(100)$ substrate by the ablation of a target with a $5 \mathrm{~mol}^{\%} \mathrm{Li}_{2} \mathrm{O}$ excess. In standard PLD conditions 
( $T_{\mathrm{S}}=550{ }^{\circ} \mathrm{C}, P_{\mathrm{O}_{2}}=5 \mathrm{~Pa}$, laser fluence of $\Phi=2 \mathrm{~J} \cdot \mathrm{cm}^{-2}, 40,000$ laser pulses), an ionic conductivity of $2 \times 10^{-6} \mathrm{~S} \cdot \mathrm{cm}^{-1}$ at $25^{\circ} \mathrm{C}$ with an activation energy of $0.42 \mathrm{eV}$ was obtained. This is comparable with the $\sigma_{i}$ of LiPON. The electronic conductivity varied from $2.87 \times 10^{-13}$ to $3.47 \times 10^{-10} \mathrm{~S} \cdot \mathrm{cm}^{-1}$ in the range of the polarization voltage from 2.8 to $4.3 \mathrm{~V}$ [273]. Saccoccio et al. fabricated garnet $\mathrm{Li}_{6.4} \mathrm{La}_{3} \mathrm{Zr}_{1.4} \mathrm{Ta}_{0.6} \mathrm{O}_{12}$ films via PLD and studied the impact of PLD parameters (fluence of 1 to $4 \mathrm{~J} \cdot \mathrm{cm}^{-2}, T_{\mathrm{s}}$ in the range of 50 to $700{ }^{\circ} \mathrm{C}$, and a post-annealing process) on the structural and transport properties. The ionic conductivity was measured by impedance spectroscopy. It was concluded that $\sigma_{\mathrm{i}}$ is not dependent on $T_{\mathrm{s}}$ but is strongly affected by the laser fluence [276]. $\mathrm{Li}_{7} \mathrm{La}_{3} \mathrm{Zr}_{2} \mathrm{O}_{12}$ (LLZO) garnet-like thin films were deposited on $\mathrm{Si}_{3} \mathrm{~N}_{4} / \mathrm{Si}$ substrates at temperatures in the range of $50 \leq T_{\mathrm{S}} \leq 750{ }^{\circ} \mathrm{C}$ under a fixed background of $P_{\mathrm{O}_{2}}=1.3 \mathrm{~Pa}$ with a $\mathrm{KrF}$ excimer laser set at $0.6 \mathrm{~J} \cdot \mathrm{cm}^{-2}$ [277]. The best material, which exhibited an ionic conductivity of $6.3 \times 10^{-3} \mathrm{~S} \mathrm{~cm}^{-1}$ at $400{ }^{\circ} \mathrm{C}\left(E_{\mathrm{a}}=0.6 \mathrm{eV}\right)$, was obtained at $T_{\mathrm{s}}=300{ }^{\circ} \mathrm{C}$. The review of garnet-like solid electrolyte thin films grown via PLD is summarized in Table 9.

Table 9. Literature review of garnet-like solid electrolyte thin films grown via PLD.

\begin{tabular}{ccccc}
\hline Material & Substrate & $\boldsymbol{\sigma}_{\mathbf{i}}$ at $\mathbf{2 5}{ }^{\circ} \mathbf{C}\left(\mathbf{S ~ c m}^{\mathbf{- 1}}\right)$ & $\boldsymbol{E}_{\mathbf{a}}(\mathbf{e V})$ & Ref. \\
\hline $\mathrm{Li}_{6} \mathrm{BaLa}_{2} \mathrm{Ta}_{2} \mathrm{O}_{12}$ & $\mathrm{MgO}(100)$ & $2 \times 10^{-6}$ at $25^{\circ} \mathrm{C}$ & 0.42 & {$[278]$} \\
$\mathrm{Li}_{7} \mathrm{La}_{3} \mathrm{Zr}_{2} \mathrm{O}_{12}$ & $\mathrm{Si}_{3} \mathrm{~N}_{4} / \mathrm{Si}$ & $6.3 \times 10^{-3}$ at $400{ }^{\circ} \mathrm{C}$ & 0.60 & {$[279]$} \\
$\mathrm{Li}_{7} \mathrm{La}_{3} \mathrm{Zr}_{2} \mathrm{O}_{12}$ & $\mathrm{SrTiO}_{3}$, sapphire & $7.4 \times 10^{-7}$ at $25^{\circ} \mathrm{C}$ & 0.32 & {$[280]$} \\
$\mathrm{Li}_{7} \mathrm{La}_{3} \mathrm{Zr}_{2} \mathrm{O}_{12}$ & $\mathrm{Si}_{1} \mathrm{SiO}_{2}, \mathrm{MgO}$ & $1.6 \times 10^{-6}$ at $25^{\circ} \mathrm{C}$ & 0.35 & {$[281]$} \\
$\mathrm{Al}$-doped $\mathrm{Li}_{7} \mathrm{La}_{3} \mathrm{Zr}_{2} \mathrm{O}_{12}$ & $\mathrm{Gd}_{3} \mathrm{Ga}_{3} \mathrm{O}_{12}$ & $2.5 \times 10^{-6}$ at $25^{\circ} \mathrm{C}$ & 0.52 & {$[275]$} \\
Al-doped $\mathrm{Li}_{7} \mathrm{La}_{3} \mathrm{Zr}_{2} \mathrm{O}_{12}$ & $\mathrm{MgO}$ & $8.3 \times 10^{-4}$ at $300{ }^{\circ} \mathrm{C}$ & 0.60 & {$[264]$} \\
\hline
\end{tabular}

\subsection{P- and Si-Based Electrolytes}

Several phosphorus- or silicon-based oxides and sulfides are solid electrolytes for lithium batteries, such as $\mathrm{Li}_{3} \mathrm{PO}_{4}, \mathrm{Li}_{4} \mathrm{SiO}_{4}-\mathrm{Li}_{3} \mathrm{PO}_{4}, \mathrm{Li}_{2} \mathrm{~S}_{-} \mathrm{P}_{2} \mathrm{~S}_{5}$ glass ceramic, $\mathrm{Li}_{2+2 x} \mathrm{Zn}_{1-x} \mathrm{GeO}_{4}$ (LiSICON), $\mathrm{Li}_{3.25} \mathrm{Ge}_{0.25} \mathrm{P}_{0.75} \mathrm{~S}_{4}$ (thio-LiSICON), etc., that can be prepared as thin films. Kuwata et al. prepared high quality $\mathrm{Li}_{3} \mathrm{PO}_{4}$ thin films by $\mathrm{PLD}$ for applications in $\mathrm{Li} / \mathrm{Li}_{3} \mathrm{PO}_{4} / \mathrm{LiCoO}_{2}$ all-solid-state thin-film batteries. The $\mathrm{Li}_{3} \mathrm{PO}_{4}$ film exhibited an ionic conductivity of $4 \times 10^{-7} \mathrm{~S} \cdot \mathrm{cm}^{-1}$ at $25^{\circ} \mathrm{C}$ and an activation energy of $0.58 \mathrm{eV}$. This solid electrolyte showed an electrochemical stability in the potential range of 0.0 to $4.7 \mathrm{~V}$ vs. $\mathrm{Li}^{+} / \mathrm{Li}$ and was applied in $\mathrm{Li} / \mathrm{Li}_{3} \mathrm{PO}_{4} / \mathrm{LiCoO}_{2}$ cells $[14,282]$. Amorphous PLD thin films of LiSICON display higher conductivities than that of $\mathrm{Li}_{4} \mathrm{SiO}_{4}$ and $\mathrm{Li}_{3} \mathrm{PO}_{4}$ films. The solid electrolyte $0.5 \mathrm{Li}_{4} \mathrm{SiO}_{4}-0.5 \mathrm{Li}_{3} \mathrm{PO}_{4}$ dense films deposited on an $\mathrm{Si}$ wafer at $\Phi=2-6 \mathrm{~J} \cdot \mathrm{cm}^{-2}$ under an argon gas of $P_{\mathrm{Ar}}=0.01-5 \mathrm{~Pa}$ had an ionic conductivity of $1.6 \times 10^{-6} \mathrm{~S} \cdot \mathrm{cm}^{-1}$ at $25^{\circ} \mathrm{C}$ and an activation energy of $52 \mathrm{~kJ} \cdot \mathrm{mol}^{-1}$ [283]. Nakagawa et al. determined that $\mathrm{PLD} \mathrm{Li}_{2} \mathrm{SiO}_{3}$ films stable to $\mathrm{CO}_{2}$ have an ionic conductivity of $2.5 \times 10^{-8} \mathrm{~S} \cdot \mathrm{cm}^{-1}$ at $25^{\circ} \mathrm{C}$ lower than that of $\mathrm{Li}_{2} \mathrm{SiO}_{3}$ films (i.e., $4.1 \times 10^{-7} \mathrm{~S} \cdot \mathrm{cm}^{-1}$ ), which are unstable to $\mathrm{CO}_{2}$ [284]. PLD thin films of lithium meta-silicate (LSO) deposited at a growth rate of $0.17 \AA$ per pulse on various substrates (i.e., $\mathrm{SiO}_{2}$, quartz, sapphire, $\mathrm{Al}_{2} \mathrm{O}_{3}$ ceramic, and $\mathrm{MgO}$ ) from an $\mathrm{Li}_{2} \mathrm{SiO}_{3}$ sintered tablet were grown in the amorphous state. The ionic conductivity slightly depends on the substrate species with the best results $\left(\sigma_{\mathrm{i}}=4.5 \times 10^{-4} \mathrm{~S} \cdot \mathrm{cm}^{-1}\right.$ at $\left.300{ }^{\circ} \mathrm{C}, E_{\mathrm{a}}=0.88 \mathrm{eV}\right)$ found for an 80-nm thick film deposited on $\mathrm{SiO}_{2}$ glass [262,285]. The PLD conditions for the growth of thio-LiSICON $\mathrm{Li}_{3.25} \mathrm{Ge}_{0.25} \mathrm{P}_{0.75} \mathrm{~S}_{4}$ solid electrolyte thin films were carefully chosen (especially the $\mathrm{Li}$ content of 3.2 in the target, which maintains the number of Li vacancies) to obtain a high $\sigma_{i}$ value of $1.7 \times 10^{-4} \mathrm{~S} \cdot \mathrm{cm}^{-1}$ at $25^{\circ} \mathrm{C}$ [265]. PLD 80 $\mathrm{Li}_{2} \mathrm{~S}-20 \mathrm{P}_{2} \mathrm{O}_{5}$ thin film prepared under $P_{\mathrm{Ar}}=5 \mathrm{~Pa}$ exhibited an ionic conductivity and activation energy of $7.9 \times 10^{-5} \mathrm{~S} \cdot \mathrm{cm}^{-1}$ and $43 \mathrm{~kJ} \mathrm{~mol}^{-1}$ at $25^{\circ} \mathrm{C}$, respectively. Heat treatment increased the $\sigma_{\mathrm{I}}$ to $2.8 \times 10^{-4} \mathrm{~S} \cdot \mathrm{cm}^{-1}$ [286]. To avoid the formation of a Li-deficient phase, such as $\mathrm{Li}_{4} \mathrm{P}_{2} \mathrm{~S}_{6}$, an $\mathrm{Li}_{2} \mathrm{~S}$-enriched $\mathrm{Li}_{3} \mathrm{PS}_{4}$ target was used to grow PLD solid-electrolyte thin films. Using an $\mathrm{Li}_{3.42} \mathrm{PS}_{4.21}$ target, $\mathrm{PLD} \mathrm{Li}_{3} \mathrm{PS}_{4}$ films exhibited a higher ionic conductivity of $5.3 \times 10^{-4} \mathrm{~S} \cdot \mathrm{cm}^{-1}$ at $20^{\circ} \mathrm{C}$ [287]. 


\subsection{PLD Electrolyte as Buffer Layers}

Solid-state electrolyte (SSE) thin films have been used as a conductive buffer layer for the reduction of high resistance at the electrode/SSE interface of high-power all-solid-state lithium batteries. Coating the $\mathrm{Li}_{3} \mathrm{PO}_{4}$ thin films on electrode materials by the PLD method was found to be efficient for this purpose. Konishi et al. [288] reported the effect of surface $\mathrm{Li}_{3} \mathrm{PO}_{4}$ coating on $\mathrm{LiNi}_{0.5} \mathrm{Mn}_{1.5} \mathrm{O}_{4}$ epitaxial thin film electrodes. Amorphous $\mathrm{Li}_{3} \mathrm{PO}_{4}$ film (1-4 nm thick) was deposited at $25{ }^{\circ} \mathrm{C}$ with a laser energy of $150 \mathrm{~mJ}$ under $P_{\mathrm{O}_{2}}=3.3 \mathrm{~Pa}$. It was also pointed out that such a coating reduces the $\mathrm{Mn}$ dissolution in the non-aqueous electrolyte. Yubuchi et al. [289] fabricated the same coated electrode with $\Phi=2 \mathrm{~J} \mathrm{~cm}^{-2}$ but under a lower oxygen gas pressure of $0.01 \mathrm{~Pa}$. With a $100-\mathrm{nm}$ thick $\mathrm{Li}_{3} \mathrm{PO}_{4}$ deposit, the total resistance of the $\mathrm{Li}$ cell decreased from 15 to $350 \Omega$. A PLD protective coating of $80 \mathrm{Li}_{2} \mathrm{~S}_{-} 20 \mathrm{P}_{2} \mathrm{~S}_{5}$ solid electrolytes on $\mathrm{LiCoO}_{2}$ particles was performed at room temperature under $\mathrm{Ar}$ gas at $P_{\mathrm{Ar}}=5 \mathrm{~Pa}$ with a fluence of ca. $2 \mathrm{~J} \cdot \mathrm{cm}^{-2}(200 \mathrm{~mJ}$ per pulse). After SSE deposition for 120 min, the deposited film was $~ 150$-nm thick, corresponding to $3 \mathrm{wt} . \% \mathrm{LiCoO}_{2}$. Annealing the SSE deposit at $200{ }^{\circ} \mathrm{C}$ increased the capacity of the all-solid-state cell [42]. Another example of the buffer function of the $\mathrm{Li}_{2} \mathrm{~S}-\mathrm{P}_{2} \mathrm{~S}_{5}$ solid electrolyte is given by the PLD coating of NiS-carbon fiber composite electrodes. The high ionic conductivity of $80 \mathrm{Li}_{2} \mathrm{~S}-20 \mathrm{P}_{2} \mathrm{~S}_{5}$ film deposited on an $\mathrm{Si}$ wafer was $7.9 \times 10^{-5}$ $\mathrm{S} \cdot \mathrm{cm}^{-1}$ at $25^{\circ} \mathrm{C}$ [290]. A capacity of $300 \mathrm{mAh} \cdot \mathrm{g}^{-1}$ was delivered after 50 cycles at a current density of $3.8 \mathrm{~mA} \cdot \mathrm{cm}^{-2}$ (1C-rate). This SSE coating favors the lithium ion and electron conduction paths in the NiS framework. Ito et al. [291] successfully deposited $\mathrm{Li}_{2} \mathrm{~S}-\mathrm{GeS}_{2}$ thin films as the buffer electrolyte $\left(\sigma_{\mathrm{i}}=1.8 \times 10^{-4} \mathrm{~S} \cdot \mathrm{cm}^{-1}\right)$ on $\mathrm{LiCoO}_{2}$ particles by the PLD technique. The amorphous $78 \mathrm{Li}_{2} \mathrm{~S}-22 \mathrm{GeS}_{2}$ solid electrolyte thin films prepared using standard PLD conditions exhibited an ionic conductivity of $1.8 \times 10^{-4} \mathrm{~S} \cdot \mathrm{cm}^{-1}$ at $25^{\circ} \mathrm{C}$. These SSE films were applied to form an electrode-electrolyte buffer interface with $\mathrm{LiCoO}_{2}$ [291]. The coating of a $\mathrm{LiNbO}_{3} \mathrm{SSE}$ buffer coated onto the $\mathrm{LiMn}_{2} \mathrm{O}_{4}$ cathode resulted in an enhancement of the high rate capability and cycling stability of the electrode [292]. A similar process ensured a high thermal stability for the $\mathrm{LiNi}_{0.8} \mathrm{Co}_{0.15} \mathrm{Al}_{0.05} \mathrm{O}_{2}$ electrode operating over 500 charge-discharge cycles at $150{ }^{\circ} \mathrm{C}$ [293].

\section{5. $\mathrm{Li}_{2} \mathrm{O}-\mathrm{V}_{2} \mathrm{O}_{5}-\mathrm{Si}_{2} \mathrm{O}(\mathrm{LVSO})$}

PLD films of $\mathrm{Li}_{2.2} \mathrm{~V}_{0.54} \mathrm{Si}_{0.46} \mathrm{O}_{3.4}$ are amorphous solid-state electrolytes of the system, $\mathrm{Li}_{2} \mathrm{O}-\mathrm{V}_{2} \mathrm{O}_{5}-\mathrm{Si}_{2} \mathrm{O}$ (LVSO), which exhibits a conductivity of $\sim 2.5 \times 10^{-7} \mathrm{~S} \cdot \mathrm{cm}^{-1}$ at $25^{\circ} \mathrm{C}$ [44]. $\mathrm{Li}_{4} \mathrm{SiO}_{4}$ thin films were successfully deposited by PLD using both an Nd:YAG laser $(\lambda=266 \mathrm{~nm})$ and $\operatorname{ArF}$ excimer laser $(\lambda=193 \mathrm{~nm})$ at the fluence of $2.5 \mathrm{~J} \cdot \mathrm{cm}^{-2}$ in the flow of $\mathrm{O}_{2}$ gas at $P_{\mathrm{O}_{2}}=0.2 \mathrm{~Pa}$. Having a conductivity of $4.1 \times 10^{-7} \mathrm{~S} \cdot \mathrm{cm}^{-1}$ at $25^{\circ} \mathrm{C}$, thermally activated with $E_{\mathrm{a}}=0.52 \mathrm{eV}$, these films were applied in SSMBs [44]. Zhao et al. prepared PLD Li-V-Si-O thin films' electrolytes on an Si wafer and Al-coated glass as substrates placed $4 \mathrm{~cm}$ from the target. The film deposition was carried out at a fluence of $1.2 \mathrm{~J} \mathrm{~cm}^{-2}$ under an ambient of $P_{\mathrm{O}_{2}}=6 \mathrm{~Pa}$ [294]. For $T_{\mathrm{s}}=300^{\circ} \mathrm{C}$, the Li-V-Si-O film exhibited $\sigma_{\mathrm{i}}=3.98 \times 10^{-7} \mathrm{~S} \cdot \mathrm{cm}^{-1}$ at $25^{\circ} \mathrm{C}$ and $E_{\mathrm{a}}=0.55 \mathrm{eV}$. Workers at Kawamura's lab reported the PLD growth of several LVSO solid electrolytes. The $\mathrm{Li}_{2.2} \mathrm{~V}_{0.54} \mathrm{Si}_{0.46} \mathrm{O}_{3.4}$ film deposited with a continuous flow of $\mathrm{O}_{2}$ gas maintained at $P_{\mathrm{O}_{2}}=0.2 \mathrm{~Pa}$ displayed an ionic conductivity of $2.5 \times 10^{-7} \mathrm{~S} \cdot \mathrm{cm}^{-1}$ at $25^{\circ} \mathrm{C}$ with an activation energy of $0.54 \mathrm{eV}$ [41]. PLD amorphous $0.6\left(\mathrm{Li}_{4} \mathrm{SiO}_{4}\right)-0.4\left(\mathrm{Li}_{3} \mathrm{VO}_{4}\right)$ films deposited on $\mathrm{Si}(111)$ or fused silica plate exhibited an ionic conductivity of $10^{-7} \mathrm{~S} \mathrm{~cm}^{-1}$. at $25^{\circ} \mathrm{C}$, which is one order higher than the value for $\mathrm{PLD} \mathrm{Li}_{2} \mathrm{TiO}_{3}$ film [295]. All-solid-state thin film batteries were fabricated using both LCO and LMO PLD film cathodes and amorphous LVSO solid electrolytes as shown in Figure 15 [121]. 

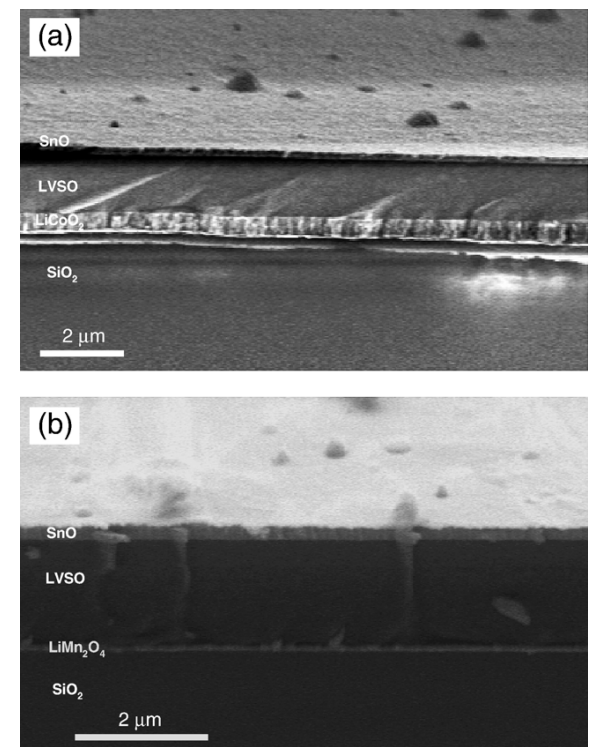

Figure 15. SEM cross-sectional images of solid-state thin film lithium batteries, (a) SnO/LVSO/LCO and (b) SnO/LVSO/LMO. (Reproduced with permission from [121]. Copyright 2006 Elsevier).

\section{6. $\mathrm{LiNbO}_{3}$}

Because of its high room-temperature ionic conductivity and low electronic conductivity $\left(10^{-5}\right.$ and $10^{-11} \mathrm{~S} \cdot \mathrm{cm}^{-1}$, respectively), $\mathrm{LiNbO}_{3}(R 3 c$ crystal structure) is considered as a good SSE for electrode coating [296]. $\mathrm{LiNbO}_{3}$ was applied as a buffer layer between an LCO cathode and thio-LISICON electrolyte $\left(\mathrm{Li}_{3.25} \mathrm{Ge}_{0.25} \mathrm{P}_{0.75} \mathrm{~S}_{4}\right)$. The resultant electrochemical cell showed low interfacial resistance and a high-rate capability [297]. A high quality was obtained for $\mathrm{PLD} \mathrm{LiNbO}_{3}$ thin films deposited at $730{ }^{\circ} \mathrm{C}$ on sapphire substrates by using a relatively high oxygen partial pressure of $P_{\mathrm{O}_{2}}=133 \mathrm{~Pa}$ and a laser fluence of 3 to $5 \mathrm{~J} \mathrm{~cm}^{-2}$ [298]. Contrastingly, Perea et al. prepared $\mathrm{PLD} \mathrm{LiNbO}_{3}$ films using a lower laser fluence $\left(0.8\right.$ to $\left.1.6 \mathrm{~J} \cdot \mathrm{cm}^{-2}\right)$ in a residual pressure of $\approx 4 \times 10^{-4} \mathrm{~Pa}$ [299].

\section{Negative Electrode PLD Films}

\section{1. $\mathrm{TiO}_{2}$}

Due to the theoretical capacity of $\sim 335 \mathrm{mAh} \cdot \mathrm{g}^{-1}$ of titanium dioxide (comparable to $\sim 372 \mathrm{mAh} \cdot \mathrm{g}^{-1}$ for graphite and the small volume expansion ( $\sim 4 \%$ for anatase)) significant interest has been devoted to the applied anode material in Li-ion batteries. The tetragonal anatase polymorph of $\mathrm{TiO}_{2}$ is a good anode candidate due to its insertion potential of around $1.5 \mathrm{~V} \mathrm{vs.} \mathrm{Li}^{+} / \mathrm{Li}$ [300]. Several works of the literature report the growth of $\mathrm{TiO}_{2}$ thin films with either a rutile or anatase structure fabricated by the PLD technique [301,302]. The growth conditions were studied on $\mathrm{TiO}_{2}$ films deposited by PLD using an Nd:YAG laser (532 nm wavelength beam) and a rutile-type $\mathrm{TiO}_{2}$ target. The effects of the substrate temperature $\left(T_{\mathrm{S}}\right)$ and oxygen partial pressure $\left(P_{\mathrm{O}_{2}}\right)$ were investigated by Raman spectroscopy [13]. The parameters of $T_{\mathrm{s}}=300{ }^{\circ} \mathrm{C}$ and $P_{\mathrm{O}_{2}}=50$ mTorr were optimized to obtain crystalline $\mathrm{TiO}_{2}$ films with a preferential (110) orientation. Kim et al. discussed the effects of the target morphology and target density on the size and distribution density of crystalline in PLD rutile-type $\mathrm{TiO}_{2}$ films deposited on (100)-oriented Si wafers maintained at $700{ }^{\circ} \mathrm{C}$ in a chamber with an oxygen partial pressure of $1.33 \mathrm{~Pa}$ [303]. A nearly particulate-free film was obtained from a dense target and the laser shots were adjusted for clear ripple patterns from the target surface. The optical bandgap energies of $\mathrm{TiO}_{2}$ PLD films grown on an $\alpha-\mathrm{Al}_{2} \mathrm{O}_{3}(0001)$ substrate with an anatase and rutile structure were evaluated to be 3.22 and $3.03 \mathrm{eV}$, respectively [304]. Inoue et al. reported that films deposited at $T_{\mathrm{s}}=150{ }^{\circ} \mathrm{C}$ have an anatase structure, while $T_{\mathrm{s}}=300{ }^{\circ} \mathrm{C}$ provides rutile-type $\mathrm{TiO}_{2}$ films [305]. Choi et al. [306] prepared anatase $\mathrm{TiO}_{2}$ thin films with nanograins of 11 to $28 \mathrm{~nm}$ using a TiC target with $T_{\mathrm{s}}=500{ }^{\circ} \mathrm{C}$ under $4 \mathrm{~Pa} \mathrm{O}_{2}$ gas. 


\section{2. $\mathrm{Li}_{4} \mathrm{Ti}_{5} \mathrm{O}_{12}(\mathrm{LTO})$}

$\mathrm{Li}_{4} \mathrm{Ti}_{5} \mathrm{O}_{12}$ (LTO) cubic structure ( $\mathrm{Li}\left[\mathrm{Li}_{1 / 3} \mathrm{Ti}_{5 / 3}\right] \mathrm{O}_{4}$ in spinel notation), considered as a "zero-strain" anode material, exhibits the advantage of very minor volumetric changes $(<0.2 \%)$ upon cycling. This electrode displays a large voltage plateau at $\sim 1.5 \mathrm{~V} \mathrm{vs.} \mathrm{Li}^{+} / \mathrm{Li}$ and a theoretical specific capacity of $175 \mathrm{mAh} \cdot \mathrm{g}^{-1}$ [307]. The first PLD growth of LTO thin films deposited onto $\mathrm{Pt} / \mathrm{Ti} / \mathrm{SiO}_{2} / \mathrm{Si}$ substrates using a $\mathrm{KrF}$ excimer laser beam $(248 \mathrm{~nm}, 250 \mathrm{~mJ})$ were reported by Deng et al. [308]. Films annealed at $800{ }^{\circ} \mathrm{C}(410 \mathrm{~nm}$ thick) exhibited a cubic structure with a lattice constant $8.375 \AA$ Alarger than that of the LTO crystal ( $8.359 \AA$ ). The SEM cross-section image (Figure 16a) revealed the porous morphology induced by the high temperature treatment. The discharge specific capacity was the largest for films annealed at $700{ }^{\circ} \mathrm{C}$ due to the optimized adhesion strength between the film and substrate (Figure 16b). The anode films discharged at a current density of $10 \mu \mathrm{A} \cdot \mathrm{cm}^{-2}(0.58 \mathrm{C}$ rate) showed excellent cycleability; the discharge capacity remained as $149 \mathrm{mAh} \cdot \mathrm{g}^{-1}$ after 50 cycles. $\mathrm{Li}_{4} \mathrm{Ti}_{5} \mathrm{O}_{12}$ films ( $545 \mathrm{~nm}$ thick) deposited on conducting fluorine-doped tin oxide (LTO/FTO) with a crystallite size of 50 to $80 \mathrm{~nm}$ were investigated as electrochromic active material with the highest contrast at a wavelength of $705 \mathrm{~nm}$ (transmittance change of $\sim 48 \%$ ) [309]. Epitaxial LTO thin-film grown on $\mathrm{SrTiO}_{3}$ single crystal from an Li-rich target, $\mathrm{Li}_{5.2} \mathrm{Ti}_{5} \mathrm{O}_{12}$, have a structural orientation identical to the substrate and are impurity-free when deposited at $T_{\mathrm{s}}=700^{\circ} \mathrm{C}$. The electrochemical features of LTO film anodes $(20 \mathrm{~nm}$ thick) exhibited discharge capacities of $\sim 200$ and $\sim 250 \mathrm{mAh} \cdot \mathrm{g}^{-1}$ for the (100)- and (111)-orientation, respectively [310]. Kim et al. prepared nano-sized epitaxial LTO(110) deposited on $\mathrm{Nb}: \mathrm{SrTiO}_{3}(110)$ substrate. These films ( $\sim 28 \mathrm{~nm}$ thick) were tested by cyclic voltammetry at a scan rate of $1 \mathrm{mV} \cdot \mathrm{s}^{-1}$ and exhibited redox peaks at 1.53 and $1.60 \mathrm{~V}$, corresponding to the insertion and extraction of $\mathrm{Li}^{+}$ions. As-deposited films at a substrate temperature of $700{ }^{\circ} \mathrm{C}$ in a $6.6 \mathrm{~Pa}$ oxygen partial pressure exhibited a high initial capacity $\left(\sim 200 \mathrm{mAh} \cdot \mathrm{g}^{-1}\right)$ but poor stability [311]. Kumatani et al. investigated the PLD growth process of epitaxial LTO films deposited on an $\mathrm{MgAl}_{2} \mathrm{O}_{4}$ (111) substrate. With $T_{\mathrm{s}}=800{ }^{\circ} \mathrm{C}$ and $P_{\mathrm{O}_{2}}=1 \times 10^{-3}$ Torr, LTO films had excellent crystallinity and a low resistivity of $3.3 \times 10^{-4} \Omega \mathrm{cm}$. at $25^{\circ} \mathrm{C}$. At lower $P_{\mathrm{O}_{2}}$, the PLD LiTi $2 \mathrm{O}_{4}$ film was formed, while at higher $P_{\mathrm{O}_{2}}$, Ti was segregated as $\mathrm{TiO}_{2}$ rutile and $\mathrm{Li}_{0.74} \mathrm{Ti}_{3} \mathrm{O}_{6}$ [312].
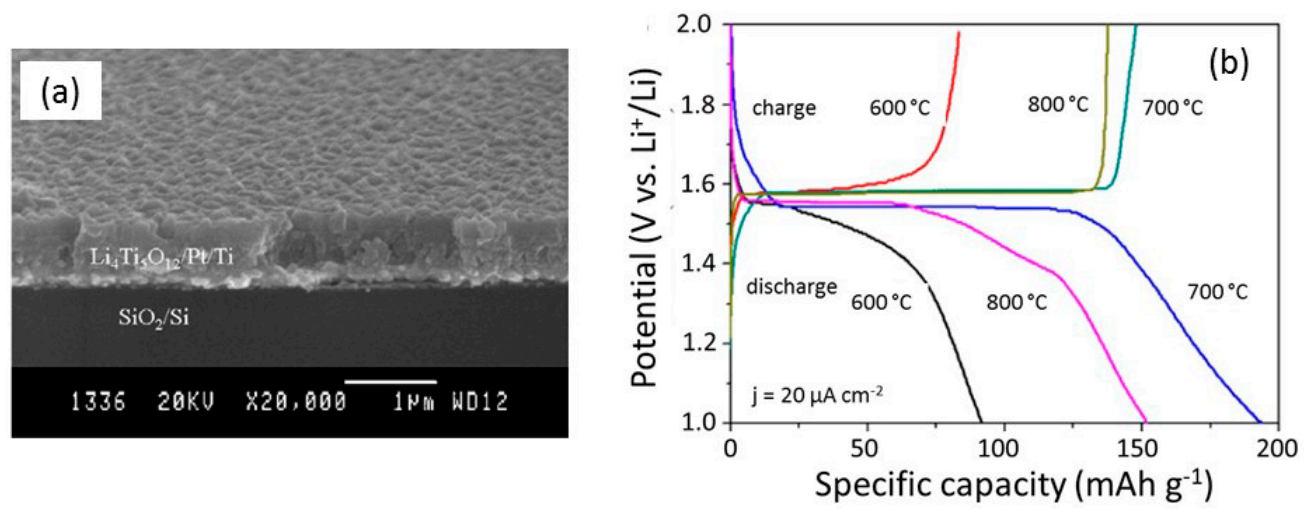

Figure 16. (a) SEM cross-section image of LTO film (410 nm thick) heat treated at $800{ }^{\circ} \mathrm{C}$. (b) Charge-discharge profiles recorded at $20 \mu \mathrm{A} \mathrm{cm} \mathrm{cm}^{-2}$ (i.e., $\sim 1.15 \mathrm{C}$ ) current density in the voltage range of 1 to $2 \mathrm{~V}$ vs. $\mathrm{Li}^{+} / \mathrm{Li}$ of PLD films heated at various temperatures. (Reproduced with permission from [308]. Copyright 2009 Elsevier).

Studies of the electrochemical performance and kinetic behavior of PLD LTO films deposited on $\mathrm{Pt} / \mathrm{Ti} / \mathrm{SiO}_{2} / \mathrm{Si}$ substrates were reported by Deng et al. [313]. Using an Li-rich target (i.e., excess $5 \mathrm{wt} . \% \mathrm{Li}_{2} \mathrm{O}$ ), the films annealed at $700{ }^{\circ} \mathrm{C}$ for $2 \mathrm{~h}$ in air were well-crystallized items with densely packed grains. The galvanic charge-discharge plateau was observed around $1.56 \mathrm{~V}$ and an initial specific capacity of $159 \mathrm{mAh} \mathrm{g}^{-1}$ was delivered with a retention of $93.7 \%$ after 20 cycles. The diffusion coefficient of $\mathrm{Li}^{+}$ions in such an LTO framework was in the range of $10^{-15}$ to $10^{-12} \mathrm{~cm}^{2} \cdot \mathrm{s}^{-1}$. The energy 
barrier of the diffusion of lithium ions was estimated to be $E_{\mathrm{a}}=0.11 \mathrm{eV}$ in LTO (111)-oriented PLD thin films (190 nm thick) grown on a spinel $\mathrm{MgAl}_{2} \mathrm{O}_{4}$ (111) substrate [314].

Zhao et al. reported the optical properties of epitaxially grown LTO films on (001)-oriented $\mathrm{MgAl}_{2} \mathrm{O}_{4}$ substrate. The optical bandgap of $3.14 \mathrm{eV}$ was measured for $86 \mathrm{~nm}$ thick films (surface roughness of $4.61 \mathrm{~nm}$ ) [315]. Schichtel et al. fabricated all-solid-state microbatteries with LTO as the positive electrode. PLD films were obtained on various substrates at $T_{\mathrm{s}}=650^{\circ} \mathrm{C}$ under a 0.3 Pa pure oxygen atmosphere using a commercially available LTO powder. As-prepared films ( $650 \mathrm{~nm}$ thick) revealed columnar growth that allowed a coulombic efficiency $>97 \%$ after the second cycle and a discharge capacity of $33 \mu \mathrm{Ah} \cdot \mathrm{cm}^{-2}$ at a $3.5 \mu \mathrm{A} \mathrm{cm}^{-2}$ current density [43]. Pfenninger et al. demonstrated that LTO thin films deposited by PLD on an MgO substrate kept at $500{ }^{\circ} \mathrm{C}$ using a dense $\mathrm{Li}_{7.1} \mathrm{Ti}_{5} \mathrm{O}_{12}$ target sintered at $1000{ }^{\circ} \mathrm{C}$ for $12 \mathrm{~h}$ are compatible with the $\mathrm{Li}_{6.25} \mathrm{Al}_{0.25} \mathrm{La}_{3} \mathrm{Zr}_{2} \mathrm{O}_{12}$ electrolyte pellet. Such films display a stable structure and cycleability almost close to $175 \mathrm{mAh} \cdot \mathrm{g}^{-1}$. The typical voltage plateau at $1.57 \mathrm{~V}$ (oxidation) and $1.53 \mathrm{~V}$ (reduction) was observed at a rate of $2.5 \mathrm{~mA} \cdot \mathrm{g}^{-1}$ [316]. Among the $\mathrm{Li}_{1+x} \mathrm{Ti}_{1-x} \mathrm{O}_{4}$ ternary system, $\mathrm{LiTi}_{2} \mathrm{O}_{4}$ thin films were grown by the PLD route in the temperature range of 400 to $800{ }^{\circ} \mathrm{C}$ using a target with a higher $\mathrm{Li} / \mathrm{Ti}$ ratio of 0.8 [317]. Chopdekar et al. grew epitaxial PLD $\mathrm{LiTi}_{2} \mathrm{O}_{4}$ thin films on various crystalline-oriented substrates, such as single crystalline substrates of $\mathrm{MgAl}_{2} \mathrm{O}_{4}, \mathrm{MgO}$, and $\mathrm{SrTiO}_{3}$ [318]. The authors state the PLD conditions with $T_{\mathrm{s}}$ held at 450 to $600^{\circ} \mathrm{C}$ in a vacuum of better than $5 \times 10^{-6}$ Torr without any mention of the oxygen partial pressure, while Kumatani determined that stoichiometric $\mathrm{LiTi}_{2} \mathrm{O}_{4}$ thin films were obtained at a $P_{\mathrm{O}_{2}}$ of $5 \times 10^{-6}$ Torr with $T_{\mathrm{s}}=800{ }^{\circ} \mathrm{C}$ [312]. Recently, PLD LTO films grown on Nd-doped oriented STO substrates at $T_{\mathrm{s}}=700{ }^{\circ} \mathrm{C}$ under $P_{\mathrm{O}_{2}}=20 \mathrm{~Pa}$ showed high discharge capacities of 280 to $310 \mathrm{mAh} \cdot \mathrm{g}^{-1}$. The best rate performance of $30 \mathrm{C}$ was obtained for the (100)-oriented $\mathrm{Li}_{4} \mathrm{Ti}_{5} \mathrm{O}_{12}$ films [319].

\section{3. $\mathrm{LiNiVO}_{4}$}

Amorphous $\mathrm{LiNiVO}_{4}$ thin-film anodes for microbatteries were grown by pulsed laser deposition using a sintered $\mathrm{Li}_{1.2} \mathrm{NiVO}_{4}$ target. The film grown at $T_{\mathrm{s}}=25^{\circ} \mathrm{C}$ and $P_{\mathrm{O}_{2}}=8 \mathrm{mTorr}$ showed the best electrochemical performance with a retainable capacity as high as $410 \mu \mathrm{Ah} \cdot \mathrm{cm}^{-2} \cdot \mu \mathrm{m}^{-1}$ after 50 cycles [320].

\section{4. $\mathrm{TiNb}_{2} \mathrm{O}_{7}$}

An alternative to $\mathrm{LTO}$, titanium-niobium oxide, $\mathrm{TiNb}_{2} \mathrm{O}_{7}(\mathrm{TNO})$, is considered a promising anode material for long life Li-ion batteries, due to its high $\mathrm{Li}^{+}$ion transport, average voltage of $1.66 \mathrm{~V}$, and theoretical capacity of $\sim 387 \mathrm{mAh} \cdot \mathrm{g}^{-1}$ [321]. Fabrication of PLD $\mathrm{TiNb}_{2} \mathrm{O}_{7}$ thin films as anode electrodes for Li-ion micro-batteries was demonstrated by the ablation of a $\mathrm{Nb}_{2} \mathrm{O}_{5}+\mathrm{TiO}_{2}$ mixture as a target at a laser fluence of $4.6 \mathrm{~J} \cdot \mathrm{cm}^{-2}$. Pure monoclinic TNO films were deposited on $\mathrm{Pt} / \mathrm{TiO}_{2} / \mathrm{SiO}_{2} / \mathrm{Si}(100)$ substrates at $750{ }^{\circ} \mathrm{C}$ under an $\mathrm{O}_{2}$ gas of $P_{\mathrm{O}_{2}}=6-13 \mathrm{~Pa}$. The 380-nm thick films grown at $P_{\mathrm{O}_{2}}=13 \mathrm{~Pa}$ delivered an initial specific capacity of $142 \mu \mathrm{Ah} \mathrm{cm}^{-2} \mu \mathrm{m}^{-1}$ at a current density of $50 \mu \mathrm{A} \cdot \mathrm{cm}^{-2}$ with a $58 \%$ capacity retention after 25 cycles [322]. Recently, the same co-workers reported a high specific discharge capacity of $226 \mu \mathrm{Ah} \cdot \mathrm{cm}^{-2} \cdot \mu \mathrm{m}^{-1}\left(\sim 460 \mathrm{mAh} \cdot \mathrm{g}^{-1}\right)$ at a current density of $17 \mu \mathrm{A} \cdot \mathrm{cm}^{-2}$ for amorphous TNO films grown by PLD. $\mathrm{Li}^{+}$diffusion coefficient of $\approx 10^{-13} \mathrm{~cm}^{2} \cdot \mathrm{s}^{-1}$ and an electronic conductivity of $\approx 10^{-9} \mathrm{~S} \cdot \mathrm{cm}^{-1}$ were also reported [323].

\subsection{Silicon}

Pulsed-laser deposited silicon thin films have been widely studied for applications in opto-electronics. With a large theoretical capacity $\left(4200 \mathrm{mAh} \cdot \mathrm{g}^{-1}\right)$, silicon is also considered as a promising anode material for the replacement of graphite anode $\left(\mathrm{LiC}_{6}, 372 \mathrm{mAh} \cdot \mathrm{g}^{-1}\right)$ for $\mathrm{Li}$-ion batteries [324]. Despite the huge volume expansion of $>300 \%$ during lithiation up to $\mathrm{Li}_{22} \mathrm{Si}_{5}$, it is possible to obtain anodes with Si thin films grown by physical vapor deposition (PVD), reaching a cycling life of up to 3000 cycles due to the limited volume change in the 2D film [325]. For example, a film deposited on $\mathrm{Ni}$ foil maintained a capacity of $3000 \mathrm{mAh} \cdot \mathrm{g}^{-1}$ at a $12 \mathrm{C}$ rate over 1000 cycles [326]. PLD-grown $\mathrm{Mg}_{2} \mathrm{Si}$ thin film (30-380 nm thick) exhibited electrochemical activity with a stable cycling behavior in 
the voltage range of 0.1 to $1.0 \mathrm{~V} \mathrm{vs}$. $\mathrm{Li}^{+} / \mathrm{Li}$; however, the initial irreversible capacity loss increased with the film thickness. The superior capacity of the 30-nm thick film was attributed to the formation of Li-Si alloys at the Si-rich surface [327]. Park et al. prepared PLD amorphous $\mathrm{Si}$ (a-Si) thin films on a stainless-steel substrate at temperature of $500{ }^{\circ} \mathrm{C}$ under an Ar gas pressure $P_{\mathrm{Ar}}=6.5 \mathrm{mPa}$. Furthermore, $1.5-\mu \mathrm{m}$ thick a-Si films were obtained at the growth rate of $25 \mathrm{~nm} \cdot \mathrm{min}^{-1}$. Electrochemical tests carried out in the voltage range of 0.005 to $1.5 \mathrm{~V}$ showed a first discharge capacity of 9 to $0.7 \mu \mathrm{Ah} \cdot \mathrm{cm}^{-2}$ with a $54.4 \%$ coulombic efficiency. Although, after 70 cycles, the $1-\mu \mathrm{m}$ thick Si film exhibited a good cyclic performance [328]. Xia et al. reported the growth of a-Si using the standard conditions $\left(T_{\mathrm{s}}=25^{\circ} \mathrm{C}\right.$, $P=1.3 \mathrm{mPa}$, fluence of 150 to $160 \mathrm{~mJ}$ per pulse, deposition time of $30 \mathrm{~min}$ ). Electrochemical tests showed that 120-nm thick a-Si films exhibited an initial charge capacity of $\sim 64 \mu \mathrm{Ah} \cdot \mathrm{cm}^{-2}$ at a current density of $100 \mu \mathrm{A} \cdot \mathrm{cm}^{-2}$, a discharge capacity of $\sim 50 \mu \mathrm{Ah} \mathrm{cm}{ }^{-2}$ was maintained after 40 cycles, and the diffusion coefficient of $\mathrm{Li}$ ions determined from the cyclic voltammograms was $\sim 10^{-13} \mathrm{~cm}^{2} \cdot \mathrm{s}^{-1}[329]$. Some Si-based composite thin films prepared by PLD combine the advantages of both components. The most popular are the carbon-based composites [330-333]. Chou et al. obtained a flexible anode material by the deposition of Si film onto single-wall carbon nanotubes (SWCNTs) using standard PLD conditions $\left(\lambda=248 \mathrm{~nm}, T_{\mathrm{s}} \approx 30^{\circ} \mathrm{C}, \Phi=3 \mathrm{~J} \cdot \mathrm{cm}^{-2}, P_{\mathrm{Ar}}=13 \mathrm{~Pa}\right.$, target-substrate distance of $50 \mathrm{~mm}$ ). After 50 cycles, this Si/SWCNT nanocomposite delivered a specific capacity of $163 \mathrm{mAh} \cdot \mathrm{g}^{-1}$ at a $25 \mathrm{~mA} \cdot \mathrm{g}^{-1}$ current density, which is $60 \%$ higher than for CNT [330]. The ultrathin film of Si grown by PLD was deposited on multilayer graphene (MLG) by CVD on an Ni foam substrate. The specific capacity of this binder-free Si/MLG anode appeared to be stable at ca. $1400 \mathrm{mAh} \cdot \mathrm{g}^{-1}$ [331]. Silicon nitride $\mathrm{SiN}_{0.92}$ thin films were prepared by PLD and investigated as a negative electrode in lithium batteries. A 200-nm thick film grown on buffed stainless-steel substrates kept at $25^{\circ} \mathrm{C}$ from an $\mathrm{Si}_{3} \mathrm{~N}_{4}$ pellet as the target delivered a high specific capacity of $1300 \mathrm{mAh} \cdot \mathrm{g}^{-1}$ after 100 cycles [334].

\subsection{Graphene}

Most of the commercial lithium batteries have a carbon anode. Graphene is the most conductive form of carbon, and as such, it is considered as a promising electrode, especially when it is doped with nitrogen [229]. A recent review was devoted to PLD-graphene synthesized from a solid carbon source [335]. Since nitrogen modifies the intrinsic properties of graphene, it is important to control its concentration. PLD, which allows for a one-step synthesis of N-doped carbon films, is particularly suited to this purpose. The first N-doped amorphous carbon film (a-C:N) synthesized by PLD dates from 2013 [336]. It contained 2 at. \% of nitrogen. More recently, using the same approach, the upper nitrogen concentration in PLD a-C:N film was raised to 3.2 at.\% [337]. These films, however, were not used as electrodes. On the other hand, a N-doped graphene (NG) electrode prepared by PLD coupled with in-situ thermal annealing (PLD-TA) was achieved by Fortgang et al. [338]. More recently, Bourquard et al. used the PLD-TA process to form an N-doped graphene film by high temperature condensation of the laser-induced carbon plasma plume onto the Si electrode previously covered by an Ni catalytic film [339], using a protocol published by the same group [340] Carbon was ablated at $780^{\circ} \mathrm{C}$ from the graphite target using a femtosecond laser $(\lambda=800 \mathrm{~nm}$, pulse width of $60 \mathrm{~ns}$, repetition rate of $1 \mathrm{kHz}$, and $\Phi=5 \mathrm{~J} \cdot \mathrm{cm}^{-2}$ ) at a distance of $36 \mathrm{~mm}$ from the graphite target, with $P_{\mathrm{N}}=10 \mathrm{~Pa}$ in the vacuum chamber. The electrochemical properties were measured with the thus-obtained $40 \mathrm{~nm}$-thick film with a nitrogen concentration of $1.75 \%$ as the working electrode and an active area of $0.07 \mathrm{~cm}^{2}$, saturated calomel electrode as the reference electrode, and platinum as the counter electrode, in a $0.5 \mathrm{~mol} \cdot \mathrm{L}^{-1} 1,1^{\prime}$ ferrocene-dimethanol solution of $0.1 \mathrm{~mol} \cdot \mathrm{L}^{-1} \mathrm{NaClO}_{4}$. Aiming to detect $\mathrm{H}_{2} \mathrm{O}_{2}$ in $0.1 \mathrm{~mol} \mathrm{~L}^{-1}$ phosphate buffer saline (PBS) solution ( $\mathrm{pH}$ 7.4), linear sweep voltammetry was used in the anodic range from 0 to $1000 \mathrm{mV}$ with a scan rate of $100 \mathrm{mV} \cdot \mathrm{s}^{-1}$. The electrode showed excellent reversibility, $60 \mathrm{mV}$, close to the theoretical value, and a detection limit of $1 \mathrm{mM}$ of hydrogen peroxide, which constitutes a major improvement of the electroanalytical oxidation of $\mathrm{H}_{2} \mathrm{O}_{2}$ in comparison with undoped graphite electrodes. Such results are recent, and to our knowledge, no such electrode has been tested yet as an anode for lithium batteries. 


\subsection{Other PLD Anodes}

Significant efforts have been devoted to the design and development of new PLD-grown anode materials for SSMBs, yielding a high energy density (from 500 to $1500 \mathrm{mAh} \cdot \mathrm{g}^{-1}$ ) and electrochemical stability [341-354]. Table 10 summarizes the PLD-growth conditions and electrochemical properties of some new anodes proposed for lithium microbatteries. All transition-metal oxide $\mathrm{M}_{x} \mathrm{O}_{y}$ materials are subjected to electrochemical lithiation via a conversion reaction, which implies a two-step process, i.e., first, fine metallic $(M)$ nanoparticles embedded in an insulating matrix, such as $\mathrm{Li}_{2} \mathrm{O}$, are in situ formed during the first (irreversible) discharge, and secondly, an alloying reversible reaction (Li-M) occurs on subsequent cycles [341].

Recently, Wu et al. proposed a novel anode consisting of a $\mathrm{Li}_{3} \mathrm{P}-\mathrm{VP}$ nanocomposite fabricated by PLD [353] using a 5-Hz Nd:YAG laser $\left(\lambda=355 \mathrm{~nm}, \Phi=2 \mathrm{~J} \cdot \mathrm{cm}^{-2}\right)$ concentrated on the target surface with an incident angle of $45^{\circ}$, with $P_{\mathrm{Ar}}=10 \mathrm{~Pa}$ in the vacuum chamber. The stainless-steel substrate was placed $3 \mathrm{~cm}$ from the surface and kept at $400{ }^{\circ} \mathrm{C}$. The weight of the film thus obtained (without the substrate) was $0.10 \mathrm{mg} \cdot \mathrm{cm}^{-2}$. The excessive lithium in this composite was used to stabilize the $\mathrm{VP}_{2}$ structure after the first charge. Electrochemical tests were made with this film as the working electrode, while lithium metal sheets were used as counter and reference electrodes with $1 \mathrm{~mol} \cdot \mathrm{L}^{-1}$ $\mathrm{LiPF}_{6}$ in EC:DMC (1:1 in volume) electrolyte. When cycled in the range of 0.01 and $4 \mathrm{~V} \mathrm{vs}^{-\mathrm{Li}^{+} / \mathrm{Li} \text { at }}$ a current density of $5 \mu \mathrm{A} \cdot \mathrm{cm}^{-2}$, a capacity of $1040 \mathrm{mAh} \cdot \mathrm{g}^{-1}$ was delivered at the second discharge, $987 \mathrm{mAh} \cdot \mathrm{g}^{-1}$ at the 50 th cycle.

Table 10. Growth conditions and electrochemical properties of new anode materials.

\begin{tabular}{|c|c|c|c|c|c|}
\hline $\begin{array}{c}\text { Anode } \\
\text { Material }\end{array}$ & $T_{\mathrm{s}}\left({ }^{\circ} \mathrm{C}\right)$ & Ambient (Pa) & $\begin{array}{l}\text { Laser Energy } \\
\quad\left(\mathrm{J} \mathrm{cm}^{-2}\right)\end{array}$ & Electrochemical Properties & Ref. \\
\hline C-monocolumn & 25 & $\left(\mathrm{~N}_{2}\right) 6.7$ & 0.08 & $315 \mathrm{mAh} \cdot \mathrm{g}^{-1}$ at $0.1 \mathrm{~A} \cdot \mathrm{g}^{-1}$ (50th cycle) & [342] \\
\hline $\mathrm{NiFe}_{2} \mathrm{O}_{4}$ & 650 & $\left(\mathrm{O}_{2}\right) 2.0$ & 2.5 & $370 \mathrm{mAh} \cdot \mathrm{g}^{-1}$ at $25 \mu \mathrm{A} \cdot \mathrm{cm}^{-2}$ & [343] \\
\hline $\mathrm{Co}_{2} \mathrm{O}_{3}$ & 700 & $\left(\mathrm{O}_{2}\right) 100$ & 2.0 & $750 \mathrm{mAh} \cdot \mathrm{g}^{-1}$ at $2 \mathrm{C}$ (350th cycle) & [344] \\
\hline $\mathrm{Cu}_{2} \mathrm{Sb}$ & 25 & (Ar) 1.3 & $3-4$ & $>135 \mathrm{mAh} \cdot \mathrm{g}^{-1}$ at $35 \mu \mathrm{A} \cdot \mathrm{cm}^{-2}(100$ th cycle $)$ & [345] \\
\hline $\mathrm{Fe}_{2} \mathrm{O}_{3}$ & 25 & $\left(\mathrm{O}_{2}\right) 0.3$ & 0.5 & $905 \mathrm{mAh} \cdot \mathrm{g}^{-1}$ at $0.1 \mathrm{~A} \cdot \mathrm{g}^{-1}$ (200th cycle) & [346] \\
\hline $\mathrm{Co}_{3} \mathrm{O}_{4}$ & 600 & $\left(\mathrm{O}_{2}\right) 40$ & 2 & $600 \mathrm{mAh} \cdot \mathrm{g}^{-1}$ at $10 \mu \mathrm{A} \cdot \mathrm{g}^{-1}(2 \mathrm{th}$ cycle $)$ & [347] \\
\hline $\mathrm{Co}_{3} \mathrm{O}_{4} \mathrm{Co}(\mathrm{OH})_{2}$ & 250 & $\left(\mathrm{O}_{2} / \mathrm{H}_{2}\right) 30$ & - & $360 \mathrm{mAh} \cdot \mathrm{g}^{-1}$ at $32 \mathrm{~A} \cdot \mathrm{g}^{-1}$ (1000th cycle) & [348] \\
\hline $\mathrm{In}_{2} \mathrm{O}_{3}$ & 200 & $\left(\mathrm{O}_{2}\right) 5$ & 2 & $500 \mathrm{mAh} \cdot \mathrm{g}^{-1}$ at $10 \mu \mathrm{A} \cdot \mathrm{g}^{-1}$ (30th cycle) & [349] \\
\hline $\mathrm{Sb}_{2} \mathrm{Se}_{3}$ & 200 & (Ar) 5 & 2 & $530 \mathrm{mAh} \cdot \mathrm{g}^{-1}$ at $5 \mu \mathrm{A} \cdot \mathrm{g}^{-1}$ (100th cycle) & [350] \\
\hline $\mathrm{FeOF}$ & 25 & (Ar) 5 & 2 & $110 \mathrm{mAh} \cdot \mathrm{g}^{-1}$ at $5 \mu \mathrm{A} \cdot \mathrm{g}^{-1}$ (100th cycle) & [351] \\
\hline $\mathrm{SrLi}_{2} \mathrm{Ti}_{6} \mathrm{O}_{14}$ & 700 & $\left(\mathrm{O}_{2}\right) 2$ & 2 & $130 \mathrm{mAh} \cdot \mathrm{g}^{-1}$ at C/20 (40th cycle) & [352] \\
\hline $\mathrm{MnO}$ & 500 & (Ar) 20 & 5 & $425 \mathrm{mAh} \cdot \mathrm{g}^{-1}$ at C/8 (25th cycle) & [352] \\
\hline $\mathrm{VP}_{2}$ & 400 & (Ar) 10 & 2 & $987 \mathrm{mAh} \cdot \mathrm{g}^{-1}$ at $5 \mu \mathrm{A} \cdot \mathrm{cm}^{-2}$ (50th cycle) & [354] \\
\hline
\end{tabular}

\section{Discussion}

There is general agreement on the beneficial results of the pulsed-laser deposition of thin films used as active materials in lithium microbatteries. This is a technique prone to fabricate thin film rapidly, from a small amount of target material, while maintaining the ideal stoichiometry by the control of different growth parameters. We observed (Table 2) that there is a strong trend to develop microcell technologies using $\mathrm{LiCoO}_{2}$ film (typical thickness of $4-\mu \mathrm{m}$ ) as the cathode, $\mathrm{LiPON}$ thin film (typical thickness of $1 \mu \mathrm{m}$ ) as the solid electrolyte, and Li thin film anode, which may have advantages in terms of the following key requirements: High energy density, high voltage, sustainability, and easy fabrication. For such microbatteries, let us recall the energy units used by authors. For a comparison of the volumetric specific energy, one generally refers to that of the cathode material (i.e., the limiting electrode); thus, considering a dense LCO film $\left(d=4.3 \mathrm{~g} \cdot \mathrm{cm}^{-3}\right)$, a gravimetric specific energy of $100 \mathrm{mAh} \cdot \mathrm{g}^{-1}$ is equivalent to $43 \mu \mathrm{Ah} \cdot \mathrm{cm}^{-2} \cdot \mu \mathrm{m}^{-1}$ or $154.8 \mathrm{mC} \cdot \mathrm{cm}^{-2} \cdot \mu \mathrm{m}^{-1}$.

Let us compare and discuss the growth conditions that allow the best electrochemical performance of each component, i.e., cathode, anode, and electrolyte. Regarding the growth of lithiated oxides used as cathode materials, an excess of lithium (at least $15 \mathrm{wt} . \%$ ) is mandatory for any material 
to compensate the loss of volatile lithium species during the ablation process. Given the different materials' available candidates for the cathode, $\mathrm{LiCoO}_{2}$ appears to be the most electrochemically efficient. From Figure 17, comparing the Ragone plots of $\mathrm{LiCoO}_{2}$ and $\mathrm{LiMn}_{2} \mathrm{O}_{4}$ thin films, each curve displays a series of discharge profiles for a lithium microbattery with the cathode thickness (in $\mu \mathrm{m}$ ). As the capacity delivered by a cathode is proportional to the mass of the material, thicker films provide high energies, but often at the expense of the power performance [26]. The specific energy for a planar $\mathrm{Li} / / \mathrm{LiCoO}$ cell with a thick cathode can reach $500 \mu \mathrm{Wh} \cdot \mathrm{cm}^{-2} \cdot \mu \mathrm{m}^{-1}$. However, the rate capability depends strongly on the plane orientation of the film, which can be controlled by the nature of the substrate. Thus, the preferred orientation is the (003)-plane parallel [29]. However, a surface-electrolyte interface (SEI) is formed on epitaxial $\mathrm{LiCoO}_{2}$ films with different orientations of (104), (110), and (003) that result in anisotropic reactions of intercalation activity [102]. It has also been demonstrated that the minimized strain energy in thick LCO films allows preferential (101) and (104) textures [32]. Nevertheless, the best well-crystallized LCO thin films were fabricated in the following PLD conditions: $T_{\mathrm{s}}=500{ }^{\circ} \mathrm{C}, P_{\mathrm{O}_{2}}=13 \mathrm{~Pa}, \Phi=2 \mathrm{~J} \cdot \mathrm{cm}^{-2}$, substrate-target distance of 30 to $40 \mathrm{~mm}$, and laser beam-target incident angle of $45^{\circ}$. Interesting results reported in Ref. [53] showed impurity-free LCO films, highly (003)-oriented with a very small lattice expansion during charge (at $4.2 \mathrm{~V}$ ), when grown on stainless steel substrates at relatively low temperatures $\left(T_{\mathrm{S}} \approx 300^{\circ} \mathrm{C}\right)$. In this case, the films had a texture between the amorphous and well-crystalline state with very small grains, which is suitable for short pathways for electrons and ions during the (de)intercalation reaction.

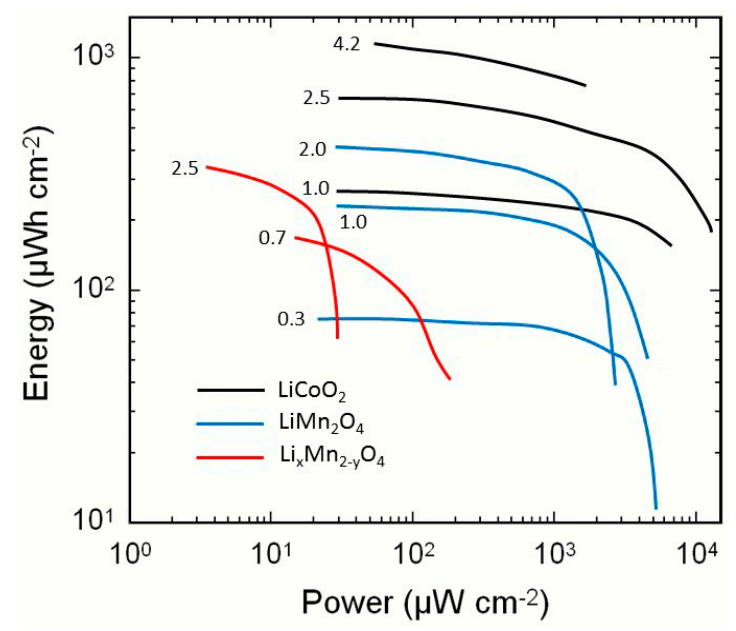

Figure 17. Ragone plot (normalized by the active cell area) for lithium thin-film microbatteries fabricated with crystalline $\mathrm{LiCoO}_{2}$ (black lines), crystalline $\mathrm{LiMn}_{2} \mathrm{O}_{4}$ (blue lines), and nanocrystalline $\mathrm{Li}_{x} \mathrm{Mn}_{2-y} \mathrm{O}_{4}$ (red lines) cathode materials with different thicknesses (in $\mu \mathrm{m}$ ).

To avoid the poor performance of LIBs derived from hindered lithium-ion diffusion at the interface between the LCO positive electrode and electrolyte, modifications of the cathode surface have been realized by the deposition of a thin layer of a fast-ionic $\mathrm{Li}^{+}$conductor, such as amorphous $\mathrm{Li}_{2} \mathrm{WO}_{4}$ or $\mathrm{Li}_{3} \mathrm{PO}_{4}$. This layer reduces the interfacial $\mathrm{Li}^{+}$-ion transfer resistance that results in a rapid charge-discharge rate. The a- $\mathrm{Li}_{2} \mathrm{WO}_{3} / \mathrm{LCO} / \mathrm{Pt} / \mathrm{Cr} / \mathrm{SiO}{ }_{2}$ electrode cycled at a high rate of $20 \mathrm{C}$ with a high capacity retention [84]. Another electrode exhibiting a fast charge-discharge rate as high as 348C has been fabricated by the multilayer PLD technique, but in this case, the LMO thin film exhibited a significant pseudocapacitive behavior (non-diffusion-controlled) instead of a faradaic mechanism. An additional promising improvement is the fabrication of an LCO thin film sandwiched between a PLD-prepared $\mathrm{SrRuO}_{3}$ film as the electronic conductor and the film of $\mathrm{Li}_{3} \mathrm{PO}_{4}(3.2 \mathrm{~nm}$ thick) as the ionic conductor with the result being limited surface structural change in the high voltage range (4.4 V) [71].

The influence of the PLD conditions on the texture of $\mathrm{LiMn}_{2} \mathrm{O}_{4}$ thin films has shown that $T_{\mathrm{S}}=500{ }^{\circ} \mathrm{C}$ and $P_{\mathrm{O}_{2}}=20 \mathrm{~Pa}$ are the optimum values that maintain the $\mathrm{Li} / \mathrm{Mn}$ ratio close to 1 , when an 
Li-enriched target is used, and obtains the best mass transfer [122]. It was also noticed that any substrate does not strongly influence the stoichiometry, but affects the out-of-plane preferred texture. The applicability of the PLD-grown $\mathrm{V}_{2} \mathrm{O}_{5}$ films in lithium microbatteries has been evidenced that, in the range of $200<T_{\mathrm{S}}<400{ }^{\circ} \mathrm{C}$ under $P_{\mathrm{O}_{2}}=6 \mathrm{~Pa}$, the films offer better electrochemical performance than those grown at other temperatures in terms of their structural quality and stability. Only two works were devoted to the fabrication of solid-state thin-film batteries with vanadium oxide as the cathode materials: The $\mathrm{Li} / \mathrm{Li}_{1.4} \mathrm{~B}_{2.5} \mathrm{~S}_{0.1} \mathrm{O}_{4.9} / \mathrm{V}_{2} \mathrm{O}_{5}$ cell delivered a capacity of $\sim 400 \mathrm{mC} \cdot \mathrm{cm}^{-2} \cdot \mu \mathrm{m}^{-1}$ [221], while the $\mathrm{Li} / \mathrm{LiPON} / \mathrm{Ag}_{0.3} \mathrm{~V}_{2} \mathrm{O}_{5}$ maintained a specific capacity of $40 \mu \mathrm{Ah} \cdot \mathrm{cm}^{-2} \cdot \mu \mathrm{m}^{-1}$ after 100 cycles [222], but the low current density was due to the poor electronic conductivity of the positive electrode. Recently, a solid-state thin-film battery, $\mathrm{Li} / \mathrm{Li}_{3} \mathrm{PO}_{4} / \mathrm{LiMnPO}$, was successfully fabricated by PLD [48]. Such a cell delivered a modest specific capacity of $10 \mu \mathrm{Ah} \cdot \mathrm{cm}^{-2} \cdot \mu \mathrm{m}^{-1}$, which was limited by the slow chemical diffusion coefficient of the $\mathrm{Li}^{+}$ion in the olivine framework $\left(3 \times 10^{-17} \mathrm{~cm}^{2} \cdot \mathrm{s}^{-1}\right)$.

Lithium phosphates, i.e., $\mathrm{Li}_{3} \mathrm{PO}_{4}$ and LiPON, are the most widely used solid electrolytes in microbatteries; they are easily fabricated by PLD using an ArF excimer laser and show a good ionic conductivity. The LiPON electrolyte is known to exhibit a better chemical stability than $\mathrm{Li}_{3} \mathrm{PO}_{4}$ [282]. However, the electrochemical stability of PLD-prepared $\mathrm{Li}_{3} \mathrm{PO}_{4}$ thin films is greater than $4.7 \mathrm{~V}$ [265].

Few works have attempted to replace the lithium metal thin-film anode by other lithiated materials (i.e., intercalation compound or alloy) for the fabrication of microbatteries. The most stable insertion compound should be $\mathrm{Li}_{4} \mathrm{Ti}_{5} \mathrm{O}_{12}$ spinel with minor volumetric changes but the high voltage plateau of $1.5 \mathrm{~V}$ is a great penalty for high energy density. The $\mathrm{In} / 80 \mathrm{Li}_{2} \mathrm{~S}_{-}-20 \mathrm{P}_{2} \mathrm{~S}_{5} / \mathrm{LiCoO}_{2}$ microbattery developed by Sakuda et al. seems to be promising as the Li-In alloy allows a high specific discharge capacity at moderate current density of $0.13 \mathrm{~mA} \cdot \mathrm{g}^{-1}$ [42].

\section{Concluding Remarks}

The results of the intensive research on the growth of thin films by pulsed laser deposition in recent years have been reviewed. Due to careful investigations of the mechanism of the sample preparation, optimized materials with adequate properties for energy storage and conversion have been obtained. The PLD technique is considered to be suitable for improving the density and adhesion properties of films. A huge effort has been mainly concentrated on the deposition of lithiated oxides, which require specific conditions due to the volatile character of lithium vapor species during the PLD process. Due to the outstanding performance of the conventional cathode materials, $\mathrm{LiCoO}_{2}$ and $\mathrm{LiMn}_{2} \mathrm{O}_{4}$, PLD films exhibiting a specific capacity close to the theoretical one are the most popular. The progress concerns mainly the epitaxial films grown with an orientation favorable to a high rate of transport of $\mathrm{Li}$ ions at the electrode/electrolyte interface. For instance, the pyramidal-type $\mathrm{LiMn}_{2} \mathrm{O}_{4}$ films cycled at the 3.3C rate demonstrate a specific capacity of $90 \mathrm{mAh} \cdot \mathrm{g}^{-1}$ after 1000 cycles.

The PLD technique has proved to also be efficient for the preparation of thin films of anode materials. The best example is the production of LTO, which is a "zero-strain" compound. Other anode thin film materials, such as silicon and conversion-type oxides, are attractive due to their high specific capacity and easy PLD fabrication.

So far, solid-electrolyte thin-films have been fabricated essentially by thermal vacuum evaporation and rf-sputtering. The manufacture of solid-electrolyte thin films by PLD has brought improvements in their intrinsic properties. For example, the electronic conductivity of PLD films is small in comparison with rf-sputtered films. LiPON and Li-V-S-O are the most popular solid-electrolyte films.

In recent years, due to a strong demand for smaller power sources, the interest in rechargeable micro-batteries has gradually increased. The progress on lithium microbatteries is remarkable, mainly due to the PLD growth of high-quality, pinhole-free, solid-state electrolyte thin films, such as $\mathrm{Li}_{6.1} \mathrm{~V}_{0.61} \mathrm{Si}_{0.39} \mathrm{O}_{5.36}$. The rechargeable thin-film lithium-ion battery designed by the Japanese group at Tohoku University was fabricated using the sequential PLD technique. This microcell delivered a specific capacity of $9.5 \mathrm{Ah} \mathrm{cm}^{-2}$ discharged at a current density of $44 \mu \mathrm{A} \cdot \mathrm{cm}^{-2}$ using an Li-Sn alloy film as the anode and showed good reversibility over 100 cycles. 
Funding: This research received no external funding.

Conflicts of Interest: The authors declare no conflict of interest.

\section{References}

1. Chrisey, D.G.; Hubler, G.K. (Eds.) Pulsed Laser Deposition of Thin Films; Wiley: New York, NY, USA, 1994.

2. Bauerle, D. Laser Processing and Chemistry; Springer: Berlin, Germany, 1996.

3. Julien, C.; Camacho-Lopez, M.A.; Escobar-Alarcon, L.; Haro-Poniatowski, E. Fabrication of $\mathrm{LiCoO}_{2}$ thin-film cathodes for rechargeable lithium microbatteries. Mater. Chem. Phys. 2001, 68, 210-216. [CrossRef]

4. Antaya, M.; Dahn, J.R.; Preston, J.S.; Rossen, E.; Reimers, J.N. Preparation and characterization of $\mathrm{LiCoO}_{2}$ thin films by laser ablation deposition. J. Electrochem. Soc. 1993, 140, 575-578. [CrossRef]

5. Tsuruhama, T.; Hitosugi, T.; Oki, H.; Hirose, Y.; Hasegawa, T. Preparation of layered-rhombohedral $\mathrm{LiCoO}_{2}$ epitaxial thin films using pulsed laser deposition. Appl. Phys. Express 2009, 2, 085502. [CrossRef]

6. Perkins, J.D.; Bahn, C.S.; McGraw, J.M.; Parilla, P.A.; Ginley, D.S. Pulsed laser deposition and characterization of crystalline lithium cobalt dioxide $\left(\mathrm{LiCoO}_{2}\right)$ thin films. J. Electrochem. Soc. 2001, 148, A1301-A1312. [CrossRef]

7. Julien, C.; Haro-Poniatowski, E.; Camacho-Lopez, M.A.; Escobar-Alarcon, L.; Jimenez-Jarquin, J. Growth of $\mathrm{LiMn}_{2} \mathrm{O}_{4}$ thin films by pulsed-laser deposition and their electrochemical properties in lithium microbatteries. Mater. Sci. Eng. B 2000, 72, 36-46. [CrossRef]

8. Julien, C.; Haro-Poniatowski, E.; Hussain, O.M.; Ramana, C.V. Structure and electrochemistry of thin-film oxides grown by laser-pulsed deposition. Ionics 2001, 7, 165-171. [CrossRef]

9. Montenegro, M.J.; Lippert, T. Films for electrochemical applications. In Pulsed Laser Deposition of Thin Films: Applications-Led Growth of Functional Materials; Eason, R., Ed.; John Wiley \& Son Inc.: Hoboken, NJ, USA, 2007; Chapter 22; pp. 563-584.

10. Iriyama, Y.; Inaba, M.; Abe, T.; Ogumi, Z. Preparation of c-axis oriented thin films of $\mathrm{LiCoO}_{2}$ by pulsed laser deposition and their electrochemical properties. J. Power Sources 2001, 94, 175-182. [CrossRef]

11. Huo, W.; Li, J.; Chen, G.; Wang, Y.; Zou, W.; Rao, Q.; Zhou, A.; Chang, A.; Wang, Q. LiCoO 2 thin film cathode fabricated by pulsed laser deposition. Rare Met. 2011, 30 (Suppl. 1), 106-110. [CrossRef]

12. Xia, H.; Tang, S.B.; Lu, L. Thin film microbatteries prepared by pulsed laser deposition. J. Korean Phys. Soc. 2007, 51, 1055-1062. [CrossRef]

13. Escobar-Alarcon, L.; Haro-Poniatowski, E.; Camacho-Lopez, M.A.; Fernandez-Guasti, M.; Jimenez-Jarquin, J.; Sanchez-Pineda, A. Structural characterization of $\mathrm{TiO}_{2}$ thin films obtained by pulsed laser deposition. Appl. Surf. Sci. 1999, 137, 38-44. [CrossRef]

14. Kuwata, N.; Iwagami, N.; Matsuda, Y.; Tanji, Y.; Kawamura, J. Thin film batteries with $\mathrm{Li}_{3} \mathrm{PO}_{4}$ solid electrolytes fabricated by pulsed laser deposition. ECS Trans. 2009, 16, 53-60.

15. Julien, C. Solid State Batteries. In Handbook of Solid State Electrochemistry; Gellings, P.J., Bouwmeester, H.J.M., Eds.; CRC Press: Boca Raton, FL, USA, 1997; pp. 371-406.

16. Julien, C. Thin film technology and microbatteries. In Lithium Batteries-New Materials-Development and Perspectives; Pistoia, G., Ed.; Elsevier: Amsterdam, The Netherlands, 1994; pp. 167-237.

17. Sator, A. Pile réversible dont l'électrolyte est un cristal déposé en lame mince par évaporation. C. R. Acad. Sci. Paris 1952, 234, 2283-2285.

18. Kennedy, J.H. Thin film electrolyte systems. Thin Solid Film 1977, 43, 41-92. [CrossRef]

19. Bates, J.B.; Dudney, N.J.; Gruzalski, G.R.; Luck, C.F. Thin Film Battery and Method for Making Same. U.S. Patent 5,338,625, 16 April 1994.

20. Bates, J.B.; Dudney, N.J.; Gruzalski, G.R.; Zuhr, R.A.; Choudhury, A.; Luck, C.F.; Robertson, J.D. Electrical properties of amorphous lithium electrolyte thin films. Solid State Ion. 1992, 53, 647-654. [CrossRef]

21. Bates, J.B.; Dudney, N.J.; Gruzalski, G.R.; Zuhr, R.A.; Choudhury, A.; Luck, C.F.; Robertson, J.D. Fabrication and characterization of amorphous lithium electrolyte thin films and rechargeable thin-film batteries. J. Power Sources 1993, 43, 103-110. [CrossRef]

22. Bates, J.B.; Dudney, N.J.; Lubben, D.C.; Gruzalski, G.R.; Kwak, B.S.; Yu, X.H.; Zuhr, R.A. Thin-film rechargeable lithium batteries. J. Power Sources 1995, 54, 58-62. [CrossRef]

23. Bates, J.B.; Dudney, N.J.; Luck, C.F.; Sales, B.C.; Zuhr, R.A.; Robertson, J.D. Deposition and characterization of $\mathrm{Li}_{2} \mathrm{O}-\mathrm{SiO}_{2}-\mathrm{P}_{2} \mathrm{O}_{5}$ thin films. J. Am. Ceram. Soc. 1993, 76, 929-943. [CrossRef] 
24. Bates, J.B.; Gruzalski, G.R.; Dudney, N.J.; Luck, C.F.; Yu, X.H. Rechargeable thin-film lithium batteries. Solid State Ion. 1994, 70, 619-628. [CrossRef]

25. Julien, C. Lithium microbatteries. In Materials for Lithium-Ion Batteries; Julien, C., Stoynov, Z., Eds.; Springer: Dordrecht, The Netherlands, 2000; pp. 381-400.

26. Dudney, N.J. Thin film micro-batteries. Electrochem. Interface 2001, 17, 44-48.

27. Oudenhoven, J.F.M.; Baggetto, L.; Notten, P.H.L. All-solid-state lithium-ion microbatteries: A review of various three-dimensional concepts. Adv. Energy Mater. 2011, 1, 10-33. [CrossRef]

28. Wang, Y.; Liu, B.; Li, Q.; Cartmell, S.; Ferrara, S.; Deng, Z.D.; Xiao, J. Lithium and lithium-ion microbatteries for applications in microelectronic devices: A review. J. Power Sources 2015, 286, 330-345. [CrossRef]

29. Ferrari, S.; Loveridge, M.; Beattie, S.D.; Jahn, M.; Dashwood, R.J.; Bhagat, R. Latest advances in the manufacturing of 3D rechargeable lithium microbatteries. J. Power Sources 2015, 286, 25-46. [CrossRef]

30. Meng, Y.S.; McGilway, T.; Yang, M.-C.; Gostovic, D.; Wang, F.; Zeng, D.; Zhu, Y.; Graetz, J. In situ analytical electron microscopy for probing nanoscale electrochemistry. Electrochem. Interface 2011, 20, 49-53. [CrossRef]

31. Jones, S.D.; Akridge, J.R. Athin film solid state microbattery. Solid State Ion. 1992, 53, 628-634. [CrossRef]

32. Laik, B.; Ressejac, I.; Venet, C.; Pereira-Ramos, J.P. Comparative study of electrochemical performance of commercial solid-state thin film Li microbatteries. Thin Solid Films 2018, 649, 69-74. [CrossRef]

33. Enfucell Powers the Internet of Things Revolution. Available online: http://www.enfucell.com/softbattery (accessed on 28 September 2018).

34. Enerchip ${ }^{\mathrm{TM}}$ Smart Solid State Batteries. Available online: http://www.cymbet.com/products/enerchip-solidstate-batteries.php (accessed on 1 January 2019).

35. Thin Film Battery Technology. Available online: http://www.excellatron.com./thin-film-battery-technology (accessed on 1 January 2018).

36. Thinergy Micro-Energy Cell Product Family. Available online: https://www.batterypoweronline.com/ markets/batteries/thinergy-micro-energy-cell-product-family/ (accessed on 1 January 2019).

37. NanoEnergy ${ }^{\mathrm{TM}}$. Available online: http:/www.frontedgetechnology.com./gen.htm (accessed on 1 January 2014).

38. Ulvac Enables Flexible Li-Ion Battery. Available online: https://fr.scribd.com/document/118211050/196729Ulvac-Enables (accessed on 22 December 2008).

39. Batteries Ultraminces à Durée de vie Etendue de STMicroelectronics Pour L'Alimentation Des Technologies Miniatures de Demain. Available online: https://www.digikey.fr/fr/product-highlight/s/stmicroelectronics/ efl700a39-enfilm-rechargeable-battery/ (accessed on 13 January 2016).

40. Thin Film Rechargeable Batteries from Korea. Available online: https:/www.idtechex.com/research/articles/ thin-film-rechargeable-batteries-from-korea-00003130.ja.asp?donotredirect=true\&setlang=ja (accessed on 23 February 2011).

41. Kuwata, N.; Kawamura, J.; Toribami, K.; Hattori, T.; Sata, N. Thin-film lithium-ion battery with amorphous solid electrolyte fabricated by pulsed laser deposition. Electrochem. Commun. 2004, 6, 417-421. [CrossRef]

42. Sakuda, A.; Hayashi, A.; Ohtomo, T.; Hama, S.; Tatsumisago, M. All-solid-state lithium secondary batteries using $\mathrm{LiCoO}_{2}$ particles with pulsed laser deposition coatings of $\mathrm{Li}_{2} \mathrm{~S}_{-} \mathrm{P}_{2} \mathrm{~S}_{5}$ solid electrolytes. J. Power Sources 2011, 196, 6735-6741. [CrossRef]

43. Schichtel, P.; Geiß, M.; Leichtweiß, T.; Sann, J.; Weber, D.A.; Janek, J. On the impedance and phase transition of thin film all-solid-state batteries based on the $\mathrm{Li}_{4} \mathrm{Ti}_{5} \mathrm{O}_{12}$ system. J. Power Sources 2017, 360, 593-604. [CrossRef]

44. Nakagawa, A.; Kuwata, N.; Matsuda, Y.; Kawamura, J. Thin film lithium battery using stable solid electrolyte $\mathrm{Li}_{4} \mathrm{SiO}_{4}$ fabricated by PLD. ECS Trans. 2010, 25, 155-161.

45. Fujimoto, D.; Kuwata, N.; Matsuda, Y.; Kawamura, J.; Kang, F. Fabrication of solid-state thin-film batteries using $\mathrm{LiMnPO}_{4}$ thin films deposited by pulsed laser deposition. Thin Solid Films 2015, 579, 81-88. [CrossRef]

46. Ohzuku, T.; Ueda, A. Solid-state redox reactions of $\mathrm{LiCoO}_{2}(\mathrm{R} 3 \mathrm{~m})$ for 4 volt secondary lithium cells. J. Electrochem. Soc. 1994, 141, 2972-2977. [CrossRef]

47. Striebel, K.A.; Deng, C.Z.; Wen, S.J.; Cairns, E.J. Electrochemical behavior of $\mathrm{LiMn}_{2} \mathrm{O}_{4}$ and $\mathrm{LiCoO}_{2}$ thin films produced with pulsed laser deposition. J. Electrochem. Soc. 1996, 143, 1821-1827. [CrossRef]

48. Bouwman, P.J.; Boukamp, B.A.; Bouwmeester, J.M.; Notten, P.H.L. Influence of diffusion plane orientation on electrochemical properties of thin film $\mathrm{LiCoO}_{2}$ electrodes. J. Electrochem. Soc. 2002, 149, A699-A709. [CrossRef]

49. McGraw, J.; Bahn, C.; Parilla, P.; Perkins, J.; Readey, D.; Ginley, D. Li ion diffusion measurements in $\mathrm{V}_{2} \mathrm{O}_{5}$ and $\mathrm{Li}\left(\mathrm{Co}_{1-\mathrm{x}} \mathrm{Al}_{\mathrm{x}}\right) \mathrm{O}_{2}$ thin-film battery cathodes. Electrochim. Acta 1999, 45, 187-196. [CrossRef] 
50. Escobar-Alarcon, L.; Haro-Poniatowski, E.; Massot, M.; Julien, C. Physical properties of lithium-cobalt oxides grown by laser ablation. Mater. Res. Soc. Symp. Proc. 1999, 548, 223-228. [CrossRef]

51. Okada, K.; Ohnishi, T.; Mitsuishi, K.; Takada, K. Epitaxial growth of $\mathrm{LiCoO}_{2}$ thin films with (001) orientation. AIP Adv. 2017, 7, 115011. [CrossRef]

52. Ohnishi, T.; Hang, B.T.; Xu, X.; Osada, M.; Takada, K. Quality control of epitaxial $\mathrm{LiCoO}_{2}$ thin films grown by pulsed laser deposition. J. Mater. Res. 2010, 25, 1886-1889. [CrossRef]

53. Ohnishi, T.; Nishio, K.; Takada, K. Composition controlled $\mathrm{LiCoO}_{2}$ epitaxial thin film growth by pulsed laser deposition. Proc. SPIE 2015, 9364, 93640L.

54. Zhang, Y.; Zhong, Z.Y.; Zhu, M. Effect of deposition condition on structure and morphology of pulsed-laser deposited $\mathrm{LiCoO}_{2}$ films. J. Funct. Mater. 2007, 38, 1971-1974.

55. Bouwman, P.J.; Boukamp, B.A.; Bouwmeester, H.J.M.; Wondergem, H.J.; Notten, P.H.L. Structural analysis of submicrometer $\mathrm{LiCoO}_{2}$ films. J. Electrochem. Soc. 2001, 148, A311-A317. [CrossRef]

56. Tang, S.B.; Lu, L.; Lai, M.O. Characterization of a $\mathrm{LiCoO}_{2}$ thin film cathode grown by pulsed laser deposition. Philos. Mag. 2005, 85, 2831-2842. [CrossRef]

57. Nishio, K.; Ohnishi, T.; Akatsuka, K.; Takada, K. Crystal orientation of epitaxial $\mathrm{LiCoO}_{2}$ films grown on $\mathrm{SrTiO}_{3}$ substrates. J. Power Sources 2014, 247, 687-691. [CrossRef]

58. Rao, M.C.; Muntaz-Begum, S.K. Substrate effect on microstructure of $\mathrm{LiCoO}_{2}$ thin film cathodes. Optoelectron. Adv. Mater. 2012, 6, 508-510.

59. Xia, H.; Lu, L.; Ceder, G. Substrate effect on the microstructure and electrochemical properties of $\mathrm{LiCoO}_{2}$ thin films grown by PLD. J. Alloy Compd. 2006, 417, 304-310. [CrossRef]

60. Nishio, K.; Ohnishi, T.; Mitsuishi, K.; Ohta, N.; Watanabe, K.; Takada, K. Orientation alignment of epitaxial $\mathrm{LiCoO}_{2}$ thin films on vicinal $\mathrm{SrTiO}_{3}$ (100) substrates. J. Power Sources 2016, 325, 306-310. [CrossRef]

61. Liu, D.; Chao, Y.; Wu, S.; Zhong, S.; Lei, M. Morphology control of $\mathrm{LiCoO}_{2}$ thin film prepared by pulsed laser deposition. In Proceedings of the 2013 International Conference on Materials for Renewable Energy and Environment, Chengdu, China, 19-21 August 2014; Volume 2, pp. 529-531.

62. Ohnishi, T.; Takada, K. High-rate growth of high-crystallinity $\mathrm{LiCoO}_{2}$ epitaxial thin films by pulsed laser deposition. Appl. Phys. Express 2012, 5, 055502. [CrossRef]

63. Nishio, K.; Ohnishi, T.; Osada, M.; Ohta, N.; Watanabe, K.; Takada, K. Influences of high deposition rate on $\mathrm{LiCoO}_{2}$ epitaxial films prepared by pulsed laser deposition. Solid State Ion. 2016, 285, 91-95. [CrossRef]

64. Funayama, K.; Nakamura, T.; Kuwata, N.; Kawamura, J.; Kawada, T.; Amezawa, K. Electromotive force measurements of $\mathrm{LiCoO}_{2}$ electrode on a lithium ion-conducting glass ceramics under mechanical stress. Solid State Ion. 2016, 285, 75-78. [CrossRef]

65. Rao, M.C. Structure and surface morphology of $\mathrm{LiCoO}_{2}$ thin film cathodes prepared by pulsed laser deposition. J. Intense Pulsed Lasers Appl. Adv. Phys. 2012, 2, 35-38.

66. Rao, M.C. Optical absorption studies of $\mathrm{LiCoO}_{2}$ thin films grown by pulsed laser deposition. Int. J. Pure Appl. Phys. 2010, 6, 365-370.

67. Rao, M.C.; Hussain, O.M. Optical and electrical properties of laser ablated amorphous $\mathrm{LiCoO}_{2}$ thin film cathodes. In IOP Conference Series: Materials Science and Engineering; IOP Publishing: Bristol, UK, 2009; Volume 2, p. 012037.

68. Bouwman, P.J.; Boukamp, B.A.; Bouwmeester, H.J.M.; Notten, P.H.L. Structure-related intercalation behaviour of $\mathrm{LiCoO}_{2}$ films. Solid State Ion. 2002, 152, 181-188. [CrossRef]

69. Xia, H.; Lunney, J.; Ceder, G. Li diffusion in $\mathrm{LiCoO}_{2}$ thin films prepared by pulsed laser deposition. J. Power Sources 2006, 159, 1422-1427. [CrossRef]

70. Xia, H.; Lu, L. Texture effect on the electrochemical properties of $\mathrm{LiCoO}_{2}$ thin films prepared by PLD. Electrochim. Acta 2007, 52, 7014-7020. [CrossRef]

71. Taminato, S.; Hirayama, M.; Suzuki, K.; Tamura, K.; Minato, T.; Arai, H.; Uchimoto, Y.; Ogumi, Z.; Kanno, R. Lithium intercalation and structural changes at the $\mathrm{LiCoO}_{2}$ surface under high voltage battery operation. J. Power Sources 2016, 307, 599-603. [CrossRef]

72. Vasanthi, R.; Mangani, I.R.; Selladurai, S.; Manoravi, P. Comparison of $\mathrm{LiCo}_{0.97} \mathrm{Mg}_{0.03} \mathrm{O}_{2}$ PLD film with bulk for the application of lithium micro-batteries. In Proceedings of the 8th Asian Conference on Solid State Ionics: Trends in the New Millennium, Langkawi, Malaysia, 15-19 December 2002; pp. 163-170.

73. Rao, M.C.; Hussain, O.M. Growth and characterization of tetravalent doped $\mathrm{LiCoO}_{2}$ thin film cathodes. Indian J. Eng. Mater. Sci. 2009, 16, 335-340. 
74. Rao, M.C.; Hussain, O.M. Synthesis and electrochemical properties of Ti doped $\mathrm{LiCoO}_{2}$ thin film cathodes. J. Alloy. Compd. 2010, 491, 503-506. [CrossRef]

75. Hirayama, M.; Sonoyama, N.; Abe, T.; Minoura, M. Characterization of electrode/electrolyte interface for lithium batteries using in situ synchrotron X-ray reflectometry-A new experimental technique for $\mathrm{LiCoO}_{2}$ model electrode. J. Power Sources 2007, 168, 493-500. [CrossRef]

76. Yamada, I.; Iriyama, Y.; Abe, T.; Ogumi, Z. Lithium-ion transfer on a $\mathrm{Li}_{x} \mathrm{CoO}_{2}$ thin film electrode prepared by pulsed laser deposition-Effect of orientation. J. Power Sources 2007, 172, 933-937. [CrossRef]

77. Tang, S.B.; Lai, M.O.; Lu, L. Li-ion diffusion in highly (003) oriented $\mathrm{LiCoO}_{2}$ thin film cathode prepared by pulsed laser deposition. J. Alloy. Compd. 2008, 449, 300-303. [CrossRef]

78. Takeuchi, S.; Tan, H.; Bharathi, K.K.; Stafford, G.R.; Shin, J.; Yasui, S.; Takeuchi, I.; Bendersky, L.A. Epitaxial $\mathrm{LiCoO}_{2}$ films as a model system for fundamental electrochemical studies of positive electrodes. ACS Appl. Mater. Interfaces 2015, 7, 7901-7911. [CrossRef]

79. Tan, H.; Takeuchi, S.; Bharathi, K.K.; Takeuchi, I.; Bendersky, L.A. Microscopy study of structural evolution in epitaxial $\mathrm{LiCoO}_{2}$ positive electrode films during electrochemical cycling. ACS Appl. Mater. Interfaces 2016, 8, 6727-6735. [CrossRef] [PubMed]

80. Li, Z.; Yasui, S.; Takeuchi, S.; Creuziger, A.; Maruyama, S.; Herzing, A.A.; Takeuchi, I.; Bendersky, L.A. Structural study of epitaxial $\mathrm{LiCoO}_{2}$ films grown by pulsed laser deposition on single crystal $\mathrm{SrTiO}_{3}$ substrates. Thin Solid Films 2016, 612, 472-482. [CrossRef]

81. Hussain, O.M.; Rao, M.C.; Julien, C.M. Growth of nano-structured $\mathrm{TiO}_{2}$-doped $\mathrm{LiCoO}_{2}$ PLD films and their electrochemical properties. In New Trends in Intercalation Compounds for Energy Storage and Conversion; Zaghib, K., Julien, C.M., Prakash, J., Eds.; The Electrochemical Society: Pennington, NJ, USA, 2003; pp. 627-631.

82. Kato, M.; Hayashi, T.; Hasegawa, G.; Lu, X.; Miyazaki, T.; Matsuda, Y.; Kuwata, N.; Koji Kurihara, K.; Kawamura, J. Electrochemical properties of $\mathrm{LiCoO}_{2}$ thin film surface modified by lithium tantalate and lithium niobate coatings. Solid State Ion. 2017, 308, 54-60. [CrossRef]

83. Hayashi, T.; Okada, J.; Toda, E.; Kuzuo, R.; Matsuda, Y.; Kuwata, N.; Kawamura, J. Electrochemical effect of lithium tungsten oxide modification on $\mathrm{LiCoO}_{2}$ thin film electrode. J. Power Sources 2015, 285, 559-567. [CrossRef]

84. Hayashi, T.; Matsuda, Y.; Kuwata, N.; Kawamura, J. High-power durability of $\mathrm{LiCoO}_{2}$ thin film electrode modified with amorphous lithium tungsten oxide. J. Power Sources 2017, 354, 41-47. [CrossRef]

85. Hayashi, T.; Toda, E.; Kuzuo, R.; Matsuda, Y.; Kuwata, N.; Junichi Kawamura, J. Contribution of randomly oriented $\mathrm{Li}_{2} \mathrm{WO}_{4}$ with tetragonal symmetry to $\mathrm{Li}^{+}$ion transfer resistance reduction in lithium ion batteries. Int. J. Electrochem. Sci. 2015, 10, 8150-8157.

86. Hayashi, T.; Miyazaki, T.; Matsuda, Y.; Kuwata, N.; Saruwatari, M.; Furuichi, Y.; Kurihara, K.; Kuzuo, R.; Kawamura, J. Effect of lithium-ion diffusibility on interfacial resistance of $\mathrm{LiCoO}_{2}$ thin film electrode modified with lithium tungsten oxides. J. Power Sources 2016, 305, 46-53. [CrossRef]

87. Kuwata, N.; Ise, K.; Matsuda, Y.; Kawamura, J.; Tsurui, T.; Kamishima, O. Detection of degradation in LiCoO 2 thin films by in situ micro Raman microscopy. In Ionics for Sustainable World, Proceedings of the 13th Asian Conference on Solid State Ionics, Sendai, Japan, 17-20 July 2012; Chowdari, B.V.R., Kawamura, J., Mizusaki, J., Amezawa, K., Eds.; World Scientific Publishing Co.: Singapore, 2013; pp. 138-143.

88. Matsuda, Y.; Kuwata, N.; Kawamura, J. Thin-film lithium batteries with 0.3-30 $\mu$ m thick $\mathrm{LiCoO}_{2}$ films fabricated by high-rate pulsed laser deposition. Solid State Ion. 2014, 320, 38-44. [CrossRef]

89. Shiraki, S.; Oki, H.; Takagi, Y.; Suzuki, T.; Kumatani, A.; Shimizu, R.; Haruta, M.; Ohsawa, T.; Sato, Y.; Ikuhara, Y.; et al. Fabrication of all-solid-state battery using epitaxial $\mathrm{LiCoO}_{2}$ thin films. J. Power Sources 2014, 267, 881-887. [CrossRef]

90. Wen, S.-J.; von Rottkay, K.; Rubin, M. Electrochromic lithium nickel oxide thin film by pulsed laser deposition. ECS Symp. Proc. 1997, 96, 54-63.

91. Bouessay, I.; Rougier, A.; Tarascon, J.M. Electrochromic mechanism in nickel oxide thin films grown by pulsed laser deposition. Electrochem. Soc. Proc. 2003, 2003, 91-102.

92. Jahromi, S.P.; Huang, N.M.; Kamalianfar, A.; Lim, H.N.; Muhamad, M.R.; Yousef, R. Facile synthesis of porous-structured nickel oxide thin film by pulsed laser deposition. J. Nanomater. 2012, 2012, 173825.

93. Wang, H.; Wang, Y.; Wang, X. Pulsed laser deposition of the porous nickel oxide thin film at room temperature for high-rate pseudocapacitive energy storage. Electrochem. Commun. 2012, 18, 92-95. [CrossRef] 
94. López-Iturbe, J.; Camacho-López, M.A.; Escobar-Alarcón, L.; Camps, E. Synthesis and characterization of $\mathrm{LiNiO}_{2}$ targets for thin film deposition by pulsed laser ablation. Superficies Y Vacío 2005, 18, 27-30.

95. Rao, M.C.; Ravindranadh, K.; Srikanth, K.S. Microstructural and electrochemical studies on laser ablated $\mathrm{LiNiO}_{2}$ thin films. J. Chem. Pharm. Res. 2016, 8, 677-684.

96. Yuki, Y.; Uchiyama, T.; Yamamoto, K.; Uchimoto, Y. Preparation of $\mathrm{Li}_{1-x} \mathrm{Ni}_{1+x} \mathrm{O}_{2}$ thin films by pulsed laser deposition and the electrochemical performance for oxygen evolution reaction in alkaline media. In ESC Meeting Abstracts; The Electrochemical Society: Pennington, NJ, USA, 2018; p. 2585.

97. Razeg, K.H.; Al-Hilli, M.F.; Khalefa, A.A.; Aadim, K.A. Structural and optical properties of $\left(\mathrm{Li}_{x} \mathrm{Ni}_{2-x} \mathrm{O}_{2}\right)$ thin films deposited by pulsed laser deposited (PLD) technique at different doping ratio. Int. J. Phys. 2017, 5, 46-52.

98. Julien, C.; El-Farh, L.; Rangan, S.; Massot, M. studies of $\mathrm{LiNi}_{0.8} \mathrm{Co}_{0.2} \mathrm{O}_{2}$ cathode material prepared by the citric acid-assisted sol-gel method for lithium batteries. J. Sol-Gel Sci. Technol. 1999, 15, 63-72. [CrossRef]

99. Ramana, C.V.; Zaghib, K.; Julien, C.M. Synthesis, structural and electrochemical properties of pulsed laser deposited $\mathrm{Li}(\mathrm{Ni}, \mathrm{Co}) \mathrm{O}_{2}$ films. J. Power Sources 2006, 159, 1310-1315. [CrossRef]

100. Ramana, C.V.; Zaghib, K.; Julien, C.M. Highly oriented growth of pulsed-laser deposited $\mathrm{LiNi}_{0.8} \mathrm{Co}_{0.2} \mathrm{O}_{2}$ films for application in microbatteries. Chem. Mater. 2006, 18, 1397-1400. [CrossRef]

101. Ramana, C.V.; Zaghib, K.; Julien, C.M. Growth and electrochemical properties of pulsed laser deposited Al-doped Li-Ni-Co oxide films. In Proceedings of the Extended Abstracts of the 231st ACS National Meeting, Atlanta, GA, USA, 26-30 March 2006; p. 944631.

102. Hirayama, M.; Sakamoto, K.; Hiraide, T.; Mori, D.; Yamada, A.; Kanno, R.; Sonoyama, N.; Tamura, K.; Mizuki, J. Characterization of electrode/electrolyte interface using in situ X-ray reflectometry and $\mathrm{LiNi}_{0.8} \mathrm{Co}_{0.2} \mathrm{O}_{2}$ epitaxial film electrode synthesized by pulsed laser deposition method. Electrochim. Acta 2007, 53, 871-881. [CrossRef]

103. Wang, G.X.; Lindsay, M.J.; Ionescu, M.; Bradhurst, D.H.; Dou, S.X.; Liu, H.K. Physical and electrochemical characterization of $\mathrm{LiNi}_{0.8} \mathrm{Co}_{0.2} \mathrm{O}_{2}$ thin-film electrodes deposited by laser ablation. J. Power Sources 2001, 97, 298-302. [CrossRef]

104. Imanishi, N.; Shizuka, K.; Matsumura, T.; Hirano, A.; Takeda, Y.; Kanno, R. Impedance analysis of PLD $\mathrm{LiNi}_{0.8} \mathrm{Co}_{0.2} \mathrm{O}_{2}$ film electrode. J. Power Sources 2007, 174, 751-755. [CrossRef]

105. Baskaran, R.; Kuwata, N.; Kamishima, O.; Kawamura, J.; Selvasekarapandian, S. Structural and electrochemical studies on thin film $\mathrm{LiNi}_{0.8} \mathrm{Co}_{0.2} \mathrm{O}_{2}$ by PLD for micro battery. Solid State Ion. 2009, 180, 636-643. [CrossRef]

106. Xia, H.; Lu, L.; Meng, Y.S. Growth of layered $\mathrm{LiNi}_{0.5} \mathrm{Mn}_{0.5} \mathrm{O}_{2}$ thin films by pulsed laser deposition for application in microbatteries. Appl. Phys. Lett. 2008, 92, 011912. [CrossRef]

107. Xia, H.; Lu, L.; Lai, M.O. Li diffusion in $\mathrm{LiNi}_{0.5} \mathrm{Mn}_{0.5} \mathrm{O}_{2}$ thin film electrodes prepared by pulsed laser deposition. Electrochim. Acta 2009, 54, 5986-5991. [CrossRef]

108. Sakamoto, K.; Konishi, H.; Sonoyama, N.; Yamada, A.; Tamura, K.; Mizuki, J.; Kanno, R. Mechanistic study on lithium intercalation using a restricted reaction field in $\mathrm{LiNi}_{0.5} \mathrm{Mn}_{0.5} \mathrm{O}_{2}$. J. Power Sources 2007, 174, 678-682. [CrossRef]

109. Sakamoto, K.; Hirayama, M.; Konishi, H.; Sonoyama, N.; Dupre, N.; Guyomard, D.; Tamura, K.; Mizuki, J.; Kanno, R. Structural changes in surface and bulk $\mathrm{LiNi}_{0.5} \mathrm{Mn}_{0.5} \mathrm{O}_{2}$ during electrochemical reaction on epitaxial thin-film electrodes characterized by in situ X-ray scattering. Phys. Chem. Chem. Phys. 2010, 12, 3815-3823. [CrossRef]

110. Ramana, C.V.; Zaghib, K.; Julien, C.M. Pulsed-laser deposited $\mathrm{LiNi}_{0.8} \mathrm{Co}_{0.15} \mathrm{Al}_{0.05} \mathrm{O}_{2}$ thin films for application in microbatteries. Appl. Phys. Lett. 2007, 90, 21916. [CrossRef]

111. Deng, J.; Xi, L.; Wang, L.; Wang, Z.; Chung, C.Y.; Han, X.; Zhou, H. Electrochemical performance of $\mathrm{LiNi}_{1 / 3} \mathrm{Co}_{1 / 3} \mathrm{Mn}_{1 / 3} \mathrm{O}_{2}$ thin film electrodes prepared by pulsed laser deposition. J. Power Sources 2012, 217, 491-497. [CrossRef]

112. Jacob, C.; Lynch, T.; Chen, A.; Jian, J.; Wang, H. Highly textured $\mathrm{Li}\left(\mathrm{Ni}_{0.5} \mathrm{Mn}_{0.3} \mathrm{Co}_{0.2}\right) \mathrm{O}_{2}$ thin films on stainless steel as cathode for lithium-ion battery. J. Power Sources 2013, 241, 410-414. [CrossRef]

113. Smyrek, P.; Kim, H.; Zheng, Y.; Seifert, H.J.; Piqué, A.; Pfleging, W. Laser-printing and femtosecond laser-structuring of electrode materials for the manufacturing of 3D lithium-ion micro-batteries. Proc. SPIE 2016, 9738, 973806 . 
114. Abe, M.; Iba, H.; Suzuki, K.; Minamishima, H.; Hirayama, M.; Tamura, K.; Mizuki, J.; Saito, T.; Ikuhara, Y.; Kanno, R. Study on the deterioration mechanism of layered rock-salt electrodes using epitaxial thin films: $\mathrm{Li}(\mathrm{Ni}, \mathrm{Co}, \mathrm{Mn}) \mathrm{O}_{2}$ and their $\mathrm{Zr}-\mathrm{O}$ surface modified electrodes. J. Power Sources 2017, 345, 108-119. [CrossRef]

115. Bendersky, L.A.; Tan, H.; Karuppanan, K.B.; Li, Z.P.; Johnston-Peck, A.C. Crystallography and growth of epitaxial oxide films for fundamental studies of cathode materials used in advanced Li-ion batteries. Crystals 2017, 7, 127. [CrossRef]

116. Johnston-Peck, A.C.; Takeuchi, S.; Kamala-Bharathi, K.; Herzing, A.A.; Bendersky, L.A. Domain formation in lithium-rich manganese-nickel-cobalt-oxide epitaxial thin films and implications for interpretation of electrochemical behavior. Thin Solid Films 2018, 647, 40-49. [CrossRef]

117. Yan, B.; Liu, J.; Song, B.; Xiao, P.; Lu, L. Li-rich thin film cathode prepared by pulsed laser deposition. Sci. Rep. 2013, 3, 3332. [CrossRef] [PubMed]

118. Taminato, S.; Hirayama, M.; Suzuki, K.; Yamada, N.L.; Yonemura, M.; Son, J.Y.; Kanno, R. Highly reversible capacity at the surface of a lithium-rich manganese oxide: A model study using an epitaxial film system. Chem. Commun. 2015, 51, 1673-1676. [CrossRef] [PubMed]

119. Zheng, Y.; Taminato, S.; Suzuki, K.; Hirayama, M.; Kanno, R. Fabrication and lithium intercalation properties of epitaxial $\mathrm{Li}_{2} \mathrm{RuO}_{3}$ thin films. Thin Solid Films 2012, 520, 4889-4893. [CrossRef]

120. Taminato, S.; Hirayama, M.; Suzuki, K.; Kim, K.; Zheng, Y.; Tamura, K.; Mizuki, J.I.; Kanno, R. Mechanistic studies on lithium intercalation in a lithium-rich layered material using $\mathrm{Li}_{2} \mathrm{RuO}_{3}$ epitaxial film electrodes and in situ surface X-ray analysis. J. Mater. Chem. A 2014, 2, 17875-17882. [CrossRef]

121. Kuwata, N.; Kumar, R.; Toribami, K.; Suzuki, T.; Hattori, T.; Kawamura, J. Thin film lithium ion batteries prepared only pulsed laser deposition. Solid State Ion. 2006, 177, 2827-2832. [CrossRef]

122. Morcrette, M.; Barboux, P.; Perrière, J.; Brousse, T. $\mathrm{LiMn}_{2} \mathrm{O}_{4}$ thin films for lithium ion sensors. Solid State Ion. 1998, 112, 249-254. [CrossRef]

123. Camacho-Lopez, M.A.; Escobar-Alarcon, L.; Haro-Poniatowski, E.; Julien, C. $\mathrm{LiMn}_{2} \mathrm{O}_{4}$ films grown by pulsed-laser deposition. Ionics 1999, 5, 244-250. [CrossRef]

124. Singh, D.; Houriet, R.; Vacassy, R.; Hofinann, H.; Craciun, V.; Singh, R.K. Pulsed laser deposition and characterization of $\mathrm{LiMn}_{2} \mathrm{O}_{4}$ thin films for applications in Li-ion rechargeable battery systems. Mater. Res. Soc. Symp. Proc. 1999, 575, 83-89. [CrossRef]

125. Camacho-Lopez, M.A.; Escobar-Alarcon, L.; Haro-Poniatowski, E.; Julien, C. Physico-chemical properties of $\mathrm{LiMn}_{2} \mathrm{O}_{4}$ films grown by laser ablation. In Materials for Lithium-Ion Batteries; Julien, C., Stoynov, Z., Eds.; NATO Science Series; Kluwer Academic Publishers: Dordrecht, The Netherlands, 2000; Volume 3-85, pp. 535-541.

126. Camacho-Lopez, M.A.; Escobar-Alarcon, L.; Haro-Poniatowski, E.; Julien, C. Raman studies of $\operatorname{LiMn}_{2} \mathrm{O}_{4}$ films grown by laser ablation. Mater. Res. Soc. Symp. Proc. 2000, 617. [CrossRef]

127. Simmen, F.; Lippert, T.; Novák, P.; Neuenschwander, B.; Döbeli, M.; Mallepell, M.; Wokaun, A. The influence of lithium excess in the target on the properties and compositions of $\mathrm{Li}_{1+\mathrm{x}} \mathrm{Mn}_{2} \mathrm{O}_{4-\delta}$ thin films prepared by PLD. Appl. Phys. A 2008, 93, 711-716. [CrossRef]

128. Gao, X.; Ikuhara, Y.H.; Fisher, C.A.; Moriwake, H.; Kuwabara, A.; Oki, H.; Kohama, K.; Yoshida, R.; Huang, R.; Ikuhara, Y. Structural distortion and compositional gradients adjacent to epitaxial $\mathrm{LiMn}_{2} \mathrm{O}_{4}$ thin film interfaces. Adv. Mater. Interfaces 2014, 1, 1400143. [CrossRef]

129. Hendriks, R.; Monteiro Cunha, D.; Singh, D.P.; Huijben, M. Enhanced lithium transport by control of crystal orientation in spinel $\mathrm{LiMn}_{2} \mathrm{O}_{4}$ thin film cathodes. ACS Appl. Energy Mater. 2018, 1, 7046-7051. [CrossRef] [PubMed]

130. Sonoyama, N.; Iwase, K.; Takatsuka, H.; Matsumura, T.; Imanishi, N.; Takeda, Y.; Kanno, R. Electrochemistry of $\mathrm{LiMn}_{2} \mathrm{O}_{4}$ epitaxial films deposited on various single crystal substrates. J. Power Sources 2009, 189, 561-565. [CrossRef]

131. Canulescu, S.; Papadopoulou, E.L.; Anglos, D.; Lippert, T.; Schneider, C.W.; Wokaun, A. Mechanisms of the laser plume expansion during the ablation of $\mathrm{LiMn}_{2} \mathrm{O}_{4}$. J. Appl. Phys. 2009, 105, 063107. [CrossRef]

132. Hussain, O.M.; Hari Krishna, K.; Kalai-Vani, V.; Julien, C.M. Pulsed laser deposition of highly oriented $\mathrm{LiCoO}_{2}$ and $\mathrm{LiMn}_{2} \mathrm{O}_{4}$ thin films for microbattery applications. In Proceedings of the 10th Asian Conference on Solid State Ionics, Kandy, Sri Lanka, 12-16 June 2006; pp. 136-145.

133. Hussain, O.M.; Hari-Krishna, K.; Kalai-Vani, V.; Julien, C.M. Structural and electrical properties of lithium manganese oxide thin films grown by pulsed laser deposition. Ionics 2007, 13, 455-459. [CrossRef] 
134. Tang, S.B.; Lai, M.O.; Lu, L.; Tripathy, S. Comparative study of $\mathrm{LiMn}_{2} \mathrm{O}_{4}$ thin film cathode grown at high medium and low temperatures by pulsed laser deposition. J. Solid State Chem. 2006, 179, 3831-3838. [CrossRef]

135. Tang, S.B.; Xia, H.; Lai, M.O.; Lu, L. Characterization of $\mathrm{LiMn}_{2} \mathrm{O}_{4}$ thin films grown on Si substrates by pulsed laser deposition. J. Alloy. Compd. 2008, 449, 322-325. [CrossRef]

136. Morcrette, M.; Barboux, P.; Perrière, J.; Brousse, T.; Traverse, A.; Boilot, J.P. Non-stoichiometry in $\mathrm{LiMn}_{2} \mathrm{O}_{4}$ thin films by laser ablation. Solid State Ion. 2001, 138, 213-219. [CrossRef]

137. Yamada, I.; Abe, T.; Iriyama, Y.; Ogumi, Z. Lithium-ion transfer at $\mathrm{LiMn}_{2} \mathrm{O}_{4}$ thin film electrode prepared by pulsed laser deposition. Electrochem. Commun. 2003, 5, 502-505. [CrossRef]

138. Albrecht, D.; Wulfmeier, H.; Fritze, H. Preparation and characterization of c-LiMn $\mathrm{O}_{4}$ thin films prepared by pulsed laser deposition for lithium-ion batteries. Energy Technol. 2016, 4, 1558-1564. [CrossRef]

139. Yu, X.; Chen, X.; Buchholz, D.B.; Li, Q.; Wu, J.; Fenter, P.A.; Bedzyk, M.J.; Dravid, V.P.; Barnett, S.A. Pulsed laser deposition and characterization of heteroepitaxial $\mathrm{LiMn}_{2} \mathrm{O}_{4} / \mathrm{La}_{0.5} \mathrm{Sr}_{0.5} \mathrm{CoO}_{3}$ bilayer thin films as model lithium Ion battery cathodes. ACS Appl. Nano Mater. 2018, 1, 642-653. [CrossRef]

140. Singh, D.; Houriet, R.; Giovannini, R.; Hofmann, H.; Cruciun, V.; Singh, R.K. Challenges in making of thin films for $\mathrm{Li}_{x} \mathrm{Mn}_{y} \mathrm{O}_{4}$ rechargeable lithium batteries for MEMS. J. Power Sources 2001, 97, 826-831. [CrossRef]

141. Rao, M.C. Thermal properties of laser ablated $\mathrm{LiMn}_{2} \mathrm{O}_{4}$ thin films. J. Chem. Biol. Phys. Sci. C 2014, 4, 2555-2559.

142. Rougier, A.; Striebel, K.A.; Wen, S.J.; Cairns, E.J. Cyclic voltammetry of pulsed laser deposited $\mathrm{Li}_{x} \mathrm{Mn}_{2} \mathrm{O}_{4}$ thin films. J. Electrochem. Soc. 1998, 145, 2975-2980. [CrossRef]

143. Singh, D.; Singh, R.K. Lithium-Based Rechargeable Batteries. U.S. Patent 20030186128A1, 2 October 2003.

144. Rao, M.C.; Ravindranadh, K.; Ramesh, K.K.D.; Srikanth, K.S. Morphological and electrochemical properties of $\mathrm{LiMn}_{2} \mathrm{O}_{4}$ thin films. Der Pharma Chemica 2016, 8, 74-79.

145. Suzuki, K.; Kim, K.S.; Taminato, S.; Komo, M.; Hagiwara, A.; Son, J.Y.; Inami, T.; Konishi, H.; Tamura, K.; Mizuki, J.; et al. Modification effects on structural changes of $\mathrm{LiMn}_{2} \mathrm{O}_{4}$ electrode during the electrochemical process. In Proceedings of the Extended Abstracts of the 222nd Electrochem. Soc. Meeting, Honolulu, HI, USA, 7-12 October 2012; p. 216.

146. Striebel, K.; Sakai, E.; Cairns, E. Impedance behavior of the $\mathrm{LiMn}_{2} \mathrm{O}_{4} / \mathrm{LiPF}_{6}-\mathrm{DMC}-\mathrm{EC}$ interface during cycling. In Workshop on Interfaces, Phenomena, and Nanostructures in Lithium Batteries; Kingler, R., Landgrebe, A., Maupin, P., Eds.; The Electrochemical Society: Pennington, NJ, USA, 2000; Volume 2000-36, pp. 61-67.

147. Hirayama, M. Interfacial reactions of intercalation electrodes in lithium ion batteries. Electrochemistry 2015, 83, 701-706. [CrossRef]

148. Hirayama, M.; Ido, H.; Kim, K.S.; Cho, W.; Tamura, K.; Mizuki, J.; Kanno, R. Dynamic structural changes at $\mathrm{LiMn}_{2} \mathrm{O}_{4}$ /electrolyte interface during lithium battery reaction. J. Am. Chem. Soc. 2010, 132, 15268-15276. [CrossRef] [PubMed]

149. Inaba, M.; Doi, T.; Iriyama, Y.; Abe, T.; Ogumi, Z. Electrochemical STM observation of $\operatorname{LiMn}_{2} \mathrm{O}_{4}$ thin films prepared by pulsed laser deposition. J. Power Sources 1999, 81, 554-557. [CrossRef]

150. Tang, S.B.; Lai, M.O.; Lu, L. Electrochemical studies of low-temperature processed nano-crystalline $\mathrm{LiMn}_{2} \mathrm{O}_{4}$ thin film cathode at $55^{\circ} \mathrm{C}$. J. Power Sources 2007, 164, 372-378. [CrossRef]

151. Xie, J.; Kohno, K.; Matsumura, T.; Imanishi, N.; Hirano, A.; Takeda, Y.; Yamamoto, O. Li-ion diffusion kinetics in $\mathrm{LiMn}_{2} \mathrm{O}_{4}$ thin films prepared by pulsed laser deposition. Electrochim. Acta 2008, 54, 376-381. [CrossRef]

152. Tang, S.B.; Lai, M.O.; Lu, L. Study on $\mathrm{Li}+$-ion diffusion in nano-crystalline $\mathrm{LiMn}_{2} \mathrm{O}_{4}$ thin film cathode grown by pulsed laser deposition using CV, EIS, PITT techniques. Mater. Chem. Phys. 2008, 111, 149-153. [CrossRef]

153. Ishiyama, H.; Jeong, S.C.; Watanabe, Y.X.; Hirayama, Y.; Imai, N.; Jung, H.S.; Miyatake, H.; Oyaizu, M.; Osa, A.; Otokawa, Y.; et al. Direct measurement of nanoscale lithium diffusion in solid battery materials using radioactive tracer of ${ }^{8} \mathrm{Li}$. Nucl. Instrum. Methods Phys. Res. B 2016, 376, 379-381. [CrossRef]

154. Kuwata, N.; Nakane, M.; Miyazaki, T.; Mitsuishi, K.; Kawamura, J. Lithium diffusion coefficient in $\mathrm{LiMn}_{2} \mathrm{O}_{4}$ thin films measured by secondary ion mass spectrometry with ion-exchange method. Solid State Ion. 2018, 320, 266-271. [CrossRef]

155. Marchini, F.; Rubi, D.; del Pozo, M.; Federcio, W.J.; Calvo, E.J. Surface chemistry and lithium-ion exchange in $\mathrm{LiMn}_{2} \mathrm{O}_{4}$ for the electrochemical selective extraction of $\mathrm{LiCl}$ from natural salt lake brines. J. Phys. Chem. C 2016, 120, 15875-15883. [CrossRef] 
156. Matsumura, T.; Imanishi, N.; Hirano, A.; Sonoyama, N.; Takeda, Y. Electrochemical performances for preferred oriented PLD thin-film electrodes of $\mathrm{LiNi}_{0.8} \mathrm{Co}_{0.2} \mathrm{O}_{2}, \mathrm{LiFePO}_{4}$ and $\mathrm{LiMn}_{2} \mathrm{O}_{4}$. Solid State Ion. 2008, 179, 2011-2015. [CrossRef]

157. Tang, S.B.; Lai, M.O.; Lu, L. Properties of nano-crystalline $\mathrm{LiMn}_{2} \mathrm{O}_{4}$ thin films deposited by pulsed laser deposition. Electrochim. Acta 2006, 52, 1161-1168. [CrossRef]

158. Hirayama, M.; Sonoyama, N.; Ito, M.; Minoura, M.; Mori, D.; Yamada, A.; Tamura, K.; Mizuki, J.; Kanno, R. Characterization of electrode electrolyte interface with X-ray reflectometry and epitaxial-film $\mathrm{LiMn}_{2} \mathrm{O}_{4}$ electrode. J. Electrochem. Soc. 2007, 154, A1065-A1072. [CrossRef]

159. Shin, D.W.; Choi, J.W.; Ahn, J.P.; Choi, W.K.; Cho, Y.S.; Yoon, S.J. $\mathrm{ZrO}_{2}$-modified $\mathrm{LiMn}_{2} \mathrm{O}_{4}$ thin-film cathodes prepared by pulsed laser deposition. J. Electrochem. Soc. 2010, 157, A567-A570. [CrossRef]

160. Fehse, M.; Trocoli, R.; Hernandez, E.; Ventosa, E.; Sepulveda, A.; Morata, A.; Tarancon, A. An innovative multi-layer pulsed laser deposition approach for $\mathrm{LiMn}_{2} \mathrm{O}_{4}$ thin film cathodes. Thin Solid Films 2018, 648, 108-112. [CrossRef]

161. Kim, S.; Hirayama, M.; Suzuki, K.; Kanno, R. Hetero-epitaxial growth of $\mathrm{Li}_{0.17} \mathrm{La}_{0.61} \mathrm{TiO}_{3}$ solid electrolyte on $\mathrm{LiMn}_{2} \mathrm{O}_{4}$ electrode for all solid-state batteries. Solid State Ion. 2014, 262, 578-581. [CrossRef]

162. Suzuki, K.; Kim, K.; Taminato, S.; Hirayama, M.; Kanno, R. Fabrication and electrochemical properties of $\mathrm{LiMn}_{2} \mathrm{O}_{4} / \mathrm{SrRuO}_{3}$ multi-layer epitaxial thin film electrodes. J. Power Sources 2013, 226, 340-345. [CrossRef]

163. Yim, H.; Shin, D.W.; Choi, J.W. LiMn ${ }_{2} \mathrm{O}_{4}$-based cathode thin films for Li thin-film batteries. J. Korean Phys. Soc. 2016, 68, 41-53. [CrossRef]

164. Fehse, M.; Trocoli, R.; Hernandez, E.; Ventosa, E.; Hernandez, E.; Sepulveda, A.; Morata, A.; Tarancon, A. Ultrafast dischargeable $\mathrm{LiMn}_{2} \mathrm{O}_{4}$ thin-film electrodes with pseudocapacitive properties for microbatteries. ACS Appl. Mater. Interfaces 2017, 9, 5295-5301. [CrossRef] [PubMed]

165. Striebel, K.A.; Rougier, A.; Horne, C.R.; Reade, R.P.; Cairns, E.J. Electrochemical studies of substituted spinel thin films. J. Electrochem. Soc. 1999, 146, 4339-4347. [CrossRef]

166. Xia, H.; Tang, S.B.; Lu, L.; Meng, Y.S.; Ceder, G. The influence of preparation conditions on electrochemical properties of $\mathrm{LiNi}_{0.5} \mathrm{Mn}_{1.5} \mathrm{O}_{4}$ thin film electrodes by PLD. Electrochim. Acta 2007, 52, 1120-1126. [CrossRef]

167. Xia, H.; Meng, Y.S.; Lu, L.; Ceder, G. Electrochemical properties of nonstoichiometric $\operatorname{LiNi}_{0.5} \mathrm{Mn}_{1.5} \mathrm{O}_{4-\delta}$ thin-film electrodes prepared by pulsed laser deposition. J. Electrochem. Soc. 2007, 154, A737-A743. [CrossRef]

168. Xia, H.; Lu, L. Li diffusion in spinel $\mathrm{LiNi}_{0.5} \mathrm{Mn}_{1.5} \mathrm{O}_{4}$ thin films prepared by pulsed laser deposition. Phys. Scr. 2007, 2007, 43-48. [CrossRef]

169. Konishi, H.; Suzuki, K.; Taminato, S.; Kim, K.; Kim, S.; Lim, J.; Hirayama, M.; Kanno, R. Structure and electrochemical properties of $\mathrm{LiNi}_{0.5} \mathrm{Mn}_{1.5} \mathrm{O}_{4}$ epitaxial thin film electrodes. J. Power Sources 2014, 246, 365-370. [CrossRef]

170. Liu, D.; Zhu, W.; Trottier, J.; Gagnon, C.; Barray, F.; Gariépy, V.; Guerfi, A.; Mauger, A.; Groult, H.; Julien, C.M.; et al. Spinel materials for high-voltage cathodes in Li-ion batteries. RSC Adv. 2014, 4, 154-167. [CrossRef]

171. Kuwata, N.; Kudo, S.; Matsuda, Y.; Kawamura, J. Fabrication of thin-film lithium batteries with 5-V-class $\mathrm{LiCoMnO}_{4}$ cathodes. Solid State Ion. 2014, 262, 165-169. [CrossRef]

172. Lim, J.; Lee, S.; Suzuki, K.; Kim, K.; Kim, S.; Taminato, S.; Hirayama, M.; Oshima, Y.; Takayanagi, K.; Kanno, R. Synthesis, structure and electrochemical properties of novel $\mathrm{Li}-\mathrm{Co}-\mathrm{Mn}-\mathrm{O}$ epitaxial thin-film electrode using layer-by-layer deposition process. J. Power Sources 2015, 279, 502-509. [CrossRef]

173. Yang, D. Pulsed laser deposition of manganese oxide thin films for supercapacitor applications. J. Power Sources 2011, 196, 8843-8849. [CrossRef]

174. Xia, H.; Lai, M.O.; Lu, L. Nanoporous $\mathrm{MnO}_{\mathrm{x}}$ thin-film electrodes synthesized by electrochemical lithiation/delithiation for supercapacitors. J. Power Sources 2011, 196, 2398-2402. [CrossRef]

175. Yang, D. Pulsed laser deposition of cobalt-doped manganese oxide thin films for supercapacitor applications. J. Power Sources 2012, 198, 416-422. [CrossRef]

176. Yang, D. Pulsed laser deposition of vanadium-doped manganese oxide thin films for supercapacitor applications. J. Power Sources 2013, 228, 89-96. [CrossRef]

177. Lu, Z.G.; Cheng, H.; Lo, M.F.; Chung, C.Y. Pulsed laser deposition and electrochemical characterization of $\mathrm{LiFePO}_{4}-\mathrm{Ag}$ composite thin films. Adv. Funct. Mater. 2007, 17, 3885-3896. [CrossRef]

178. Lu, Z.G.; Lo, M.F.; Chung, C.Y. Pulse laser deposition and electrochemical characterization of $\mathrm{LiFePO}_{4}-\mathrm{C}$ composite thin films. J. Phys. Chem. C 2008, 112, 7069-7078. [CrossRef] 
179. Tang, K.; Yu, X.; Sun, J.; Li, H.; Huang, X. Kinetic analysis on $\mathrm{LiFePO}_{4}$ thin films by CV, GITT, and EIS. Electrochim. Acta 2011, 56, 4869-4875. [CrossRef]

180. Iriyama, Y.; Yokoyama, M.; Yada, C.; Jeong, S.K.; Yamada, I.; Abe, T.; Inaba, M.; Ogumi, Z. Preparation of $\mathrm{LiFePO}_{4}$ thin films by pulsed laser deposition and their electrochemical properties. Electrochem. Solid State Lett. 2004, 7, A340-A342. [CrossRef]

181. Yada, C.; Iriyama, Y.; Jeong, S.K.; Abe, T.; Inaba, M.; Ogumi, Z. Electrochemical properties of $\mathrm{LiFePO}_{4} \mathrm{thin}$ films prepared by pulsed laser deposition. J. Power Sources 2005, 146, 559-564. [CrossRef]

182. Song, S.W.; Reade, R.P.; Kostecki, R.; Striebel, K.A. Electrochemical studies of the $\mathrm{LiFePO}_{4}$ thin films prepared with pulsed laser deposition. J. Electrochem. Soc. 2006, 153, A12-A19. [CrossRef]

183. Sun, J.; Tang, K.; Yu, X.; Li, H.; Huang, X. Needle-like $\mathrm{LiFePO}_{4}$ thin films prepared by an off-axis pulsed laser deposition technique. Thin Solid Films 2009, 517, 2618-2622. [CrossRef]

184. Palomares, V.; Ruiz de Larramendi, I.; Alonso, J.; Bengoechea, M.; Goñi, A.; Miguel, O.; Rojo, T. LiFePO 4 thin films grown by pulsed laser deposition: Effect of the substrate on the film structure and morphology. Appl. Surf. Sci. 2010, 256, 2563-2568. [CrossRef]

185. Tang, K.; Sun, J.; Yu, X.; Li, H.; Huang, X. Electrochemical performance of $\mathrm{LiFePO}_{4}$ thin films with different morphology and crystallinity. Electrochim. Acta 2009, 54, 6565-6569. [CrossRef]

186. Xue, M.Z.; Fu, Z.W. Electrochemical properties of $\mathrm{LiFePO}_{4}$ cathode thin film fabricated by pulsed laser deposition. Acta Phys. Chem. Sin. 2005, 21, 707-710.

187. Sauvage, F.; Baudrin, E.; Morcrette, M.; Tarascon, J.M. Pulsed laser deposition and electrochemical properties of $\mathrm{LiFePO}_{4}$ thin films. Electrochem. Solid-State Lett. 2004, 7, A15-A18. [CrossRef]

188. Sauvage, F.; Baudrin, E.; Gengembre, L.; Tarascon, J.M. Effect of texture on the electrochemical properties of $\mathrm{LiFePO}_{4}$ thin films. Solid State Ion. 2005, 176, 1869-1876. [CrossRef]

189. Sauvage, F.; Baudrin, E.; Laffont, L.; Tarascon, J.M. Origin of electrochemical reactivity enhancement of post-annealed $\mathrm{LiFePO}_{4}$ thin films: Preparation of heterosite-type $\mathrm{FePO}_{4}$. Solid State Ion. 2007, 178, 145-152. [CrossRef]

190. Sauvage, F.; Laffont, L.; Tarascon, J.M.; Baudrin, E. Factors affecting the electrochemical reactivity vs. lithium of carbon-free $\mathrm{LiFePO}_{4}$ thin films. J. Power Sources 2008, 175, 495-501. [CrossRef]

191. Raveendran, N.R.; Kumary, T.G.; Rajkumari, S.; Pandian, R.; Janaki, J.; Mani, A. Synthesis and study of FeSe thin films and $\mathrm{LiFeO}_{2} / \mathrm{FeSe}$ bi-layers. AIP Conf. Proc. 2017, 1832, 130034.

192. Mauger, A.; Julien, C.M. $\mathrm{V}_{2} \mathrm{O}_{5}$ thin films for energy storage and conversion. AIMS Mater. Sci. 2018, 5, 349-401. [CrossRef]

193. McGraw, J.; Perkins, J.; Zhang, J.G.; Liu, P.; Parilla, P.; Turner, J.A.; Schulz, D.L.; Curtis, C.J.; Ginley, D.S. Next generation $\mathrm{V}_{2} \mathrm{O}_{5}$ cathode materials for Li rechargeable batteries. Solid State Ion. 1998, 113, 407-413. [CrossRef]

194. Julien, C.; Haro-Poniatowski, E.; Camacho-Lopez, M.A.; Escobar-Alarcon, L.; Jimenez-Jarquin, J. Applications of $\mathrm{V}_{2} \mathrm{O}_{5}$ thin films obtained by pulsed laser deposition in solid state batteries. Bull. Am. Phys. Soc. 1999, 44, 1274.

195. Julien, C.; Haro-Poniatowski, E.; Camacho-Lopez, M.A.; Escobar-Alarcon, L.; Jimenez-Jarquin, J. Growth of $\mathrm{V}_{2} \mathrm{O}_{5}$ thin films by pulsed laser deposition and their applications in lithium microbatteries. Mater. Sci. Eng. B 1999, 65, 170-176. [CrossRef]

196. Ramana, C.V.; Smith, R.J.; Hussain, O.M.; Julien, C. On the growth mechanism of pulsed-laser deposited vanadium oxide thin films. Mater. Sci. Eng. B 2004, 111, 218-225. [CrossRef]

197. McGraw, J.; Perkins, J.; Zhang, J.G.; Parilla, P.; Ciszek, T.F.; Fu, M.L.; Trickett, D.M.; Turner, J.A.; Ginley, D. Structural phase transformations in $\mathrm{V}_{2} \mathrm{O}_{5}$ thin-film cathode material for rechargeable batteries. Mater. Res. Soc. Symp. Proc. 1998, 496, 373-378. [CrossRef]

198. McGraw, J.; Bahn, C.; Parilla, P.; Perkins, J.; Readey, D.; Ginley, D. Li ion diffusion measurements in crystalline and amorphous $\mathrm{V}_{2} \mathrm{O}_{5}$ thin-film battery cathodes. Mater. Res. Soc. Symp. Proc. 1999, 575, 103-108. [CrossRef]

199. McGraw, J.M.; Perkins, J.D.; Hasoon, F.; Parilla, P.A.; Warmsingh, C.; Ginley, D.S. Pulsed laser deposition of oriented $\mathrm{V}_{2} \mathrm{O}_{5}$ thin films. J. Mater. Res. 2000, 15, 2249-2265. [CrossRef]

200. Zhang, J.G.; McGraw, J.M.; Turner, J.; Ginley, D. Charging capacity and cycling stability of $\mathrm{VO}_{x}$ films prepared by pulsed laser deposition. J. Electrochem. Soc. 1997, 144, 1630-1634. [CrossRef]

201. Madhuri, K.V.; Rao, K.S.; Naidu, B.S.; Hussain, O.M.; Pinto, R. Characterization of laser-ablated $\mathrm{V}_{2} \mathrm{O}_{5}$ thin films. J. Mater. Sci. Mater. Electron. 2002, 13, 425-432. [CrossRef] 
202. Iida, Y.; Kaneko, Y.; Kanno, Y. Fabrication of pulsed-laser deposited $\mathrm{V}_{2} \mathrm{O}_{5}$ thin films for electrochromic devices. J. Mater. Process. Technol. 2008, 197, 261-267. [CrossRef]

203. Ramana, C.V.; Hussain, O.M.; Pinto, R.; Julien, C.M. Microstructure features of pulsed-laser deposited $\mathrm{V}_{2} \mathrm{O}_{5}$ thin films. Appl. Surf. Sci. 2003, 207, 135-138. [CrossRef]

204. Ramana, C.V.; Smith, R.J.; Hussain, O.M.; Julien, C.M. Growth and surface characterization of $\mathrm{V}_{2} \mathrm{O}_{5}$ thin films made by pulsed laser deposition. J. Vac. Sci. Technol. A 2004, 22, 2453-2458. [CrossRef]

205. Ramana, C.V.; Smith, R.J.; Hussain, O.M.; Chusuei, C.C.; Julien, C.M. Correlation between growth conditions, microstructure and optical properties in pulsed-laser-deposited $\mathrm{V}_{2} \mathrm{O}_{5}$ thin films. Chem. Mater. 2005, 17, 1213-1219. [CrossRef]

206. Iida, Y.; Kanno, Y. Doping effect of $M(M=\mathrm{Nb}, \mathrm{Ce}, \mathrm{Nd}, \mathrm{Dy}, \mathrm{Sm}, \mathrm{Ag}$, and/or $\mathrm{Na})$ on the growth of pulsed-laser deposited $\mathrm{V}_{2} \mathrm{O}_{5}$ thin films. J. Mater. Process. Technol. 2009, 209, 2421-2427. [CrossRef]

207. Beke, S.; Giorgio, S.; Korosi, L.; Nanai, L.; Marine, W. Structural and optical properties of pulsed laser deposited $\mathrm{V}_{2} \mathrm{O}_{5}$ thin films. Thin Solid Films 2008, 516, 4659-4664. [CrossRef]

208. Bowman, R.M.; Gregg, J.M. $\mathrm{VO}_{2}$ thin films: Growth and the effect of applied strain on their resistance. J. Mater. Sci-Mater. Electron. 1998, 9, 187-191. [CrossRef]

209. Deng, Y.; Pelton, A.; Mayanovic, R. Comparison of vanadium oxide thin films prepared using femtosecond and nanosecond pulsed laser deposition. MRS Adv. 2016, 1, 2737-2742. [CrossRef]

210. Ramana, C.V.; Hussain, O.M.; Pinto, R.; Julien, C.M. Surface and material properties of nanostructured vanadium oxide films made by pulsed-laser ablation. In Proceedings of the 203rd ECS Meeting, Paris, France, 27 April-2 May 2003.

211. Ramana, C.V.; Smith, R.J.; Hussain, O.M.; Massot, M.; Julien, C.M. Surface analysis of pulsed-laser-deposited $\mathrm{V}_{2} \mathrm{O}_{5}$ films and their lithium intercalated products studied by Raman spectroscopy. Surf. Interface Anal. 2005, 37, 406-411. [CrossRef]

212. Iida, Y.; Takashima, H.; Kanno, Y. Optical and electrical properties of $\mathrm{V}_{2} \mathrm{O}_{5}$ thin films fabricated by pulsed laser deposition. Jpn. J. Appl. Phys. 2008, 47, 633-636. [CrossRef]

213. Shibuya, K.; Sawa, A. Optimization of conditions for growth of vanadium dioxide thin films on silicon by pulsed-laser deposition. AIP Adv. 2015, 5, 107118. [CrossRef]

214. Fang, G.J.; Liu, Z.L.; Wang, Y.Q.; Liu, H.H.; Yao, K.L. Orientated growth of $\mathrm{V}_{2} \mathrm{O}_{5}$ electrochromic thin films on transparent conductive glass by pulsed excimer laser ablation technique. J. Phys. D Appl. Phys. 2000, 33, 3018-3021. [CrossRef]

215. Fang, G.J.; Yao, K.L.; Liu, Z.L. Fabrication and electrochromic properties of double layer $\mathrm{WO}_{3}(\mathrm{~V}) / \mathrm{V}_{2} \mathrm{O}_{5}(\mathrm{Ti})$ thin films prepared by pulsed laser ablation technique. Thin Solid Films 2001, 394, 64-71. [CrossRef]

216. Fang, G.J.; Liu, Z.L.; Wang, Y.; Liu, Y.H.; Yao, K.L. Synthesis and structural, electrochromic characterization of pulsed laser deposited vanadium oxide thin films. J. Vac. Sci. Technol. A 2001, 19, 887-892. [CrossRef]

217. Rougier, A.; Blyr, A. Electrochromic properties of vanadium tungsten oxide thin films grown by pulsed laser deposition. Electrochim. Acta 2001, 46, 1945-1950. [CrossRef]

218. Huotari, J.; Lappalainen, J.; Eriksson, J.; Bjorklund, R.; Heinonen, E.; Miinalainen, I.; Puustinen, J.; Spetz, A.L. Synthesis of nanostructured solid-state phases of $\mathrm{V}_{7} \mathrm{O}_{16}$ and $\mathrm{V}_{2} \mathrm{O}_{5}$ compounds for ppb-level detection of ammonia. J. Alloy. Compd. 2016, 675, 433-440. [CrossRef]

219. Huotari, J.; Bjorklund, R.; Lappalainen, J.; Lloyd Spetz, A. Nanostructured mixed phase vanadium oxide thin films as highly sensitive ammonia sensor material. Procedia Eng. 2014, 87, 1035-1038. [CrossRef]

220. Ramana, C.V.; Julien, C.M. Electrochemical performance of pulsed-laser deposited $\mathrm{V}_{2} \mathrm{O}_{5}$ films. In ESC Meeting Abstracts; The Electrochemical Society: Pennington, NJ, USA, 2006; Volume 210, p. 221.

221. Julien, C. Technology of microbatteries and its applications. In Trends in Materials Science; Radhakrishna, S., Ed.; Narosa: New Delhi, India, 1997; pp. 24-43.

222. Zhao, S.L.; Wen, J.B.; Zhu, Y.M.; Qin, Q.Z. Fabrication and electrochemical properties of all solid state $0.3 \mathrm{Ag}_{0} \mathrm{~V}_{2} \mathrm{O}_{5} / \mathrm{Lipon} / \mathrm{Li}$ thin film battery. J. Funct. Mater. 2008, 39, 91-94.

223. Petnikota, S.; Chua, R.; Zhou, Y.; Edison, E.; Srinivasan, M. Amorphous vanadium oxide thin films as stable performing cathodes of lithium and sodium-ion batteries. Nanoscale Res. Lett. 2018, 13, 363. [CrossRef] [PubMed]

224. West, K.; Zachau-Christiansen, B.; Jacobsen, T.; Atlung, S. $\mathrm{V}_{6} \mathrm{O}_{13}$ as cathode material for lithium cells. J. Power Sources 1985, 14, 235-245. [CrossRef] 
225. Makimura, Y.; Rougier, A.; Tarascon, J.M. Pulsed laser deposited iron fluoride thin films for lithium-ion batteries. Appl. Surf. Sci. 2006, 252, 4587-4592. [CrossRef]

226. Makimura, Y.; Rougier, A.; Laffont, L.; Womes, M.; Jumas, J.C.; Leriche, J.B.; Tarascon, J.M. Electrochemical behaviour of low temperature grown iron fluoride thin films. Electrochem. Commun. 2006, 8, 1769-1774. [CrossRef]

227. Santos-Ortiz, R.; Volkov, V.; Schmid, S.; Kuo, F.L.; Kisslinger, K.; Nag, S.; Banerjee, R.; Zhu, Y.; Shepherd, N.D. Microstructure and electronic band structure of pulsed laser deposited iron fluoride thin film for battery electrodes. ACS Appl. Mater. Interfaces 2013, 5, 2387-2391. [CrossRef] [PubMed]

228. Al-Khateeb, S.; Lind, A.G.; Santos-Ortiz, R.; Shepherd, N.D.; Jones, K.S. Cycling performance and morphological evolution of pulsed laser-deposited $\mathrm{FeF}_{2}$ thin film cathodes for Li-ion batteries. J. Mater. Sci. 2015, 50, 5174-5182. [CrossRef]

229. Julien, C.M.; Mauger, A.; Vijh, A.; Zaghib, K. Lithium Batteries: Science and Technology; Springer: Cham, Switzerland, 2016.

230. Haro-Poniatowski, E.; Jouanne, M.; Morhange, J.F.; Julien, C.; Diamant, R.; Fernandez-Guasti, M.; Fuentes, G.A.; Alonso, J.C. Micro-Raman characterization of $\mathrm{WO}_{3}$ and $\mathrm{MoO}_{3}$ thin films obtained by pulsed laser irradiation. Appl. Surf. Sci. 1998, 127, 674-678. [CrossRef]

231. Ramana, C.V.; Hussain, O.M.; Julien, C.M. Effect of growth temperature on the optical properties of pulsed-laser deposited $\mathrm{MoO}_{3}$ thin films. Mater. Sci. Indian J. 2005, 1, 10-15.

232. Ramana, C.V.; Hussain, O.M.; Julien, C.M. Electronic properties of $\mathrm{MoO}_{3}$ thin films grown by PLD and ARE techniques and their performance upon lithium intercalation. In Proceedings of the Extended Abstract of the 208th ECS Meeting, Los Angeles, CA, USA, 16-21 October 2005; p. 885.

233. Al-Kuhaili, M.; Durrani, S.; Bakhtiari, I. Pulsed laser deposition of molybdenum oxide thin films. Appl. Phys. A Mater. Sci. Process. 2010, 98, 609-615. [CrossRef]

234. Ramana, C.V.; Julien, C.M. Chemical and electrochemical properties of molybdenum oxide thin films prepared by reactive pulsed-laser assisted deposition. Chem. Phys. Lett. 2006, 428, 114-118. [CrossRef]

235. Ramana, C.V.; Atuchin, V.V.; Pokrovsky, L.D.; Beker, U.; Julien, C.M. Structure and chemical properties of molybdenum oxide thin films. J. Vac. Sci. Technol. A 2007, 25, 1166-1171. [CrossRef]

236. Ramana, C.V.; Hussain, O.M.; Julien, C.M. Electronic properties and performance upon lithium intercalation of $\mathrm{MoO}_{3}$ thin films grown by PLD. ECS Trans. 2006, 1, 1-7.

237. Puppala, H.K.; Pelton, A.T.; Mayanovic, R.A. A comparative characterization study of molybdenum oxide thin films grown using femtosecond and nanosecond pulsed laser deposition. Mater. Res. Soc. Adv. 2016, 1, 2585-2590. [CrossRef]

238. Sunu, S.S.; Prabhu, E.; Jayaraman, V.; Gnanasekar, K.I.; Gnanasekaran, T. Gas sensing properties of PLD made $\mathrm{MoO}_{3}$ films. Sens. Actuators B Chem. 2003, 94, 189-196. [CrossRef]

239. Ashrafi, M.A.; Ranjbar, M.; Kalhori, H.; Salamati, H. Pulsed laser deposition of Mo-V-O thin films for chromogenic applications. Thin Solid Films 2017, 621, 220-228. [CrossRef]

240. Chang, C.C.; Luo, J.Y.; Chen, T.K.; Yeh, K.W.; Huang, T.W.; Hsu, C.H.; Chao, W.H.; Ke, C.T.; Hsu, P.C.; Wang, M.J.; et al. Pulsed laser deposition of $\left(\mathrm{MoO}_{3}\right)_{1-x}\left(\mathrm{~V}_{2} \mathrm{O}_{5}\right)_{x}$ thin films: Preparation, characterization and gasochromic studies. Thin Solid Films 2010, 519, 1552-1557. [CrossRef]

241. Rougier, A.; Portemer, F.; Quédé, A.; El Marssi, M. Characterization of pulsed laser deposited $\mathrm{WO}_{3}$ thin films for electrochromic devices. Appl. Surf. Sci. 1999, 153, 1-9. [CrossRef]

242. Qiu, H.; Lu, Y.F. Studies of pulsed laser deposition mechanism of $\mathrm{WO}_{3}$ thin films. Jpn. J. Appl. Phys. 2001, 40, 183-187. [CrossRef]

243. Ramana, C.V.; Utsunomiya, S.; Ewing, R.C.; Julien, C.M.; Becker, U. Electron microscopy investigation of structural transformations in tungsten oxide $\left(\mathrm{WO}_{3}\right)$ thin films. Phys. Status Solidi A 2005, 202, R108-R110. [CrossRef]

244. Ramana, C.V.; Utsunomiya, S.; Ewing, R.C.; Julien, C.M.; Becker, U. Structural stability and phase transitions in $\mathrm{WO}_{3}$ thin films. J. Phys. Chem. B 2006, 110, 10430-10435. [CrossRef] [PubMed]

245. Mitsugi, F.; Hiraiwa, E.; Ikegami, T.; Ebihara, K.; Thareja, R.K. $\mathrm{WO}_{3}$ thin films prepared by pulsed laser deposition. Jpn. J. Appl. Phys. 2002, 41, 5372-5375. [CrossRef]

246. Hussain, O.M.; Swapnasmitha, A.S.; John, J.; Pinto, R. Structure and morphology of laser-ablated $\mathrm{WO}_{3}$ thin films. Appl. Phys. A 2005, 81, 1291-1297. [CrossRef] 
247. Suda, Y.; Kawasaki, H.; Ohshima, T.; Yagyu, Y. Characteristics of tungsten oxide thin films prepared on the flexible substrates using pulsed laser deposition. Thin Solid Films 2008, 516, 4397-4401. [CrossRef]

248. Fang, G.J.; Liu, Z.L.; Sun, G.C.; Yao, K.L. Preparation and electrochromic properties of nanocrystalline $\mathrm{WO}_{3}$ thin films prepared by pulsed excimer laser ablation technique. Phys. Status Solidi A 2001, 184, 129-137. [CrossRef]

249. György, E.; Socol, G.; Mihailescu, I.N.; Ducu, C.; Ciuca, S. Structural and optical characterization of $\mathrm{WO}_{3}$ thin films for gas sensor applications. J. Appl. Phys. 2005, 97, 093527. [CrossRef]

250. Caruana, A.J.; Cropper, M.D. Orientationally textured thin films of $\mathrm{WO}_{x}$ deposited by pulsed laser deposition. Mater. Res. Express 2014, 1, 046408. [CrossRef]

251. Impey, S.A.; Garcia-Miguel, J.L.; Allen, S.; Blyr, A.; Boessay, I.; Rougier, A. Colour neutrality for thin oxide films from pulsed laser deposition and sol-gel. Electrochem. Soc. Proc. 2003, 2003-17, 103-118.

252. Boyadjiev, S.I.; Stefan, N.; Szilágyi, I.M.; Mihailescu, N.; Visan, A.; Mihailescu, I.N.; Stan, G.E.; Besleaga, C.; Iliev, M.T.; Gesheva, K.A. Characterization of MAPLE deposited $\mathrm{WO}_{3}$ thin films for electrochromic applications. J. Phys. Conf. Ser. 2017, 780, 012013. [CrossRef]

253. Kawasaki, H.; Ueda, T.; Suda, T.; Ohshima, T. Properties of metal doped tungsten oxide thin films for $\mathrm{NO}_{x}$ gas sensors grown by PLD method combined with sputtering process. Sens. Actuators B 2004, 100, 266-269. [CrossRef]

254. Leidinger, M.; Huotari, J.; Sauerwald, T.; Lappalainen, J.; Schütze, A. Selective detection of naphthalene with nanostructured $\mathrm{WO}_{3}$ gas sensors prepared by pulsed laser deposition. J. Sens. Sens. Syst. 2016, 5, 147-156. [CrossRef]

255. Boyadjiev, S.I.; Georgieva, V.; Stefan, N.; Stan, G.E.; Mihailescu, N.; Visan, A.; Mihailescu, I.N.; Besleag, C.; Szilágyi, I.M. Characterization of PLD grown $\mathrm{WO}_{3}$ thin films for gas sensing. Appl. Surf. Sci. 2017, 417, 218-223. [CrossRef]

256. Xia, H.; Wang, H.L.; Xiao, W.; Lai, M.O.; Li, L. Thin film Li electrolytes for all-solid-state micro-batteries. Int. J. Surf. Sci. Eng. 2009, 3, 23-43. [CrossRef]

257. Ren, Y.; Kai Chen, K.; Chen, R.; Liu, T.; Zhang, Y.; Nan, C.W. Oxide electrolytes for lithium batteries. J. Am. Ceram. Soc. 2015, 98, 3603-3623. [CrossRef]

258. Cao, C.; Li, Z.B.; Wang, X.L.; Zhao, X.B.; Han, W.Q. Recent advances in inorganic solid electrolytes for lithium batteries. Front. Energy Res. 2014, 2, 25. [CrossRef]

259. Zhao, S.L.; Fu, Z.W.; Qin, Q.Z. A solid-state electrolyte lithium phosphorous oxynitride film prepared by pulsed laser deposition. Thin Solid Films 2002, 415, 108-113. [CrossRef]

260. Ohta, N.; Takada, K.; Osada, M.; Zhang, L.Q.; Sasaki, T.; Watanabe, M. Solid electrolyte, thio-LiSICON, thin film prepared by pulsed laser deposition. J. Power Sources 2005, 146, 707-710. [CrossRef]

261. Ahn, J.K.; Yoon, S.G. Characteristics of amorphous lithium lanthanum titanate electrolyte thin films grown by PLD for use in rechargeable lithium microbatteries. Electrochem. Solid-State Lett. 2005, 8, A75-A78. [CrossRef]

262. Furusawa, S.I.; Kamiyama, A.; Tsurui, T. Fabrication and ionic conductivity of amorphous lithium meta-silicate thin film. Solid State Ion. 2008, 179, 536-542. [CrossRef]

263. Furusawa, S.I.; Shimizu, S.; Sekine, K.; Tabuchi, H. Preparation and ionic conductivity of $\beta$-LiAlSiO 4 thin film. Solid State Ion. 2004, 167, 325-329.

264. Reinacher, J.; Berendts, S.; Janek, J. Preparation and electrical properties of garnet-type $\mathrm{Li}_{6} \mathrm{BaLa}_{2} \mathrm{Ta}_{2} \mathrm{O}_{12}$ lithium solid electrolyte thin films prepared by pulsed laser deposition. Solid State Ion. 2014, 258, 1-7. [CrossRef]

265. Yu, X.-H.; Bates, J.B.; Jellison, G.E.; Hart, F.X. A stable thin-film lithium electrolyte: Lithium phosphorus oxynitride. J. Electrochem. Soc. 1997, 144, 524-532. [CrossRef]

266. Zhao, S.L.; Wen, J.B.; Fan, L.M.; Qin, Q.Z. preparation of thin film battery by pulse laser deposition. J. Funct. Mater. 2006, 37, 172-177.

267. West, W.C.; Hood, Z.D.; Adhikari, S.P.; Liang, C.; Lachgar, A.; Motoyama, M.; Iriyama, Y. Reduction of charge-transfer resistance at the solid electrolyte-electrode interface by pulsed laser deposition of films from a crystalline $\mathrm{Li}_{2} \mathrm{PO}_{2} \mathrm{~N}$ source. J. Power Sources 2016, 312, 116-122. [CrossRef]

268. Morcrette, M.; Llorente, A.G.; Laurent, A.; Perrière, J.; Barboux, P.; Boilot, J.P.; Raymond, O.; Brousse, T. Growth by laser ablation of Ti-based oxide films with different valency states. Appl. Phys. A 1998, 67, 425-428. [CrossRef]

269. Ahn, J.K.; Yoon, S.G. Characteristics of perovskite $\left(\mathrm{Li}_{0.5} \mathrm{La}_{0.5}\right) \mathrm{TiO}_{3}$ solid electrolyte thin films grown by pulsed laser deposition for rechargeable lithium microbattery. Electrochim. Acta 2004, 50, 371-374. [CrossRef] 
270. Furusawa, S.; Tabuchi, H.; Sugiyama, T.; Tao, S.; Irvine, J.T.S. Ionic conductivity of amorphous lithium lanthanum titanate thin film. Solid State Ion. 2005, 176, 553-558. [CrossRef]

271. Maqueda, O.; Sauvage, F.; Laffont, L.; Martinez-Sarrion, M.L.; Mestres, L.; Baudrin, E. Structural, microstructural and transport properties study of lanthanum lithium titanium perovskite thin films grown by pulsed laser deposition. Thin Solid Films 2008, 516, 1651-1655. [CrossRef]

272. Ohnishi, T.; Takada, K. Synthesis and orientation control of Li-ion conducting epitaxial $\mathrm{Li}_{0.33} \mathrm{La}_{0.56} \mathrm{TiO}_{3}$ solid electrolyte thin films by pulsed laser deposition. Solid State Ion. 2012, 228, 80-82. [CrossRef]

273. Aguesse, F.; Roddatis, V.; Roqueta, J.; García, P.; Pergolesi, D.; Santiso, J.; Kilner, J.A. Microstructure and ionic conductivity of LLTO thin films: Influence of different substrates and excess lithium in the target. Solid State Ion. 2015, 272, 1-8. [CrossRef]

274. Lee, J.L.; Wang, Z.; Xin, H.L.; Wynn, T.A.; Meng, Y.S. Amorphous lithium lanthanum titanate for solid-state microbatteries. J. Electrochem. Soc. 2017, 164, A6268-A6273. [CrossRef]

275. Thangadurai, V.; Kaack, H.; Weppner, W. Novel fast lithium ion conduction in garnet-type $\mathrm{Li}_{5} \mathrm{La}_{3} \mathrm{M}_{2} \mathrm{O}_{12}$ $(M=\mathrm{Nb}, \mathrm{Ta}) . J$. Am. Ceram. Soc. 2003, 86, 437-440. [CrossRef]

276. Saccoccio, M.; Yu, J.; Lu, Z.; Kwok, S.C.T.; Wang, J.; Yeung, K.K.; Yuen, M.M.F.; Ciucci, F. Low temperature pulsed laser deposition of garnet $\mathrm{Li}_{6.4} \mathrm{La}_{3} \mathrm{Zr}_{1.4} \mathrm{Ta}_{0.6} \mathrm{O}_{12}$ films as all solid-state lithium battery electrolytes. J. Power Sources 2017, 365, 43-52. [CrossRef]

277. Garbayo, I.; Struzik, M.; Bowman, W.J.; Pfenninger, R.; Stilp, E.; Rupp, J.L.M. Glass-type polyamorphism in Li-garnet thin film solid state battery conductors. Adv. Energy Mater. 2018, 8, 1702265. [CrossRef]

278. Tan, J.; Tiwari, A. Fabrication and characterization of $\mathrm{Li}_{7} \mathrm{La}_{3} \mathrm{Zr}_{2} \mathrm{O}_{12}$ thin films for lithium ion battery. ECS Solid State Lett. 2012, 1, Q57-Q60. [CrossRef]

279. Park, J.S.; Cheng, L.; Zorba, V.; Mehta, A.; Cabana, J.; Chen, G.; Doeff, M.M.; Richardson, T.J.; Park, J.H.; Son, J.-W.; et al. Effects of crystallinity and impurities on the electrical conductivity of Li-La-Zr-O thin films. Thin Solid Films 2015, 576, 55-60. [CrossRef]

280. Kim, S.; Hirayama, M.; Taminato, S.; Kanno, R. Epitaxial growth and lithium ion conductivity of lithium-oxide garnet for an all solid-state battery electrolyte. Dalton Trans. 2013, 42, 13112. [CrossRef]

281. Rawlence, M.; Garbayo, I.; Buecheler, S.; Rupp, J.L.M. On the chemical stability of post-lithiated garnet Al-stabilized $\mathrm{Li}_{7} \mathrm{La}_{3} \mathrm{Zr}_{2} \mathrm{O}_{12}$ solid state electrolyte thin films. Nanoscale 2016, 8, 14746-14753. [CrossRef]

282. Kuwata, N.; Iwagami, N.; Tanji, Y.; Matsuda, Y.; Kawamura, J. Characterization of thin-film lithium batteries with stable thin-film $\mathrm{Li}_{3} \mathrm{PO}_{4}$ solid electrolytes fabricated by ArF excimer laser deposition. J. Electrochem. Soc. 2011, 157, A521-A527. [CrossRef]

283. Sakurai, Y.; Sakuda, A.; Hayashi, A.; Tatsumisago, M. Preparation of amorphous $\mathrm{Li}_{4} \mathrm{SiO}_{4}-\mathrm{Li}_{3} \mathrm{PO}_{4}$ thin films by pulsed laser deposition for all-solid-state lithium secondary batteries. Solid State Ion. 2011, 182, 59-63. [CrossRef]

284. Nakagawa, A.; Kuwata, N.; Matsuda, Y.; Kawamura, J. Characterization of stable solid electrolyte lithium silicate for thin film lithium battery. J. Phys. Soc. Jpn. A 2010, 79, 98-101. [CrossRef]

285. Furusawa, S.I.; Kasahara, T.; Kamiyama, A. Fabrication and ionic conductivity of $\mathrm{Li}_{2} \mathrm{SiO}_{3}$ thin film. Solid State Ion. 2009, 180, 649-653. [CrossRef]

286. Sakuda, A.; Hayashi, A.; Hama, S.; Tatsumisago, M. Preparation of highly lithium-ion conductive $80 \mathrm{Li}_{2} \mathrm{~S}_{2} 20 \mathrm{P}_{2} \mathrm{O}_{5}$ thin-film electrolytes using pulsed laser deposition. J. Am. Ceram. Soc. 2010, 93, 765-768. [CrossRef]

287. Quan, Z.; Hirayama, M.; Sato, D.; Zheng, Y.; Yano, T.; Hara, K.; Suzuki, K.; Hara, M.; Kanno, R. Effect of excess $\mathrm{Li}_{2} \mathrm{~S}$ on electrochemical properties of amorphous $\mathrm{Li}_{3} \mathrm{PS}_{4}$ films synthesized by pulsed laser deposition. J. Am. Ceram. Soc. 2017, 100, 746-753. [CrossRef]

288. Konishi, H.; Suzuki, K.; Taminato, S.; Kim, K.; Zheng, Y.; Kim, S.; Lim, J.; Hirayama, M.; Son, J.Y.; Cui, Y.; et al. Effect of surface $\mathrm{Li}_{3} \mathrm{PO}_{4}$ coating on $\mathrm{LiNi}_{0.5} \mathrm{Mn}_{1.5} \mathrm{O}_{4}$ epitaxial thin film electrodes synthesized by pulsed laser deposition. J. Power Sources 2014, 269, 293-298. [CrossRef]

289. Yubuchi, S.; Ito, Y.; Matsuyama, T.; Hayashi, A.; Tatsumisago, M. 5 V class $\mathrm{LiNi}_{0.5} \mathrm{Mn}_{1.5} \mathrm{O}_{4}$ positive electrode coated with $\mathrm{Li}_{3} \mathrm{PO}_{4}$ thin film for all-solid-state batteries using sulfide solid electrolyte. Solid State Ion. 2016, 285, 79-82. [CrossRef]

290. Aso, K.; Sakuda, A.; Hayashi, A.; Tatsumisago, M. All-solid-state lithium secondary batteries using NiS-carbon fiber composite electrodes coated with $\mathrm{Li}_{2} \mathrm{~S}-\mathrm{P}_{2} \mathrm{~S}_{5}$ solid electrolytes by pulsed laser deposition. ACS Appl. Mater. Interfaces 2013, 5, 686-690. [CrossRef] 
291. Ito, Y.; Sakuda, A.; Ohtomo, T.; Hayashi, A.; Tatsumisago, M. Preparation of $\mathrm{Li}_{2} \mathrm{~S}-\mathrm{GeS}_{2}$ solid electrolyte thin films using pulsed laser deposition. Solid State Ion. 2013, 236, 1-4. [CrossRef]

292. Zhang, Z.; Chou, S.; Gu, Q.; Liu, H.; Li, H.; Ozawa, K.; Wang, J. Enhancing the high rate capability and cycling stability of $\mathrm{LiMn}_{2} \mathrm{O}_{4}$ by coating of solid-state electrolyte $\mathrm{LiNbO}_{3}$. ACS Appl. Mater. Interfaces 2014, 6, 22155-22165. [CrossRef]

293. Uemura, T.; Goto, K.; Ogawa, M.; Harada, K. High-power all-solid secondary battery with high heat resistance. SEI Technol. Rev. 2013, 77, 132-136.

294. Zhao, S.; Qin, Q. Li-V-Si-O thin film electrolyte for all-solid-state Li-ion battery. J. Power Sources 2003, 122, 174-180. [CrossRef]

295. Kawamura, J.; Kuwata, N.; Toribami, K.; Sata, N.; Kamishima, O.; Hattori, T. Preparation of amorphous thin films by pulsed laser deposition. Solid State Ion. 2004, 175, 273-276. [CrossRef]

296. Glass, A.; Nassau, K.; Negran, T. Ionic Conductivity of quenched alkali niobate and tantalate glasses. J. Appl. Phys. 1978, 49, 4808-4811. [CrossRef]

297. Ohta, N.; Takada, K.; Sakaguchi, I.; Zhang, L.; Ma, R.; Fukuda, K.; Osada, M.; Sasaki, T. LiNbO 3 -coated $\mathrm{LiCoO}_{2}$ as cathode material for all solid-state lithium secondary batteries. Electrochem. Commun. 2007, 9, 1486-1490. [CrossRef]

298. Marsh, A.M.; Harkness, S.D.; Qian, F.; Singh, R.K. Pulsed laser deposition of high quality $\mathrm{LiNbO}_{3}$ films on sapphire substrates. Appl. Phys. Lett. 1993, 62, 952-954. [CrossRef]

299. Perea, A.; Gonzalo, J.; Afonso, C.N.; Vivien, C.; Leborgne, C. Fast imaging of the plume expansion produced by laser ablation of $\mathrm{LiNbO}_{3}$. Appl. Phys. A 1999, 69, S141-S144. [CrossRef]

300. Madian, M.; Eychmüller, A.; Giebeler, L. Current advances in $\mathrm{TiO}_{2}$-based nanostructure electrodes for high performance lithium ion batteries. Batteries 2018, 4, 7. [CrossRef]

301. Murugesan, S.; Kuppusami, P.; Parvathavarthini, N.; Mohandas, E. Pulsed laser deposition of anatase and rutile $\mathrm{TiO}_{2}$ thin films. Surf. Coat. Technol. 2007, 201, 7713-7719. [CrossRef]

302. Suda, Y.; Kawasaki, H.; Ueda, T.; Ohshima, T. Preparation of high-quality nitrogen doped $\mathrm{TiO}_{2}$ thin film as a photocatalyst using a pulsed laser deposition method. Thin Solid Films 2004, 453, 162-166. [CrossRef]

303. Kim, J.H.; Seonghoon Lee, S.; Im, H.S. The effect of target density and its morphology on $\mathrm{TiO}_{2}$ thin films grown on Si(100) by PLD. Appl. Surf. Sci. 1999, 151, 6-16. [CrossRef]

304. Yamamoto, S.; Sumita, T.; Sugiharuto, M.; Miyashita, A.; Naramoto, H. Preparation of epitaxial $\mathrm{TiO}_{2}$ films by pulsed laser deposition technique. Thin Solid Films 2001, 401, 88-93. [CrossRef]

305. Inoue, N.; Yuasa, $\mathrm{H} . ;$ Okoshi, M. $\mathrm{TiO}_{2}$ thin films prepared by PLD for photocatalytic applications. Appl. Surf. Sci. 2002, 197, 393-397. [CrossRef]

306. Choi, Y.; Yamamoto, S.; Umebayashi, T.; Yoshikawa, M. Fabrication and characterization of anatase $\mathrm{TiO}_{2}$ thin film on glass substrate grown by pulsed laser deposition. Solid State Ion. 2004, 172, 105-108. [CrossRef]

307. Ohzuku, T.; Ueda, A.; Yamamoto, N. Zero-strain insertion material of $\mathrm{Li}\left[\mathrm{Li}_{1 / 3} \mathrm{Ti}_{5 / 3}\right] \mathrm{O}_{4}$ for rechargeable lithium cells. J. Electrochem. Soc. 1995, 142, 1431-1435. [CrossRef]

308. Deng, J.Q.; Lu, Z.G.; Belharouak, I.; Amine, K.; Chung, C.Y. Preparation and electrochemical properties of $\mathrm{Li}_{4} \mathrm{Ti}_{5} \mathrm{O}_{12}$ thin film electrodes by pulsed laser deposition. J. Power Sources 2009, 193, 816-821. [CrossRef]

309. Yu, X.; Wang, R.; He, Y.; Hu, Y.; Li, H.; Huang, X. Electrochromic behavior of transparent $\mathrm{Li}_{4} \mathrm{Ti}_{5} \mathrm{O}_{12} / \mathrm{FTO}$ electrode. Electrochem. Solid-State Lett. 2010, 13, J99-J101. [CrossRef]

310. Hirayama, M.; Kim, K.; Toujigamori, T.; Cho, W.; Kanno, R. Epitaxial growth and electrochemical properties of $\mathrm{Li}_{4} \mathrm{Ti}_{5} \mathrm{O}_{12}$ thin-film lithium battery anodes. Dalton Trans. 2011, 40, 2882-2887. [CrossRef] [PubMed]

311. Kim, K.; Toujigamori, T.; Suzuki, K.; Taminato, S.; Tamura, K.; Mizuki, J.; Hirayama, M.; Kanno, R. Characterization of nano-sized epitaxial $\mathrm{Li}_{4} \mathrm{Ti}_{5} \mathrm{O}_{12}(110)$ film electrode for lithium batteries. Electrochemistry 2012, 80, 800-803. [CrossRef]

312. Deng, J.; Lu, Z.; Chung, C.Y.; Hanc, X.; Wang, Z.; Zhou, H. Electrochemical performance and kinetic behavior of lithium ion in $\mathrm{Li}_{4} \mathrm{Ti}_{5} \mathrm{O}_{12}$ thin film electrodes. Appl. Surf. Sci. 2014, 314, 936-941. [CrossRef]

313. Sugiyama, J.; Umegaki, I.; Uyama, T.; McFadden, R.M.L.; Shiraki, S.; Hitosugi, T.; Salman, Z.; Saadaoui, H.; Morris, G.D.; MacFarlane, W.A.; et al. Lithium diffusion in spinel $\mathrm{Li}_{4} \mathrm{Ti}_{5} \mathrm{O}_{12}$ and $\mathrm{LiTi}_{2} \mathrm{O}_{4}$ films detected with ${ }^{8} \mathrm{Li} \beta$-NMR. Phys. Rev. B 2017, 96, 094402. [CrossRef]

314. Zhao, M.; Lian, J.; Jia, Y.; Jin, K.; Xu, L.; Hu, Z.; Yang, X.; Kang, S. Investigation of the optical properties of $\mathrm{LiTi}_{2} \mathrm{O}_{4}$ and $\mathrm{Li}_{4} \mathrm{Ti}_{5} \mathrm{O}_{12}$ spinel films by spectroscopic ellipsometry. Opt. Mater. Express 2016, 6, 3366-3374. [CrossRef] 
315. Pfenninger, R.; Afyon, S.; Garbayo, I.; Struzik, M.; Rupp, J.L.M. Lithium titanate anode thin films for Li-ion solid state battery based on garnets. Adv. Funct. Mater. 2018, 28, 1800879. [CrossRef]

316. Mesoraca, S.; Kleibeuker, J.E.; Prasad, B.; MacManus-Driscoll, J.L.; Blamire, M.G. Lithium outdiffusion in $\mathrm{LiTi}_{2} \mathrm{O}_{4}$ thin films grown by pulsed laser deposition. J. Cryst. Growth 2016, 454, 134-138. [CrossRef]

317. Chopdekar, R.V.; Wong, F.J.; Takamura, Y.; Arenholz, E.; Suzuki, Y. Growth and characterization of superconducting spinel oxide $\mathrm{LiTi}_{2} \mathrm{O}_{4}$ thin films. Phys. C Supercond. 2009, 469, 1885-1891. [CrossRef]

318. Kumatani, A.; Ohsawa, T.; Shimizu, R.; Takagi, Y.; Shiraki, S.; Hitosugi, T. Growth processes of lithium titanate thin films deposited by using pulsed laser deposition. Appl. Phys. Lett. 2012, 101, 123103. [CrossRef]

319. Cunha, D.M.; Hendriks, T.A.; Vasileiadis, A.; Vos, C.M.; Verhallen, T.; Singh, D.P.; Wagemaker, M.; Huijben, M. Doubling reversible capacities in epitaxial Li4Ti5O12 thin film anodes for microbatteries. ACS Appl. Energy Mater. 2019, 2, 3410-3418. [CrossRef]

320. Tang, S.B.; Xia, H.; Lai, M.O.; Lu, L. Amorphous $\mathrm{LiNiVO}_{4}$ thin-film anode for microbatteries grown by pulsed laser deposition. J. Power Sources 2006, 159, 685-689. [CrossRef]

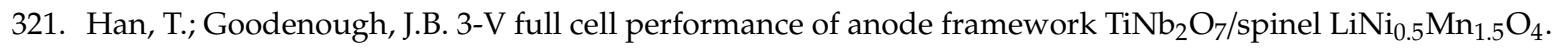
Chem. Mater. 2011, 23, 3404-3407. [CrossRef]

322. Daramalla, V.; Rao Penki, T.; Munichandraiah, N.; Krupanidhi, S.B. Fabrication of $\mathrm{TiNb}_{2} \mathrm{O}_{7}$ thin film electrodes for Li-ion micro-batteries by pulsed laser deposition. Mater. Sci. Eng. B 2016, 213, 90-97. [CrossRef]

323. Daramalla, V.; Venkatesh, G.; Kishore, B.; Munichandraiah, N.; Krupanidhi, S.B. Superior electrochemical performance of amorphous titanium niobium oxide thin films for Li-ion thin film batteries. J. Electrochem. Soc. 2018, 165, A764-A772. [CrossRef]

324. Mauger, A.; Xie, H.; Julien, C.M. Composite anodes for lithium-ion batteries: Status and trends. AIMS Mater. Sci. 2016, 3, 1054-1106. [CrossRef]

325. Chen, L.B.; Xie, J.Y.; Yu, H.C.; Wang, T.H. An amorphous thin film Si anode with high capacity and long cycling life for lithium ion batteries. J. Appl. Electrochem. 2009, 39, 1157-1162. [CrossRef]

326. Ohara, S.; Suzuki, J.; Sekine, K.; Takamura, T. A thin film silicon anode for Li-ion batteries having a very large specific capacity and long cycle life. J. Power Sources 2004, 136, 303-306. [CrossRef]

327. Song, S.W.; Sriebel, K.A.; Reade, R.P.; Roberts, G.A.; Cairns, E.J. Electrochemical studies of nanoncrystalline $\mathrm{Mg}_{2} \mathrm{Si}$ thin film electrodes prepared by pulsed laser deposition. J. Electrochem. Soc. 2003, 150, A121-A127. [CrossRef]

328. Park, M.S.; Wang, G.X.; Liu, H.K.; Dou, S.X. Electrochemical properties of Si thin film prepared by pulsed laser deposition for lithium ion micro-batteries. Electrochim. Acta 2006, 51, 5246-5249. [CrossRef]

329. Xia, H.; Tang, S.; Lu, L. Properties of amorphous Si thin film anodes prepared by pulsed laser deposition. Mater. Res. Bull. 2007, 42, 1301-1309. [CrossRef]

330. Chou, S.L.; Zhao, Y.; Wang, J.Z.; Chen, Z.X.; Liu, H.K.; Dou, S.X. Silicon/single-walled carbon nanotube composite paper as a flexible anode material for lithium ion batteries. J. Phys. Chem. C 2010, 114, 15862-15867. [CrossRef]

331. Radhakrishnan, G.; Adams, P.M.; Foran, B.; Quinzio, M.V.; Brodie, M.J. Pulsed laser deposited Si on multilayer graphene as anode material for lithium ion batteries. APL Mater. 2013, 1, 062103. [CrossRef]

332. Biserni, E.; Xie, M.; Brescia, R.; Scarpellini, A.; Hashempour, M.; Movahed, P.; George, S.M.; Bestetti, M.; Li Bassi, A.; Bruno, P. Silicon algae with carbon topping as thin-film anodes for lithium-ion microbatteries by a two-step facile method. J. Power Sources 2015, 274, 252-259. [CrossRef]

333. Garino, N.; Biserni, E.; Bassi, A.L.; Bruno, P.; Gerbaldi, C. Mesoporous Si and multi-layered Si/C films by pulsed laser deposition as Li-ion microbattery anodes. J. Electrochem. Soc. 2015, 162, A1816-A1822. [CrossRef]

334. Suzuki, N.; Butch-Cervera, R.; Ohnishi, T.; Takada, K. Silicon nitride thin film electrode for lithium-ion batteries. J. Power Sources 2013, 231, 186-189. [CrossRef]

335. Bleu, Y.; Bourquard, F.; Tite, T.; Loir, A.-S.; Maddi, C.; Donnet, C.; Garrelie, F. Review of graphene growth from a solid carbon source by pulsed laser deposition (PLD). Front. Chem. 2018, 6, 574. [CrossRef] [PubMed]

336. Kumar, S.R.; Nayak, P.K.; Hedhili, M.N.; Khan, M.A.; Alshareef, H.N. In situ growth of $\mathrm{p}$ and n-type graphene thin films and diodes by pulsed laser deposition. Appl. Phys. Lett. 2013, 103, 192109. [CrossRef] 
337. Ren, P.; Pu, E.; Liu, D.; Wang, Y.; Xiang, B.; Ren, X. Fabrication of nitrogen-doped graphenes by pulsed laser deposition and improved chemical enhancement for Raman spectroscopy. Mater. Lett. 2017, 204, 65-68. [CrossRef]

338. Fortgang, P.; Tite, T.; Barnier, V.; Zehani, N.; Maddi, C.; Lagarde, F.; Loir, A.-S.; Jaffrezic-Renault, N.; Donnet, C.; Garrelie, F.; et al. Robust electrografting on self-organized 3D graphene electrodes. ACS Appl. Mater. Interfaces 2015, 8, 1424-1433. [CrossRef] [PubMed]

339. Bourquard, F.; Bleu, Y.; Loi, A.-S.; Caja-Munoz, B.; Avila, J.; Asensio, M.-C.; Riamondi, G.; Shokouhi, M.; Rassas, I.; Farre, C.; et al. Electroanalytical performance of nitrogen-doped graphene films processed in one step by pulsed laser deposition directly coupled with thermal annealing. Materials 2019, 12, 666. [CrossRef]

340. Maddi, C.; Bourquard, F.; Barnier, V.; Avila, J.; Asensio, M.C.; Tite, T.; Donnet, C.; Garrelie, F. Nano-architecture of nitrogen-doped graphene films synthesized from a solid CN source. Sci. Rep. 2018, 8, 3247. [CrossRef]

341. Yu, S.H.; Feng, X.; Zhang, N.; Seok, J.; Abruna, H.D. Understanding conversion-type electrodes for lithium rechargeable batteries. Acc. Chem. Res. 2018, 51, 273-281. [CrossRef]

342. Wang, K.X.; Li, Y.; Wu, X.Y.; Chen, J.S. Carbon nanocolumn arrays prepared by pulsed laser deposition for lithium ion batteries. J. Power Sources 2012, 203, 140-144. [CrossRef]

343. Wei, K.; Zhao, Y.; Cui, Y.; Wang, J.; Cui, Y.; Zhu, R.; Zhuang, Q.; Xue, M. Lithium phosphorous oxynitride ( $\mathrm{LiPON}$ ) coated $\mathrm{NiFe}_{2} \mathrm{O}_{4}$ anode material with enhanced electrochemical performance for lithium ion batteries. J. Alloy Compd. 2018, 769, 110-119. [CrossRef]

344. Pralong, V.; Leriche, J.B.; Beaudoin, B.; Naudin, E.; Morcrette, M.; Tarascon, J.M. Electrochemical study of nanometer $\mathrm{Co}_{3} \mathrm{O}_{4}, \mathrm{Co}, \mathrm{CoSb}_{3}$ and $\mathrm{Sb}$ thin films toward lithium. Solid State Ion. 2004, 166, 295-305. [CrossRef]

345. Song, S.W.; Reade, R.P.; Cairns, E.; Vaughey, J.T.; Thackeray, M.M.; Striebel, K.A. Cur Sb thin-film electrodes prepared by pulsed laser deposition for lithium batteries. J. Electrochem. Soc. 2004, 151, A1012-A1019. [CrossRef]

346. Teng, X.; Qin, Y.; Wang, X.; Li, H.; Shang, X.; Fan, S.; Li, Q.; Xu, J.; Cao, D.; Li, S. A nanocrystalline $\mathrm{Fe}_{2} \mathrm{O}_{3}$ film anode prepared by pulsed laser deposition for lithium-ion batteries. Nanoscale Res. Lett. 2018, 13, 60. [CrossRef] [PubMed]

347. Fu, Z.W.; Wang, Y.; Zhang, Y.; Qin, Q.Z. Electrochemical reaction of nanocrystalline $\mathrm{Co}_{3} \mathrm{O}_{4}$ thin film with lithium. Solid State Ion. 2004, 170, 105-109. [CrossRef]

348. Wang, Y.; Wang, H.; Wang, X. The cobalt oxide/hydroxide nanowall array film prepared by pulsed laser deposition for supercapacitors with superb-rate capability. Electrochim. Acta 2013, 92, 298-303. [CrossRef]

349. Zhou, Y.; Zhang, H.; Xue, M.; Wu, C.; Wu, X.; Fu, Z. The electrochemistry of nanostructured $\operatorname{In}_{2} \mathrm{O}_{3}$ with lithium. J. Power Sources 2006, 162, 1373-1378. [CrossRef]

350. Xue, M.Z.; Fu, Z.W. Pulsed laser deposited $\mathrm{Sb}_{2} \mathrm{Se}_{3}$ anode for lithium-ion batteries. J. Alloy. Compd. 2008, 458, 351-356. [CrossRef]

351. Yu, L.; Wang, H.X.; Liu, Z.Y.; Fu, Z.W. Pulsed laser deposited FeOF as negative electrodes for rechargeable Li batteries. Electrochim. Acta 2010, 56,767-775. [CrossRef]

352. Rambabu, A.; Senthilkumar, B.; Dayamani, A.; Krupanidhi, S.B.; Barpanda, P. Preferentially oriented $\mathrm{SrLi}_{2} \mathrm{Ti}_{6} \mathrm{O}_{14}$ thin film anode for Li-ion microbatteries fabricated by pulsed laser deposition. Electrochim. Acta 2018, 269, 212-216. [CrossRef]

353. Yu, X.Q.; He, Y.; Sun, J.P.; Tang, K.; Li, H.; Chen, L.Q.; Huang, X.J. Nanocrystalline MnO thin film anode for lithium ion batteries with low overpotential. Electrochem. Commun. 2009, 11, 791-794. [CrossRef]

354. Wu, H.; Wei, K.; Tang, B.; Cui, Y.; Zhao, Y.; Xue, M.; Li, C.; Cui, Y. A novel Li 3 P-VP nanocomposite fabricated by pulsed laser deposition as anode material for high-capacity lithium ion batteries. J. Electroanal. Chem. 2019, 841, 21-25. [CrossRef]

(C) 2019 by the authors. Licensee MDPI, Basel, Switzerland. This article is an open access article distributed under the terms and conditions of the Creative Commons Attribution (CC BY) license (http://creativecommons.org/licenses/by/4.0/). 